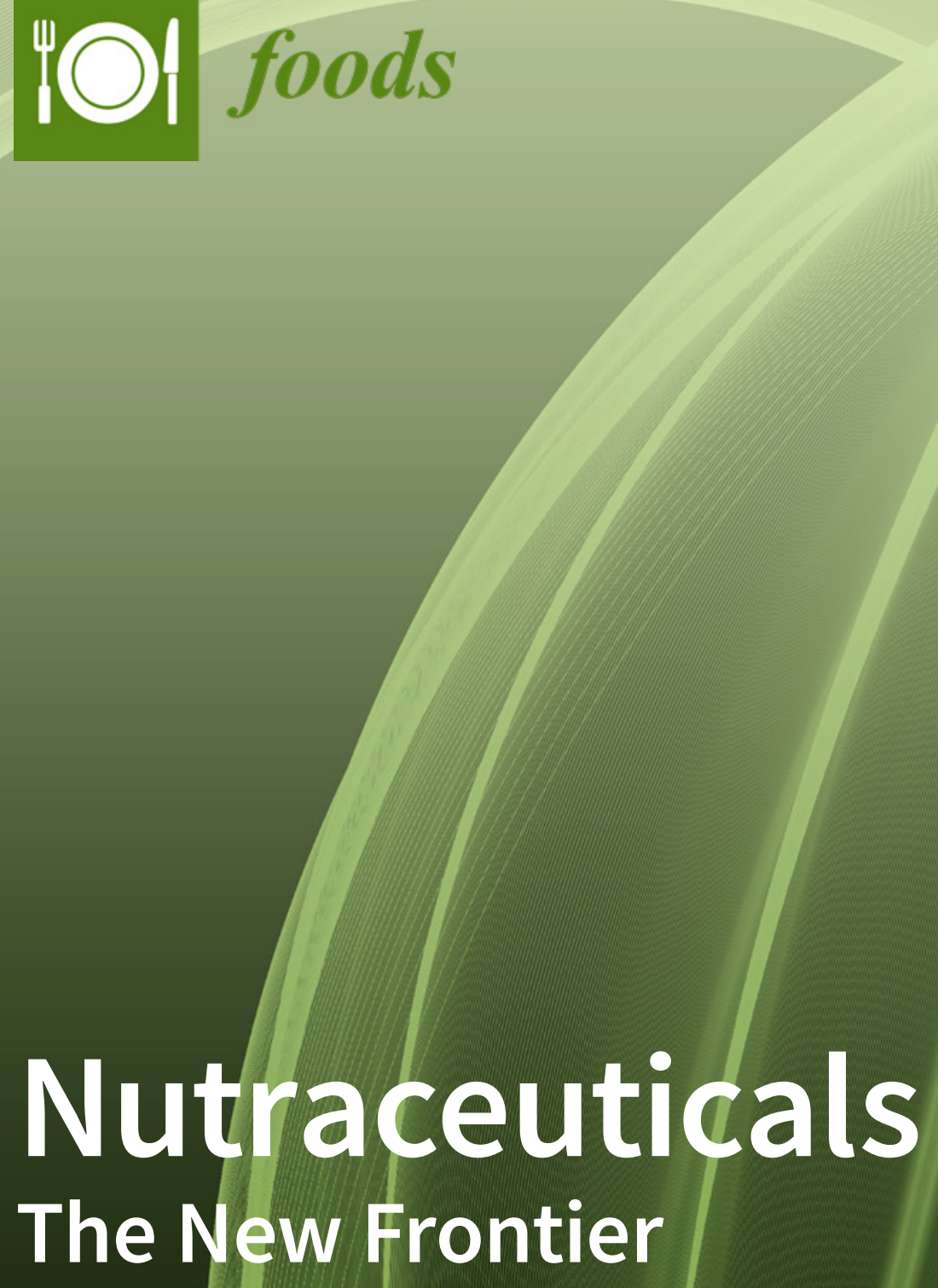

Edited by Antonello Santini

Printed Edition of the Special Issue Published in Foods 
Nutraceuticals: The New Frontier 



\section{Nutraceuticals: The New Frontier}

Special Issue Editor

Antonello Santini

MDPI • Basel • Beijing • Wuhan $\bullet$ Barcelona $\bullet$ Belgrade $\bullet$ Manchester $\bullet$ Tokyo $\bullet$ Cluj $\bullet$ Tianjin

\section{MDPI}


Special Issue Editor

Antonello Santini

University of Napoli Federico II

Italy

\section{Editorial Office}

MDPI

St. Alban-Anlage 66

4052 Basel, Switzerland

This is a reprint of articles from the Special Issue published online in the open access journal Foods (ISSN 2304-8158) (available at: https://www.mdpi.com/journal/foods/special_issues/new_ frontier).

For citation purposes, cite each article independently as indicated on the article page online and as indicated below:

LastName, A.A.; LastName, B.B.; LastName, C.C. Article Title. Journal Name Year, Article Number, Page Range.

ISBN 978-3-03936-463-3 (Hbk)

ISBN 978-3-03936-464-0 (PDF)

(C) 2020 by the authors. Articles in this book are Open Access and distributed under the Creative Commons Attribution (CC BY) license, which allows users to download, copy and build upon published articles, as long as the author and publisher are properly credited, which ensures maximum dissemination and a wider impact of our publications.

The book as a whole is distributed by MDPI under the terms and conditions of the Creative Commons license CC BY-NC-ND. 


\section{Contents}

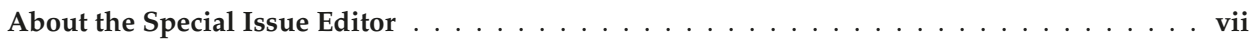

\section{Antonello Santini and Ettore Novellino}

To Nutraceuticals and Back: Rethinking a Concept

Reprinted from: Foods 2017, 6, 74, doi:10.3390/foods6090074 . . . . . . . . . . . . . . . 1

Domenico Montesano, Francesca Blasi, Maria Stella Simonetti, Antonello Santini and

Lina Cossignani

Chemical and Nutritional Characterization of Seed Oil from Cucurbita maxima L.

(var. Berrettina) Pumpkin

Reprinted from: Foods 2018, 7, 30, doi:10.3390/foods7030030 . . . . . . . . . . . . . . . .

Italian Opuntia ficus-indica Cladodes as Rich Source of Bioactive Compounds with

Health-Promoting Properties

Reprinted from: Foods 2018, 7, 24, doi:10.3390/foods7020024 . . . . . . . . . . . . . . . . . 19

Andrea Ragusa, Carla Centonze, Maria E. Grasso, Maria F. Latronico, Pier F. Mastrangelo,

Federica Sparascio, Francesco P. Fanizzi and Michele Maffia

A Comparative Study of Phenols in Apulian Italian Wines

Reprinted from: Foods 2017, 6, 24, doi:10.3390/foods6040024

Andrea Ragusa, Carla Centonze, Maria Elena Grasso, Maria Francesca Latronico, Pier Francesco Mastrangelo, Francesco Paolo Fanizzi and Michele Maffia

Composition and Statistical Analysis of Biophenols in Apulian Italian EVOOs

Reprinted from: Foods 2017, 6, 90, doi:10.3390/foods6100090 . . . . . . . . . . . . . . . .

Sang Gil Lee, Joanna A. Siaw and Hye Won Kang

Stimulatory Effects of Cinnamon Extract (Cinnamomum cassia) during the Initiation Stage of 3T3-L1 Adipocyte Differentiation

Reprinted from: Foods 2016, 5, 83, doi:10.3390/foods5040083 . . . . . . . . . . . . . . . . 57

Thu Nguyen, Mitchell Karl and Antonello Santini

Red Yeast Rice

Reprinted from: Foods 2017, 6, 19, doi:10.3390/foods6030019 . . . . . . . . . . . . . . . . . 67

Marcello Nicoletti

Microalgae Nutraceuticals

Reprinted from: Foods 2016, 5, 54, doi:10.3390/foods5030054 . . . . . . . . . . . . . . . . . . 71 



\section{About the Special Issue Editor}

Antonello Santini Ph.D., is Professor of Food Chemistry and Analysis of Food and Nutraceuticals and of Food Chemistry at the Department of Pharmacy and at the Department of Agriculture at the University of Napoli Federico II, Napoli, Italy, respectively. He is also Visiting Professor at the Albanian University of Tirana, Albania. He holds a Ph.D. in Chemical Sciences. His research areas of interest are supported by many international collaborations, mainly in the fields of food; food chemistry, nutraceuticals, and functional food; safety; supplements; recovery of natural bioactive compounds using eco-sustainable and environmentally friendly techniques from agro-food by products; nanocompounds; nanonutraceuticals; food risk assessment, safety, and contaminants; mycotoxins and secondary metabolites; food analysis; and chemistry and food education. He is responsible for funded research projects and for general cultural agreements established between the University of Napoli Federico II and many universities worldwide, and external evaluator of funded research projects for Italian and International Institutions. His research activity is documented by more than 200 papers published in reputed peer-reviewed international journals. He is a member of the European Food Safety Authority EFSA, ERWG, Parma, Italy; of the Italian Authority for Food Safety (CNSA), Italian Ministry of Health, Rome Italy; of the Managing Board, Italian Chemistry Society (SCI) Division of Teaching (DD-SCI), Rome, Italy; and Expert Member for Chemistry, EurSchool, European Commission, Bruxelles, Belgium. 



\title{
Editorial
}

\section{To Nutraceuticals and Back: Rethinking a Concept}

\author{
Antonello Santini * and Ettore Novellino \\ Department of Pharmacy, University of Napoli Federico II, Via D. Montesano, 49-80131 Napoli, Italy; \\ ettore.novellino@unina.it \\ * Correspondence: asantini@unina.it; Tel.: +39-081-2539317; Fax: +39-081-678107
}

Received: 4 August 2017; Accepted: 14 August 2017; Published: 5 September 2017

The concept of nutraceuticals as pharma-foods comes from far. This term is made from the two words "nutrient" and "pharmaceutical", was coined by Stephen DeFelice, and is defined as "a food or part of a food that provide medical or health benefits, including the prevention and/or treatment of a disease" [1].

This definition leads to a partial overlap with the definition of a food supplement. In fact, both claim beneficial effects for health; however, while nutraceuticals are made from food or part of a food, food supplements are single substances used alone or in mixtures with the scope of adding micronutrients when the body is in need of them.

The aspect outlined by DeFelice [1] —in particular the preventive aspect and the treatment of a disease-is absent in the definition and scope of food supplements, which can be an aid for the body but are not required to have a proven clinical efficacy on a health condition. Based on these considerations, it hence appears of utmost importance to develop a new definition for nutraceuticals foreseeing their use "beyond the diet, before the drugs" as tools which can be able to prevent or delay the onset of some asymptomatic long term pathological conditions (e.g. hypercholesterolemia, hypertriglyceridemia, etc.). The steps involved in a new nutraceutical formulation should start with the identification of the target pathologic condition, in a way similar to what happens for drugs.

Figure 1 shows the steps to take when assessing the possible use of a nutraceutical. It is of utmost importance the clinical target identification and the appropriate food matrix to use. The safety and the in vitro and in vivo tests are crucial. The differences between nutraceuticals and food supplements (e.g. mineral or protein food supplements) are also outlined, stressing the necessity of clinical evidences substantiating the health efficacy for nutraceuticals based on safety, efficacy, and known mechanism of action.

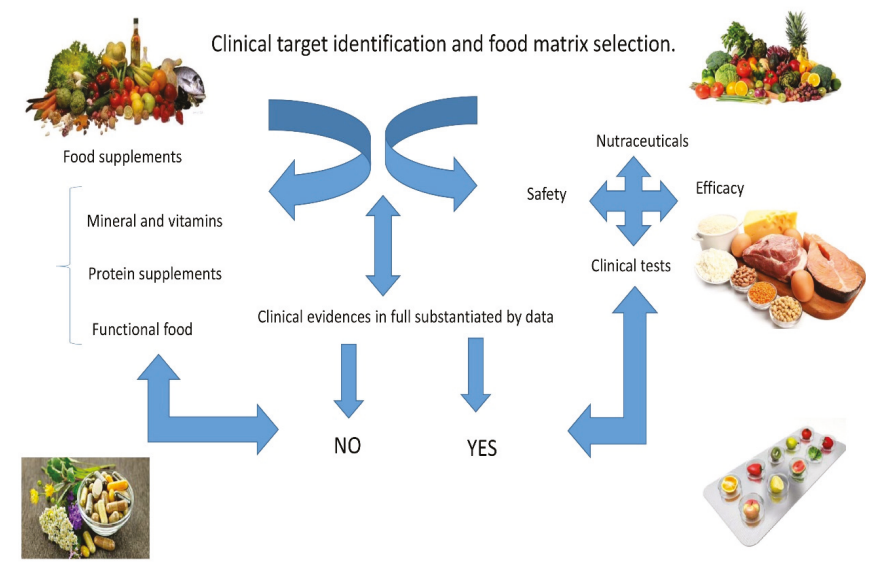

Figure 1. Food supplements and nutraceuticals. 
Once a pathologic health condition target has been identified, formulation can be prepared from vegetal or animal matrices, and tested in vitro and in vivo, keeping in mind that safety and efficacy must be substantiated by clinical tests [2].

Nutraceuticals which are extracted from vegetable sources (phytocomplex) or which are the active metabolite complex (if of animal origin) should hence be understood as a set of pharmacologically active substances which have inherent therapeutic properties due to the natural active principles of recognized effectiveness which they contain. They should be administered in the appropriate pharmaceutical form (e.g., capsule, tablet, drink, etc.). Incidentally, these forms of administration coincide with those used for both drugs and food supplements.

The assessment of nutraceuticals' optimal conditions of use should be complementary with safety information as well as bioavailability and bioaccessibility information, so that they can propose themselves as a powerful toolbox to be used to prevent and cure some pathologic conditions in subjects who, for example, are not eligible for conventional pharmacological therapy.

For this reason, and due to their natural origin, a growing demand exists for nutraceuticals, which shade the frontier existing between pharmaceuticals and food, and this is also helping the producers to diversify their agriculture and promote research and innovation. Nonetheless, different country-specific regulations, safety, and health claim substantiation are the main challenges which the nutraceuticals are experiencing. The main challenge is the absence of a shared supra-national regulation for nutraceuticals, which would recognize their potential and possible role as therapeutic tools in some pathological conditions based on assessed safety, known mechanism of action, clinically proven efficacy in both reducing the risk of illness onset and enhancing overall well-being.

The labelling of marketed products is another source of confusion, and is often due to misinformation, which could induce false expectations regarding beneficial health effect and miss the target for a product to be effective as claimed. What may be considered a functional food under a given set of circumstances may be deemed a dietary supplement, medical food, food for special dietary use, a nutraceutical, or a drug under different circumstances, depending on its ingredients and the claims as reported on the label [3].

While the definition of food supplement is quite clear and understandable (see Table 1), the definition of nutraceutical still lies in between food, food supplement, and pharmaceutical, and the legitimate assessment of their potential in medicine is still contradictory and far from being shared and accepted worldwide [4].

Table 1. Some definitions.

\begin{tabular}{clc}
\hline Terms & \multicolumn{1}{c}{ Definitions } & Reference \\
\hline Food supplement & $\begin{array}{l}\text { A product (other than tobacco) in the form of a capsule, } \\
\text { powder, softgel, or gelcap intended to supplement the diet to } \\
\text { enhance health that bears or contains one or more of the } \\
\text { following dietary ingredients: a vitamin, mineral, amino acid, } \\
\text { or other botanical or dietary substance. }\end{array}$ & $\begin{array}{c}\text { United States Government Office, } \\
\text { 1994 [5] }\end{array}$ \\
\hline Nutraceuticals & $\begin{array}{l}\text { Food or part of food that provides medical or health benefits, } \\
\text { including the prevention and/or treatment of a disease. }\end{array}$ & De Felice, 1995 [1] \\
\hline Nutraceuticals & $\begin{array}{l}\text { Nutritional products that provide health and medical benefits, } \\
\text { including the prevention and treatment of disease. }\end{array}$ & $\begin{array}{c}\text { European Nutraceutical } \\
\text { Association, 2016 [6] }\end{array}$ \\
\hline \multirow{2}{*}{ Functional food } & $\begin{array}{l}\text { Any food or ingredient that has a positive impact on an } \\
\text { individual's health, physical performance, or state of mind, in } \\
\text { addition to its nutritive value. }\end{array}$ & Hardy, 2000 [7] \\
\hline
\end{tabular}

The definition of a food supplement often overlaps with the one accepted for nutraceuticals as present in the collective imagination, and the rationale behind their use is becoming a challenge of this millennium $[8,9]$.

Food supplements should be, as per their micronutrients content, addressed to improve health if appropriately targeted to those in need. Nevertheless, many of the health claims which are currently 
associated to food supplements, pro- and pre-biotics, as well as herbal products and functional foods are often not properly substantiated by in vivo data on safety, efficacy, and effect on health and/or on pathologic conditions. This is mainly due to the lack of in vivo and mechanism of action studies confirming the claimed health beneficial effect. Many literature data refer to in vitro studies, and focus on single food constituents (micronutrients). Any health beneficial effect for nutraceuticals is related to the fact that they derive from food or part of food, and consequently they can be considered safe or generally recognized as safe (GRAS). Safety is of utmost importance, since possible contaminants of inorganic [10] and organic origin [11] can contaminate these products and cause health issues.

It seems necessary to restructure the entire regulatory framework of dietary supplements and include nutraceuticals as a new category, by giving credit to their role in the prevention and cure of some pathological conditions. The pre-market approval system should be under any circumstance substantiated by in vivo clinical data to determine and assess their safety and efficacy. This approach could look similar to the one used for pharmaceuticals, which includes clinical trials to in vitro and safety tests. The likelihood of this happening in the foreseeable future is unfortunately quite low, but it seems reasonable to hypothesize that the competent national authorities could ask the manufacturers to provide data that substantiates safety, efficacy, and mechanism of action of any claims attributed to food supplements and nutraceuticals, avoiding any possible source of confusion.

Conflicts of Interest: The authors declare no conflict of interest.

\section{References}

1. DeFelice, S.L. The nutraceutical revolution: Its impact on food industry R\&D. Trends Food Sci. Technol. 1995, $6,59-61$.

2. Santini, A.; Tenore, G.C.; Novellino, E. Nutraceuticals: A paradigm of proactive medicine. Eur. J. Pharm. Sci. 2017, 96, 56-61. [CrossRef] [PubMed]

3. Borchers, A.T.; Keen, C.L.; Gerswin, M.E. The basis of structure/function claims of nutraceuticals. Clin. Rev. Allergy Immunol. 2016, 51, 370-382. [CrossRef] [PubMed]

4. Aronson, J.K. Defining nutraceuticals: Neither nutritious nor pharmaceutical. Br. J. Clin. Pharmacol. 2017, 83, 8-19. [CrossRef] [PubMed]

5. United States Food and Drug Administration (FDA). Dietary Supplement Health and Education Act (DSHEA). U.S. Department of Health and Human Services, 1994. United States. Public Law 103-417. Available online: http:/ / www.fda.gov (accessed on 1 August 2017).

6. European Nutraceutical Association (ENA). Available online: http://www.enaonline.org/index.php?lang= en\&path=news (accessed on 18 August 2017).

7. Hardy, G. Nutraceuticals and functional foods: Introduction and meaning. Nutrition 2000, 16, 688-689. [CrossRef]

8. Volpe, R.; Sotis, G. Nutraceuticals: Definition and Epidemiological Rationale for Their Use in Clinical Practice. High Blood Press. Cardiovasc. Prev. 2015, 22, 199-201. [CrossRef] [PubMed]

9. Finley, J.W. The nutraceutical revolution: Emerging vision or broken dream? Understanding scientific and regulatory concerns. Clin. Res. Regul. Aff. 2016, 33, 1-3. [CrossRef]

10. Filipiak-Szok, A.; Kurzawa, M.; Szłyk, E.J. Determination of toxic metals by ICP-MS in Asiatic and European medicinal plants and dietary supplements. J. Trace Elem. Med. Biol. 2015, 30, 54-58. [CrossRef] [PubMed]

11. Fernando, G.; Hernández, A.F.; Martín-Domingo, M.C. Toxic Contamination of Nutraceuticals and Food Ingredients. In Nutraceuticals: Efficacy, Safety and Toxicity; Gupta, R.C., Ed.; Academic Press: Boston, MA, USA, 2016; Chapter 58; pp. 825-837.

(C) 2017 by the authors. Licensee MDPI, Basel, Switzerland. This article is an open access article distributed under the terms and conditions of the Creative Commons Attribution (CC BY) license (http:/ / creativecommons.org/licenses/by/4.0/). 

Article

\title{
Chemical and Nutritional Characterization of Seed Oil from Cucurbita maxima L. (var. Berrettina) Pumpkin
}

\author{
Domenico Montesano ${ }^{1,+}$, Francesca Blasi ${ }^{1,+}{ }^{\text {, Maria Stella Simonetti }}{ }^{1}$, Antonello Santini ${ }^{2, *}$ and \\ Lina Cossignani ${ }^{1}$ \\ 1 Department of Pharmaceutical Sciences Section of Food Science and Nutrition, University of Perugia, \\ Via San Costanzo, 06126 Perugia, Italy; domenico.montesano@unipg.it (D.M.); \\ francesca.blasi@unipg.it (F.B.); maria.simonetti@unipg.it (M.S.S.); lina.cossignani@unipg.it (L.C.) \\ 2 Department of Pharmacy, University of Napoli Federico II, via D. Montesano 49, 80131 Napoli, Italy \\ * Correspondence: asantini@unina.it; Tel.: +39-812-539-317 \\ + These authors contributed equally to this work.
}

Received: 29 January 2018; Accepted: 21 February 2018; Published: 1 March 2018

\begin{abstract}
Pumpkin (Cucurbita spp.) has received considerable attention in recent years because of the nutritional and health-protective value of seed oil. The nutritional composition of pumpkin native to central Italy, locally known as "Berrettina" (Cucurbita maxima L.), was evaluated. In particular, the lipid fraction of seed oil was characterized, and the triacylglycerol (TAG) was thoroughly studied by using a stereospecific procedure to obtain the intrapositional fatty acid composition of the three sn-positions of the glycerol backbone of TAG. Moreover, alkaline hydrolysis was carried out to study the main components of the unsaponifiable fraction, i.e., sterols and alcohols. It was observed that monounsaturated fatty acids and polyunsaturated fatty acids were the most abundant $(41.7 \%$ and $37.2 \%$, respectively) in Berrettina pumpkin seed oil, with high content of oleic and linoleic acid $(41.4 \%$ and $37.0 \%$, respectively). The main sterols of Berrettina pumpkin seed oil were $\Delta^{7,22,25}$-stigmastatrienol, $\Delta^{7,25}$-stigmastadienol, and spinasterol; with regard to the alcoholic fraction, triterpenic compounds were more abundant than aliphatic compounds (63.2\% vs. $36.8 \%$ ). The obtained data are useful to evaluate pumpkin seed oil from a nutritional point of view. The oil obtained from the seed could be used as a preservative and as a functional ingredient in different areas, e.g., cosmetics, foods, and nutraceuticals.
\end{abstract}

Keywords: pumpkin seed oil; fatty acids; stereospecific analysis; sterols; alcohols

\section{Introduction}

The pumpkin (Cucurbita spp.), one of the most popular vegetables consumed in the world, has been recently recognized as a functional food [1-3]. Pumpkin seeds, generally considered agro-industrial waste, are an extraordinarily rich source of bioactive compounds with interesting nutraceutical properties [4]. In recent years, several studies [5-7] have highlighted the health properties of pumpkin seed oil against many diseases, including hypertension, diabetes, and cancer. It also shows antibacterial, antioxidant, and anti-inflammatory properties [8,9]. Due to the presence of interesting natural bioactive compounds, such as carotenoids, tocopherols, and sterols, pumpkin-derived products have a wide spectrum of biological activity, proven by in vivo experiments [10].

Because of the positive health effects, research has been focused particularly on the content and composition of fatty acids (FA) and tocopherols in pumpkin seed oil, while, to a lesser extent, other lipid components, such as sterols, alcohols, and phenol acids, have been studied, as is done with other food matrices to identify specific markers characteristic of the plant varieties [11]. Among the 
relevant aspects to be considered when dealing with this vegetable, the beneficial effects of using environmentally friendly natural herbicides [12] must be mentioned, since the content of bioactive compounds could be affected, and there could be possible contamination of this vegetable due to the presence of Fusarium spp. microfungi and their secondary metabolites [13], affecting the content of beneficial compounds of the vegetable itself.

Stevenson et al. [14] summarized FA composition and reported significant differences among various cultivars of pumpkin seed oil extracted from various pumpkin sources. Rezig et al. [15] studied the chemical composition and oil properties of seeds of a Tunisian variety of pumpkin, Béjaoui (C. maxima). They found that the major FA were oleic, linoleic, and palmitic acids and that the seed oil was rich in $\delta$-tocopherol, while the sterol marker was $\beta$-sitosterol and the predominant phenolic acid was syringic acid. Siano et al. [16] highlighted that saturated FA (SFA) and monounsaturated FA (MUFA) of C. maxima produced in southern Italy showed similar values $(25.20 \%$ and $25.54 \%$, respectively), while the polyunsaturated FA (PUFA) content was 48.14\%. Habib et al. [17] determined the proximate composition of powdered seed and the lipid composition of the oil of $C$. maxima collected in Bangladesh. They affirmed that the high degree of unsaturation makes the oil suitable for use as valuable drying agent, and lower free FA content indicates suitability of the oil for consumption as food.

Other researchers studied the chemical composition of pumpkin seed oils from C. pepo [5,18-21]. Due to the differences among the species and/or varieties of Cucurbita spp. grown in different areas of the world, the present study focused on characterizing a native Italian cultivar (C. maxima, var. Berrettina, locally known as "priest's hat"), paying attention to the lipid composition of the seed oil. Since there is little information about the lipid structure, the present research deepens understanding of the total FA content and intrapositional composition of Berrettina pumpkin by using stereospecific analysis, and pays attention to other minor lipid components such as sterols, alcohols, and carotenoids. Butinar et al. [22] proposed high-performance liquid chromatography (HPLC) analysis of triacylglycerol (TAG) as a useful technique to evaluate the genuineness of pumpkin seed oils produced in Slovenia, but to the best of our knowledge, there are no data in the literature dealing with stereospecific analysis of pumpkin seed TAG.

\section{Materials and Methods}

\subsection{Materials and Chemicals}

Methanol $(\mathrm{MeOH})$, diethyl ether, petroleum ether, formic acid, hydrochloric acid, and acetone were purchased from J.T. Baker B.V. (Deventer, the Netherlands). Hexane, ethanol (EtOH), chloroform $\left(\mathrm{CHCl}_{3}\right)$, anhydrous sodium sulfate $\left(\mathrm{Na}_{2} \mathrm{SO}_{4}\right)$, and potassium hydroxide $(\mathrm{KOH})$ were bought from Carlo Erba Reagents (Milan, Italy). Deionized water $(>18 \mathrm{M} \Omega \mathrm{cm}$ resistivity) was obtained from a Milli-Q SP Reagent Water System (Millipore, Bedford, MA, USA). Supelco $^{\mathrm{TM}} 37$ Component FAME Mix, containing the methyl esters of 37 fatty acids (Supelco, Bellefonte, PA, USA; catalog No. 47885-U), was used. Lipase from porcine pancreas (EC 3.1.1.3), sn-1,2-diacylglycerol kinase from Escherichia coli (DAGK; EC 2.7.1.107), cholesterol ( $\geq 99 \%$ ), ergosterol ( $\geq 95 \%)$, stigmasterol ( 95\%), $\beta$-sitosterol ( $\geq 95 \%), 5$ - $\alpha$-cholestane $(\geq 97 \%), \gamma$-linolenic acid $(\geq 99 \%)$, $2^{\prime}, 7^{\prime}$-dichlorofluorescein, $N, \mathrm{O}$-bis(trimethylsilyl)trifluoroacetamide (BSTFA), 1-octadecanol (99\%), 1-docosanol (98\%), 1-octacosanol ( $\geq 99 \%)$, lutein $(\geq 97 \%)$, and $\beta$-carotene $(\geq 97 \%)$ were purchased from Sigma-Aldrich (St. Louis, MO, USA).

\subsection{Collection of Pumpkin Samples}

Pumpkin belongs to the family Cucurbitaceae. The samples (C. maxima L., var. Berrettina) were taxonomically identified by Luigi Frassineti (Tuder Green Service, Todi, Italy). It is a leafy green vegetable with medium-large flattish fruits with green-gray, moderately hard knobby skin, edible yellow/orange flesh, and a central cavity with numerous plump, whitish-yellow seeds. 
Three pumpkins cultivated in central Italy (Todi) and collected in autumn 2016 were selected for their uniformity of shape, weight, and color. The fresh pumpkin samples were weighed (about $2.5 \mathrm{~kg}$ each), peeled, and, after manual removal of seeds, cut into small pieces $(1.5 \mathrm{~cm} \times 1.5 \mathrm{~cm} \times 1.5 \mathrm{~cm})$ and analyzed. The seeds were cleaned to remove impurities and dried at $60^{\circ} \mathrm{C}$ for $24 \mathrm{~h}$ in a hot-air fan oven. After that, the seeds were reweighed until the weight was constant. The samples were stored in a dry place in the dark at room temperature.

\subsection{Determination of Pumpkin Chemical Composition}

Crude fat, protein, moisture, and ash contents of pumpkin samples were determined according to the procedures described in the Association of Official Analytical Chemists (AOAC) method [23].

\subsection{Seed Lipid Extraction}

Dried pumpkin seed samples were ground using a kitchen grinder (Oster, model 869-50R, Lakewood, CA, USA). Extraction of lipid fraction of the pumpkin seeds was performed using petroleum ether as a solvent in a Soxhlet extractor, according to AOAC procedure [23]. The extract was dried over $\mathrm{Na}_{2} \mathrm{SO}_{4}$, and then the solvent was evaporated under reduced pressure using a rotary evaporator (Büchi Rotavapor B-480, Essen, Germany) at $40{ }^{\circ} \mathrm{C}$. Finally, the residue was weighed and dissolved in hexane. The recovered oil was stored at $4{ }^{\circ} \mathrm{C}$ until use.

\subsection{Isolation of TAG Fraction from Oil Samples}

The TAG fraction was isolated by thin layer chromatography (TLC), according to the method described by Cossignani et al. [24], from total fat of pumpkin seed samples using silica gel plates (SIL G-25, $0.25 \mathrm{~mm}, 20 \mathrm{~cm} \times 20 \mathrm{~cm}$; Macherey-Nagel, Germany) and petroleum ether/diethyl ether/formic acid (70:30:1, v/v/v) as a developing solvent. The TAG fraction was scraped off, extracted with hexane/diethyl ether $(1: 1, v / v)$, subjected to transesterification, and analyzed by high-resolution gas chromatography (HRGC) as reported in Section 2.6 to obtain the constituent fatty acid methyl esters (FAME). The obtained data represent the total composition of FA esterified in all 3 sn-positions of TAG, named $\mathrm{A}_{\mathrm{t}}$.

\subsubsection{Stereospecific Analysis of TAG}

The stereospecific analysis procedure [25] carried out on TAG of pumpkin seed oil isolated as reported in the previous paragraph involved the following steps:

- The pancreatic lipase procedure (Section 2.5.2) to obtain the FA\% intrapositional composition of sn-2 position of glycerol backbone of TAG, named $\mathrm{A}_{2}$;

- $\quad$ Preparation of $s n-1,3 / s n-1,2(2,3)$-diacylglycerol (DAG), followed by the DAGK enzymatic procedure (Section 2.5.3), to obtain the FA\% intrapositional composition of $s n-1$ and $s n-2$ positions of glycerol backbone of TAG, named $\mathrm{A}_{1,2}$.

\subsubsection{Pancreatic Lipase Procedure}

Hydrolysis of TAG was carried out according to the method provided by the Italian fat and derivate control standards (Norme Italiane per il Controllo dei Grassi e Derivati (NGD) method) [26]. Tris- $\mathrm{HCl}$ buffer ( $\mathrm{pH} 8.08$ ), bile salts, $\mathrm{CaCl}_{2}$, and pancreatic lipase were added to an aliquot of TAG. The mixture was incubated under magnetic stirring in a water bath at $40{ }^{\circ} \mathrm{C}$ for $5 \mathrm{~min}$, and then $6 \mathrm{M} \mathrm{HCl}$ and diethyl ether were added and the mixture was centrifuged. Diethyl ether was dried by anhydrous $\mathrm{Na}_{2} \mathrm{SO}_{4}$ and evaporated under nitrogen flow to small volume. The hydrolytic products were separated on TLC plates, and the developing solvent system was petroleum ether/diethyl ether/formic acid (70:30:1, v/v/v). The band corresponding to $s n$-2-monoacylglycerols (sn-2-MAG), visualized with $2^{\prime}, 7^{\prime}$-dichlorofluorescein spray, was scraped off, methylated, and analyzed by HRGC as 
reported in Section 2.6 to obtain the constituent FAME. The obtained data represent the intrapositional composition of FA esterified in $s n-2$ position, named $\mathrm{A}_{2}$.

\subsection{3. sn-1,3/sn-1,2(2,3)-Diacylglycerol (DAG) Preparation}

An aliquot of TAG was dissolved in anhydrous diethyl ether, and freshly prepared ethyl magnesium bromide in anhydrous diethyl ether was added. The mixture was shaken, and then pentane $(0.1 \%$ acetic acid) and water were added. The solution was vortexed and centrifuged (ALC 4218 centrifuge, Thermo Scientific, Waltham, MA, USA). The water was removed and the organic phase was dried over anhydrous $\mathrm{Na}_{2} \mathrm{SO}_{4}$ and concentrated with solvent removal under nitrogen stream. The DAG mixture was applied to TLC plates previously treated with 5\% boric acid solution (methanol/water, $80: 20, v / v)$ and then activated for $1 \mathrm{~h}$ at $120^{\circ} \mathrm{C}$. The developing system was hexane/diethyl ether (60:40, $v / v)$. The band containing the $s n-1,2(2,3)$-DAG fraction $(\operatorname{Rf} \approx 0.30$; $\operatorname{Rf}$ of the $s n-1,3$-DAG band $\approx 0.35)$, located by iodine vapor exposition, was scraped off and extracted with diethyl ether.

\subsubsection{DAGK Enzymatic Procedure}

The sn-1,2(2,3)-DAG ethereal solution was concentrated under nitrogen stream, then cardiolipin solution, buffered $s n$-1,2-DAGK, buffer, and $\mathrm{Na}_{2}$ ATP were added, mixing each time. After incubation at $40{ }^{\circ} \mathrm{C}$ for $90 \mathrm{~min}$ under constant stirring, chloroform/methanol $(2: 1, v / v)$ was added to the mixture to stop the reaction and extract the products of interest. The combined extracts were concentrated, treated with anhydrous $\mathrm{Na}_{2} \mathrm{SO}_{4}$, and applied to TLC plates. The developing system was chloroform/methanol $/ 25 \%$ ammonia $(65: 25: 5, v / v / v)$. The band of the $s n-1,2$-phosphatidic acids (sn-1,2-PA), visualized with $2^{\prime}, 7^{\prime}$-dichlorofluorescein spray ( $\mathrm{Rf} \approx 0.1$ ), was scraped off, methylated, and analyzed by HRGC with flame ionization detection (FID) as reported in the following paragraph to obtain the constituent FAME. The obtained data represent the intrapositional composition of FA esterified in $s n-1,2$ positions, named $\mathrm{A}_{1,2}$.

The FA composition at the $s n-1$ - and $s n$-3-positions was obtained applying the following formulas:

$$
\begin{gathered}
\mathrm{A}_{1}=2 \mathrm{~A}_{1,2}-\mathrm{A}_{2} \\
\mathrm{~A}_{3}=3 \mathrm{~A}_{\mathrm{t}}-\mathrm{A}_{2}-\mathrm{A}_{1}
\end{gathered}
$$

where $\mathrm{A}_{1}=\%$ intrapositional composition of FA esterified in $s n-1$ position; $\mathrm{A}_{1,2}=\%$ intrapositional composition of FA esterified in $s n-1$ and sn-2 positions; $\mathrm{A}_{2}=\%$ intrapositional composition of FA esterified in sn-2 position; $A_{t}=\%$ total composition of FA esterified in all 3 sn-positions of TAG; $A_{3}=\%$ intrapositional composition of FA esterified in $s n-3$ position.

\subsection{Preparation of FAME and HRGC-FID Analysis}

The FAME of TAG, sn-2-MAG, and sn-1,2-PA fractions were prepared by transesterification. Hexane and $2 \mathrm{~N}$ methanolic $\mathrm{KOH}$ were added to the fraction and stirred for $3 \mathrm{~min}$, then water was added. The organic phase (upper) containing the FAME was dried over anhydrous $\mathrm{Na}_{2} \mathrm{SO}_{4}$, then analyzed by HRGC. A DANI GC1000 DPC gas chromatograph (Norwalk, CT, USA) equipped with a split-splitless injector and a flame ionization detector (FID) was used. Separation was obtained using the CP-Select CB for FAME fused silica capillary column (50 $\mathrm{m} \times 0.25 \mathrm{~mm}$ i.d., $0.25 \mu \mathrm{m}$ f.t.; Varian, Superchrom, Milan, Italy). Chromatograms were acquired and processed using Clarity integration software (DataApex Ltd., Prague, Czech Republic). The injector and detector temperature was $250{ }^{\circ} \mathrm{C}$. The oven temperature was held at $180{ }^{\circ} \mathrm{C}$ for $6 \mathrm{~min}$, and raised to $250{ }^{\circ} \mathrm{C}$ at $3{ }^{\circ} \mathrm{C} / \mathrm{min}$; the final temperature was held for $10 \mathrm{~min}$. Carrier gas $(\mathrm{He})$ flow rate was $1 \mathrm{~mL} / \mathrm{min}$; the injection volume was $1 \mu \mathrm{L}$ with a split ratio of 1:70. A standard solution containing 37 FAME was used to identify the individual FA. The percentage of each FA was calculated using the peak area of the samples. The data were normalized considering only the main reported FA ( $\%$ mol mean values $\geq 0.1$ ). 


\subsection{Alkaline Hydrolysis of Pumpkin Seed Oil}

Alkaline hydrolysis of pumpkin seed oil was carried out according to the method reported by Cossignani et al. [27]. Prior to alkaline hydrolysis, $0.2 \% 5$ - $\alpha$-cholestane in $\mathrm{CHCl}_{3}$ and $1 \%$ 1-octacosanol (used as internal standards) were added to the oil samples, then the American Oil Chemists' Society (AOCS) method (Ch 6-91) was used [28]. The products obtained after alkaline reaction were applied to TLC silica gel plates previously treated with $0.2 \mathrm{~N} \mathrm{KOH}$ in $\mathrm{MeOH}$, then activated for $1 \mathrm{~h}$ at $100{ }^{\circ} \mathrm{C}$. The developing system was hexane/diethyl ether $(65: 35, v / v)$. The band containing the sterols, visualized with $2^{\prime}, 7^{\prime}$-dichlorofluorescein spray, was scraped off and extracted with $\mathrm{CHCl}_{3}$. Then the solvent was evaporated and removed under nitrogen stream.

\subsection{Preparation of Trimethylsilyl Ether Derivatives and HRGC-FID Analysis}

The silylation reaction was carried out as described by Lombardi et al. [29] with slight modifications. In brief, BSTFA and acetone were added to the sterol fraction and the reaction was carried out at $40^{\circ} \mathrm{C}$ for $20 \mathrm{~min}$ to obtain trimethylsilyl ether (TMSE) derivatives. Sterols and alcohols, as TMSE derivatives, were analyzed using a DANI GC1000 DPC gas chromatograph equipped with a split-splitless injector and FID.

Separation of TMSE sterols and alcohols was obtained using the AT-1701 fused silica capillary column $(25 \mathrm{~m} \times 0.25 \mathrm{~mm}$ i.d., $0.2 \mu \mathrm{m}$ f.t.; Alltech, Milan, Italy).

For analysis of TMSE sterols, the following chromatographic conditions were used: injector and detector temperature was $300^{\circ} \mathrm{C}$; oven temperature of $260^{\circ} \mathrm{C}$ was held for $4 \mathrm{~min}$, then increased to $300^{\circ} \mathrm{C}$ at $1.5^{\circ} \mathrm{C} / \mathrm{min}$, and the final temperature was held for $30 \mathrm{~min}$; carrier gas (He) flow rate was $1.2 \mathrm{~mL} / \mathrm{min}$.

For analysis of TMSE alcohols, the following chromatographic conditions were used: injector and detector temperature was $290^{\circ} \mathrm{C}$; oven temperature was held at $180{ }^{\circ} \mathrm{C}$ for $3 \mathrm{~min}$, raised to $260^{\circ} \mathrm{C}$ at $6{ }^{\circ} \mathrm{C} / \mathrm{min}$ for $15 \mathrm{~min}$, then raised to $280{ }^{\circ} \mathrm{C}$ at $2{ }^{\circ} \mathrm{C} / \mathrm{min}$ for $30 \mathrm{~min}$.

Chromatograms were acquired and processed using Clarity integration software. The percentage of each sterol was calculated by using the peak area of the samples corrected with the correction factor equal to 1 as reported by Laakso [30]. TMSE sterols were also analyzed by HRGC coupled with mass spectrometry (MS) detector as described in Section 2.9.

\subsection{HRGC-MS Analysis}

A Shimadzu GCMS-QP2010 gas chromatograph equipped with a quadrupole mass spectrometer (Shimadzu, Milan, Italy) and split-splitless injector maintained at $300{ }^{\circ} \mathrm{C}$ was used. The following MS parameters were used: interface temperature $270{ }^{\circ} \mathrm{C}$; MS ionization mode electron ionization; detector voltage $0.9 \mathrm{kV}$; acquisition mass range $50-500 \mathrm{u}$; scan speed $1000 \mathrm{u}$ /s; acquisition mode full scan; scan interval $0.5 \mathrm{~s}$; solvent delay $6 \mathrm{~min}$. Data were collected by GC-MS Solution software (Shimadzu). The column and the chromatographic conditions were the same as those reported in Section 2.8.

TMSE sterols and alcohols were identified by comparing retention times and mass spectra to those of authentic TMSE-derivatized compounds. Confirmation of these structures was achieved by HRGC-MS using the National Institute of Standards and Technology (NIST; Gaithersburg, MD, USA) 2008 library to match mass spectral peaks of phytosterol standards to those found in pumpkin seed oil samples. Comparisons of parent molecular ion $(\mathrm{M}+)$ and fragmentation ions/patterns were employed to assist in elucidating the identities of the phytosterols. In addition to the presence of specific ion fragments, the relative intensity of the ion fragments was considered. Some compounds, for which commercial standards are not available, were tentatively identified by comparison of relative retention times, M+ values, and fragmentation patterns with data obtained from olive oil analysis or from MS spectra reported in the literature. 


\subsection{Carotenoid Analysis}

The seed oil carotenoids were analyzed by HPLC with diode-array and mass spectrometry detection systems (DAD-MS). To perform this determination, a seed oil sample was diluted fourfold and injected into the HPLC system. Quali-quantitative determination of carotenoids was carried out using the HPLC-DAD-MS validated method described in Blasi et al. [31].

\subsection{Statistical Analysis}

FA, sterol, alcohol, and carotenoid composition data are reported as mean values and standard deviation (SD). HRGC analyses were carried out in duplicate. Data were processed and edited with Microsoft Excel 2016 (Microsoft, Redmond, MA, USA).

\section{Results and Discussion}

\subsection{Nutritional Composition and Caloric Value}

Data on nutritional composition and caloric value of pumpkin (C. maxima, var. Berrettina) are reported in Table 1 . The samples had a high content of water $(82.50 \%)$; in fact, a variety of vegetables have water composition in the range of $80-90 \%$. The flesh is characterized by a low fat content. Simple sugars and ash showed similar values $(0.82 \%$ and $0.84 \%$, respectively), while the protein content was higher $(1.28 \%)$. Data relative to moisture, ash, and protein are in good agreement with those reported by Kim et al. [32] for Korean pumpkin (C. maxima) flesh. Generally, the proximate composition is extremely variable [32-34], due to the differences among the species and/or varieties of Cucurbita spp. grown in different areas of the world. The low caloric value of pumpkin (C. maxima, var. Berrettina) is $25.35 \mathrm{kcal} / 100 \mathrm{~g}$, according to data in the literature $[35,36]$.

Table 1. Nutritional composition (g/100 g edible part) of pumpkin (C. maxima, var. Berrettina) (mean value \pm standard deviation (SD), $n=3$ ).

\begin{tabular}{cc}
\hline Component & Mean Value \pm SD \\
\hline Energy (kcal/100 g) & 25.35 \\
Moisture & $82.50 \pm 0.37$ \\
Dry matter & $17.50 \pm 0.14$ \\
Total ash & $0.84 \pm 0.04$ \\
Crude protein & $1.28 \pm 0.03$ \\
Crude oil & $0.08 \pm 0.01$ \\
Total sugars & $4.90 \pm 0.09$ \\
Starch & $4.10 \pm 0.05$ \\
Simple sugars & $0.82 \pm 0.03$ \\
\hline
\end{tabular}

\subsection{Fatty Acid Composition of Seed Oils and Nutritional Quality Index}

Total FA\% compositions, corresponding to each FA component of oil and TAG fraction, are reported in Table 2. SFA with carbon chains shorter than 14 carbon atoms, called short- and medium-chain FA, was not found in pumpkin seed oil, as confirmed in other papers $[14,20,37,38]$. SFA was represented especially by palmitic (C16:0) and stearic (C18:0) acids, at $14.2 \%$ and $5.8 \%$, respectively. It is reported that oils rich in myristic (C14:0) and palmitic acids affect the ratio of total to high-density lipoprotein (HDL) cholesterol only a little, and stearic acid slightly reduces this ratio [35]. PUFA and MUFA fractions were the most abundant (37.2\% and $41.7 \%$, respectively, for oil; $37.8 \%$ and $43.0 \%$, respectively, for TAG); in fact, the main FA were oleic (C18:1n-9) and linoleic (C18:2n-6) acids. Berrettina pumpkin seed oil showed a higher content of oleic acid than linoleic acid ( $41.4 \%$ vs. $37.0 \%$ for oil); on the contrary, Procida et al. [20] reported a higher content of linoleic acid (44.30-51.58\%) than oleic acid (34.16-42.59\%) for three Italian samples of pumpkin (Crudigno, Pepo, and Winter). It has been reported by some authors [14] that oleic acid is the predominant FA (41-46\%), followed 
by linoleic acid (33.4-34.3\%), in pumpkin seed oil from Italy and Libya. Siano et al. [16] found that the main FA of southern Italian pumpkin (C. maxima) seed oil were linoleic acid (47.45\%), followed by oleic (25.54\%) and palmitic (17.58\%) acids. Habib et al. [17] found that pumpkin (C. maxima, known as "Misti Kumra") seed oil contained a high amount of oleic acid, 40.58\%, while linoleic acid was $14.97 \%$.

Table 2. Total and intrapositional $\%$ fatty acid composition ( $\%$ mol, mean value $\pm \mathrm{SD}, n=3$ ) of oil and triacylglycerol (TAG) fraction of pumpkin (C. maxima, var. Berrettina) seed oil.

\begin{tabular}{|c|c|c|c|c|c|c|}
\hline & & Total Lipids & TAG & $s n-1-$ & sn-2- & $s n-3-$ \\
\hline Yield (\%) & & $29.0 \pm 0.9$ & & & & \\
\hline \multicolumn{7}{|l|}{$\begin{array}{l}\text { Saturated fatty acids } \\
\text { (SFA) }\end{array}$} \\
\hline Mystiric acid & C14:0 & $0.2 \pm 0.0$ & $0.1 \pm 0.0$ & $0.5 \pm 0.0$ & - & - \\
\hline Palmitic acid & $\mathrm{C} 16: 0$ & $14.2 \pm 0.4$ & $12.2 \pm 0.4$ & $28.5 \pm 0.0$ & $1.0 \pm 0.0$ & $7.1 \pm 0.0$ \\
\hline Margaric acid & $\mathrm{C} 17: 0$ & $0.2 \pm 0.0$ & $0.1 \pm 0.0$ & $0.5 \pm 0.0$ & - & - \\
\hline Stearic acid & C18:0 & $5.8 \pm 0.2$ & $6.2 \pm 0.2$ & $13.7 \pm 0.0$ & $0.4 \pm 0.0$ & $4.4 \pm 0.0$ \\
\hline Arachidic acid & C20:0 & $0.5 \pm 0.0$ & $0.4 \pm 0.0$ & - & - & $1.1 \pm 0.0$ \\
\hline Behenic acid & C22:0 & $0.1 \pm 0.0$ & $0.2 \pm 0.0$ & $1.5 \pm 0.0$ & - & - \\
\hline Lignoceric acid & $\mathrm{C} 24: 0$ & $0.1 \pm 0.0$ & - & - & - & - \\
\hline Total SFA & & 21.1 & 19.2 & 44.7 & 1.5 & 11.6 \\
\hline \multicolumn{7}{|l|}{$\begin{array}{c}\text { Monounsaturated fatty } \\
\text { acids (MUFA) }\end{array}$} \\
\hline Palmitoleic acid & $\mathrm{C} 16: 1 n-7$ & $0.2 \pm 0.0$ & $0.2 \pm 0.0$ & - & $0.1 \pm 0.0$ & $0.4 \pm 0.0$ \\
\hline Heptadecenoic acid & $\mathrm{C} 17: 1 n-7$ & $0.1 \pm 0.0$ & $0.1 \pm 0.0$ & - & $0.1 \pm 0.0$ & $0.3 \pm 0.0$ \\
\hline Oleic acid & $\mathrm{C} 18: 1 n-9$ & $41.4 \pm 0.7$ & $42.7 \pm 0.7$ & $46.5 \pm 0.0$ & $36.0 \pm 0.0$ & $44.6 \pm 0.0$ \\
\hline Eicosenoic acid & C20:1n-9 & $0.1 \pm 0.0$ & - & - & - & - \\
\hline Total MUFA & & 41.7 & 43.0 & 46.4 & 36.2 & 46.3 \\
\hline \multicolumn{7}{|l|}{$\begin{array}{l}\text { Polyunsaturated fatty } \\
\text { acids (PUFA) }\end{array}$} \\
\hline Linoleic acid & C18:2n-6 & $37.0 \pm 0.5$ & $37.4 \pm 0.5$ & $7.7 \pm 0.0$ & $62.1 \pm 0.0$ & $42.0 \pm 0.0$ \\
\hline Linolenic acid & $\mathrm{C} 18: 3 n-3$ & $0.2 \pm 0.0$ & $0.4 \pm 0.0$ & $1.1 \pm 0.0$ & $0.3 \pm 0.0$ & $0.1 \pm 0.0$ \\
\hline $\begin{array}{l}\text { Total PUFA } \\
\text { Index }\end{array}$ & & 37.2 & 37.8 & 8.8 & 62.4 & 24.1 \\
\hline UFA/SFA & & 3.7 & 4.2 & 1.2 & 65.7 & 6.1 \\
\hline MUFA/SFA & & 2.0 & 2.2 & 1.0 & 24.1 & 4.0 \\
\hline PUFA/SFA & & 1.8 & 2.0 & 0.2 & 41.6 & 2.1 \\
\hline PUFA $n-6 /$ PUFA $n-3$ & & 185 & 93.5 & 7.0 & 207 & 420 \\
\hline UI & & 116.3 & 118.9 & 65.2 & 161.3 & 129.6 \\
\hline $\mathrm{AI}$ & & 0.19 & 0.16 & 0.55 & 0.01 & 0.10 \\
\hline $\mathrm{TI}$ & & 0.50 & 0.44 & 1.38 & 0.03 & 0.32 \\
\hline
\end{tabular}

-: $<0.1 \%$; UI: unsaturation index: $\Sigma(\mathrm{mol} \%$ of each FA $) \times($ number of double bonds of each FA $)$; AI: atherogenic index $(\mathrm{C} 12: 0+4 \times \mathrm{C} 14: 0+\mathrm{C} 16: 0) /(\mathrm{MUFA}+\mathrm{PUFA} n-6+\mathrm{PUFA} n-3) ; \mathrm{TI}:$ thrombogenic index $(\mathrm{C} 14: 0+\mathrm{C} 16: 0+\mathrm{C} 18: 0) /(0.5 \times$ MUFA $+0.5 \times$ PUFA $n-6+3 \times$ PUFA $n-3+($ PUFA $n-3 /$ PUFA $n-6))$.

It was reported by Orsavova et al. [38] that MUFA may reduce low-density lipoprotein (LDL) cholesterol, while it may possibly increase HDL cholesterol, and that oleic acid (C18:1n-9) may promote insulin resistance contrary to PUFA, with protection against insulin resistance. The high content of linoleic acid is an important nutritional aspect, because it is an essential FA (EFA), together with linolenic acid (C18:3n-3), and a lack of either of the two leads to ill health and causes deficiency symptoms. In addition, several studies [39] have positively correlated EFA intake with reduction of numerous disorders (cardiovascular, neurological, visual, and cancerous).

Minor FA (contents lower than $0.5 \%$ ) of Berrettina pumpkin seed oil were myristic, palmitoleic (C16:1n-7), margaric (C17:0), heptadecenoic (C17:1n-7), arachidic (C20:0), behenic (C22:0), and lignoceric (C24:0) acids. These data are in good agreement with similar studies $[14,20,37,38]$.

The extreme variability of FA composition of pumpkin seeds, and consequently of the corresponding pumpkin seed oils, is affected not only by the variety of the cultivar, but also by the growth conditions and degree of ripeness [40].

In addition, the nutritional quality of pumpkin (C. maxima, var. Berrettina) cultivated in central Italy was evaluated, using different indices, based on the FA composition of the oils. It is known 
that some FA can help to prevent or promote coronary thrombosis and atherosclerosis based on their effects on LDL concentration and serum cholesterol [41]. The equations proposed by Ulbricht and Southgate [41] for the atherogenic index (AI) and thrombogenic index (TI) showed that C12:0, C14:0, and C16:0 FA are atherogenic, while C14:0, C16:0, and C18:0 are thrombogenic. PUFA $n-3$, PUFA $n-6$, and MUFA are antiatherogenic and antithrombogenic. Atherogenic indices have been described as powerful indicators of the risk of cardiovascular disease; the higher the value, the higher the risk of developing the disease, and vice versa. The AI of pumpkin (C. maxima) seed oil was lower than that reported by Siano et al. [16] (0.19 for Berrettina vs. 0.34$)$, while the TI was comparable (0.50 for Berrettina vs. 0.65).

\subsection{Stereospecific Analysis Data}

The indirect method of analyzing TAG was based on a chemical-enzymatic-instrumental (stereospecific analysis) procedure and allowed us to carry out qualitative and quantitative analysis of all molecular TAG species, including enantiomeric ones. In fact, it is known that in TAG molecules the positions esterified by FA are numbered relative to their stereospecific numbering $(s n)$ as $s n-1, s n-2$, and $s n-3$. The procedure allowed us to evaluate the FA \% composition of each of the three sn-positions of TAG (\% intrapositional composition). These data could be used to obtain the distribution of FA among the three $s n$-positions of TAG $[24,25,42,43]$.

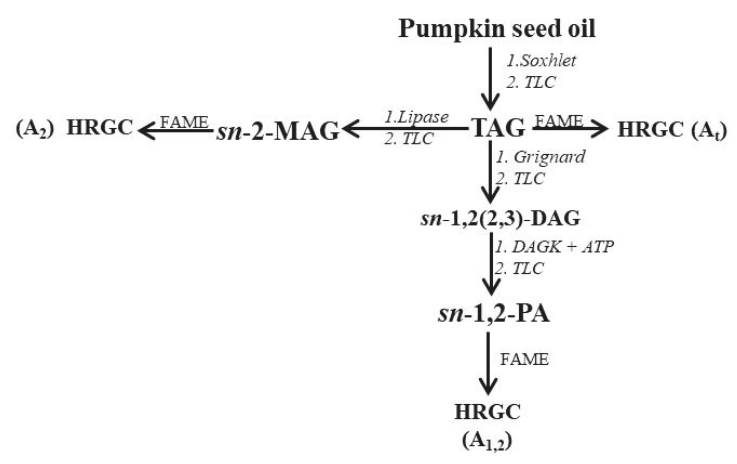

Figure 1. Scheme of the procedure used for stereospecific analysis of TAG from pumpkin (C. maxima, var. Berrettina) seed oil. HRGC: high-resolution gas chromatography; FAME: fatty acid methyl esters; TAG: triacylglycerol; sn-2-MAG: sn-2-monoacylglycerols; PA: phosphatidic acids; TLC: thin layer chromatography; DAG: diacylglycerol; DAGK: diacylglycerol kinase.

Initially, the lipid fraction was isolated by Soxhlet extraction, and then the TAG fraction was purified by TLC. As shown in Figure 1, several steps were carried out. Initially, the total FA\% composition $\left(A_{t}\right)$ was determined by HRGC. Figure 2a shows the characteristic HRGC profile of the FAME of the TAG fraction of pumpkin samples. Then, enzymatic hydrolysis of TAG with pancreatic lipase was used to obtain sn-2-MAG, and finally, after HRGC analysis of the FAME (Figure $2 b$ ), the acidic composition of $s n$-2-position $\left(\mathrm{A}_{2}\right)$ of the glycerol backbone of TAG was obtained. TAG was also subjected to chemical hydrolysis with Grignard reagent, then separation of enantiomeric $s n-1,2(2,3)-\mathrm{DAG}$, realized by enzymatic synthesis of $s n-1,2-\mathrm{PA}$, allowed us to obtain the acidic composition of the sn-1,2-positions $\left(\mathrm{A}_{1,2}\right)$ of the glycerol backbone of TAG, after HRGC analysis of the FAME (Figure 2c). 


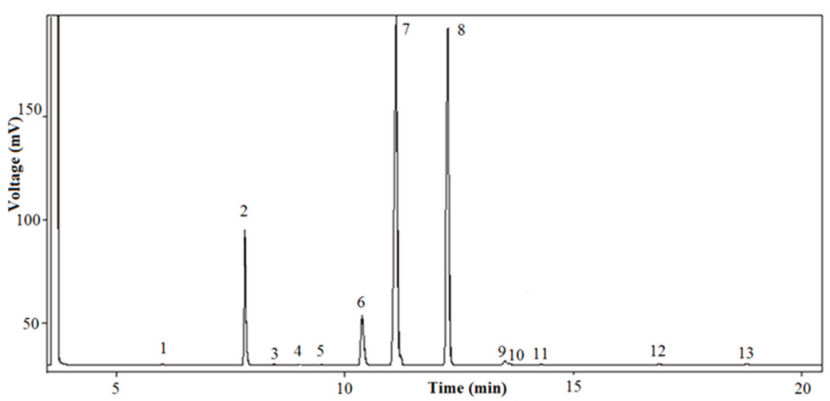

(a)

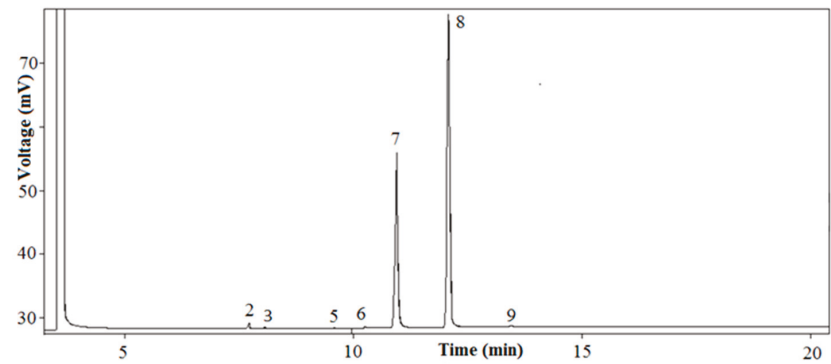

(b)

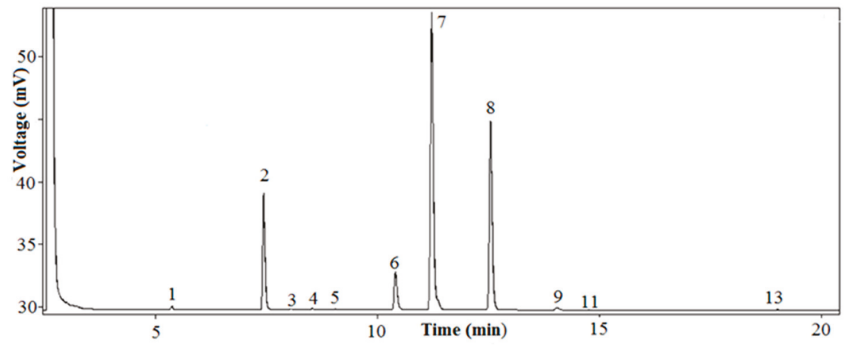

(c)

Figure 2. Characteristic high-resolution gas chromatography (HRGC) profiles of pumpkin (C. maxima, var. Berrettina) seed oil samples. (a) Fatty acid methyl esters (FAME) of TAG fraction; (b) FAME of monoacylglycerol (MAG) fraction; (c) FAME of PA fraction. 1. Myristic acid, 2. Palmitic acid, 3. Palmitoleic acid, 4. Margaric acid, 5. Heptadecenoic acid, 6. Stearic acid, 7. Oleic acid, 8. Linoleic acid, 9. Linolenic acid, 10. Arachidic acid, 11. Behenic acid, 12. Eicosenoic acid, 13. Lignoceric acid.

The stereospecific analysis represents a potent analytical-investigative procedure to give the fingerprint of TAG fraction for each botanical variety or animal species. The results of the stereospecific analysis procedure are shown in Table 2. It was observed that Berrettina pumpkin seed oil had a high percentage of UFA (98.5\%) in $s n-2$ position, represented by MUFA (36.2\%) and PUFA (62.4\%). In $s n-2$ position, the main FA was linoleic acid (62.1\%), followed by oleic acid (36.0\%). SFA are preferentially esterified in $s n-1$ position (44.7\%), represented essentially by palmitic and stearic acids $(28.6 \%$ and $13.7 \%$, respectively). Regarding the two primary positions, oleic acid was equally distributed between the $s n-1$ and $s n-3$ positions, while linoleic acid prefers the $s n-3$ position $(42.2 \%)$. 


\subsection{Unsaponifiable Fraction}

Another part of the research was analyzing the main components of unsaponifiable fractions, i.e., sterols and alcohols. Alkaline hydrolysis was carried out on pumpkin seed oils to obtain data relative to the qualitative composition of sterol and alcohol fractions. Phytosterols have been studied for their role in lowering cholesterol levels. In addition to this property, plant sterols have antiatherogenic, anti-inflammatory, anticancer, and antioxidation activities [44]. Together with the high content of linoleic acid, sterols can help in the treatment of lipid-associated disorders such as atherosclerosis.

In contrast to the other vegetable oils with $\Delta^{5}$-sterols ( $\beta$-sitosterol, campesterol, and stigmasterol) as the major components, Wenzl et al. [45] showed that pumpkin seed oil contains specific $\Delta^{7}$-phytosterols, typical of only a few plant families (e.g., Cucurbitaceae), that provide a fingerprint for detection of adulteration. These $\Delta^{7}$-sterols are supposed to give the pumpkin seed oil a beneficial effect in the treatment and prophylaxis of disorders of the prostate gland and the urinary bladder [46].

In this paper, sterol identification was carried out by HRGC-MS. Each peak was analyzed via detection of the parent molecular ion and the fragmentation pattern of the TMSE derivative. In addition to the presence of specific ion fragments, the relative intensity of the ion fragments was considered. Some TMSE sterols were identified by comparison with the NIST mass spectra library; typical fragmentation is reported in Table 3, together with sterol composition (\% and $\mathrm{mg} / 100 \mathrm{~g}$ ). TMSE sterols give a molecular ion that is not abundant, while the first significant ion observed in the high mass range was usually equivalent to $[\mathrm{M}-15]^{+}$, due to the loss of the methyl terminal group. Other main fragment ions useful for identifying the single sterol compounds are $[\mathrm{M}-90]^{+},[\mathrm{M}-105]^{+}$, and $[\mathrm{M}-129]^{+}$. They correspond to the loss of the trimethylsilanol, methyl group with trimethylsilanol, and fragmentation of the 1,2-cyclopenthanophenanthrene structure, respectively. The predominant sterols of Berrettina pumpkin seed oil are $\Delta^{7}$-sterols, in particular $\Delta^{7,22,25}$-stigmastatrienol, $\Delta^{7,25}$-stigmastadienol, and spinasterol, which accounted for about $76.8 \%$ of the total sterols, followed by $\Delta^{7}$-avenasterol and $\Delta^{7}$-stigmastenol. The $\Delta^{5}$-sterols were represented by campesterol, stigmasterol, and only a little cholesterol, as in other foodstuff [47]. Differences between the contents of $\Delta^{5}$ - and $\Delta^{7}$-sterols could be attributed to the maturity stage of seeds or to the solvent used in the extraction procedure [15]. A total sterol content of $295 \mathrm{mg} / 100 \mathrm{~g}$ oil was measured in C. maxima seed oil; $15.7 \mathrm{mg} / 100 \mathrm{~g}$ was represented by $\Delta^{5}$-sterols and $279.3 \mathrm{mg} / 100 \mathrm{~g}$ by $\Delta^{7}$-sterols. The total content was in agreement with other studies [9,48], even if a wide range of variability is reported [9]. Hence, more detailed examinations of the composition of the sterol fraction of this oil could be of special interest. For example, analysis of a more extensive sampling is required for better characterization of pumpkin seed oils and for their authentication.

The alcoholic fraction (aliphatic and triterpenic classes) was also studied, after derivatization as TMSE and analysis by HRGC-MS; the typical fragmentation is reported in Table 4, together with the alcohol composition (\% and mg/100 g). Some aliphatic alcohols (from C16 to C25 members of the 1-alkanol homologous series) with odd and even numbers of carbon atoms of the aliphatic chain were identified. The TMSE alcohols were identified by comparison with the NIST mass spectra library. TMSE alcohols give a molecular ion that is not abundant, while the first significant ion observed in the high mass range was equivalent to $[\mathrm{M}-15]^{+}$, due to the loss of the methyl terminal group, and $[\mathrm{M}-117]^{+}$, equivalent to the loss of $\left[(\mathrm{CH} 3)_{3}-\mathrm{Si}-\mathrm{O}\right]^{+}$, i.e., the OTMSi group. Moreover, HRGC-MS analysis of alcohols after BSTFA derivatization resulted in various peaks with MS fragments $m / z 73,75,103$, and 117 characteristics for OTMSi groups. The peak at $m / z 129$, corresponding to $\left[(\mathrm{CH} 3)_{3}-\mathrm{Si}-\mathrm{O}^{+}=\mathrm{CH}-\mathrm{CH}=\mathrm{CH}_{2}\right]^{+}$, has been identified as the fragment originating from the breakdown of ring A along with the TMS moiety. Four main triterpenic alcohols were identified: butyrospermol, obtusifoliol, $\beta$-amyrine, and cycloartenol. The key fragmentation ions were molecular ion $[\mathrm{M}]^{+}$, $[\mathrm{M}-15]^{+},[\mathrm{M}-90]^{+}$, and $[\mathrm{M}-105]^{+}$. Aliphatic alcohol content was $36.8 \%$, of which hexadecanol and octadecanol were the most abundant (each about $4.4 \mathrm{mg} / 100 \mathrm{~g}$ oil), while triterpenic alcohol content was around $63.2 \%$, of which obtusifoliol was the most abundant $(11.9 \mathrm{mg} / 100 \mathrm{~g}$ oil). 
Table 3. Fragmentation ions used for identification of trimethylsilyl ether (TMSE) sterols of pumpkin (C. maxima, var. Berrettina) seed oil and sterol composition ( $\%$ and $\mathrm{mg} / 100 \mathrm{~g}$ oil; mean value $\pm \mathrm{SD}, n=3$ ).

\begin{tabular}{cccccccc}
\hline Sterol & {$[\mathbf{M}]^{+}$} & [M-15 $^{+}$ & [M-90 $^{+}$ & [M-105 $^{+}$ & [M-129] $^{+}$ & \% & mg/100 g \\
\hline Cholesterol & 458 & 443 & 368 & 353 & 329 & $0.3 \pm 0.1$ & $0.9 \pm 0.1$ \\
Campesterol & 472 & 457 & 382 & 367 & 343 & $3.3 \pm 1.0$ & $10.3 \pm 1.0$ \\
Stigmasterol & 484 & 469 & 394 & 379 & 355 & $1.6 \pm 0.4$ & $4.5 \pm 0.8$ \\
Spinasterol & 484 & 469 & 394 & 379 & - & $20.5 \pm 1.9$ & $61.8 \pm 4.2$ \\
$\Delta^{7,25}$-Stigmastadienol & 484 & 469 & 394 & 379 & - & $26.4 \pm 2.3$ & $78.4 \pm 5.5$ \\
$\Delta^{7,22,25}$-Stigmastatrienol & 482 & 467 & 392 & 377 & - & $29.9 \pm 2.5$ & $91.2 \pm 6.8$ \\
$\Delta^{7}$-Stigmastenol & 486 & 471 & 396 & 381 & - & $5.7 \pm 1.0$ & $15.1 \pm 1.5$ \\
$\Delta^{7}$-Avenasterol & 484 & 469 & 394 & 379 & - & $12.3 \pm 0.9$ & $32.8 \pm 2.8$ \\
$\Delta^{5}$-Sterol (total) & & & & & & 5.2 & 15.7 \\
$\Delta^{7}$-Sterol (total) & & & & & & 94.8 & 279.3 \\
\hline
\end{tabular}

$[\mathrm{M}]^{+}$indicates molecular ion. $[\mathrm{M}-15]^{+},[\mathrm{M}-90]^{+},[\mathrm{M}-105]^{+}$, and $[\mathrm{M}-129]^{+}$correspond to loss of the methyl group, trimethylsilanol, methyl group with trimethylsilanol, and to fragmentation of the 1,2-cyclopenthanophenanthrene structure, respectively.

Table 4. Fragmentation ions used for identification of TMSE alcohols of pumpkin (C. maxima, var. Berrettina) seed oil and alcohol composition (\% and $\mathrm{mg} / 100 \mathrm{~g}$ oil; average value $\pm \mathrm{SD}, n=3)$.

\begin{tabular}{|c|c|c|c|c|c|c|}
\hline Aliphatic Alcohols & {$[\mathrm{M}]^{+}$} & {$[\mathrm{M}-15]^{+}$} & {$[\mathrm{M}-90]^{+}$} & {$[\mathrm{M}-117]^{+}$} & $\%$ & $\mathrm{mg} / 100 \mathrm{~g}$ \\
\hline Hexadecanol & 314 & 299 & 224 & 195 & $7.4 \pm 2.0$ & $4.3 \pm 1.0$ \\
\hline Heptadecanol & 328 & 313 & 238 & 209 & $3.1 \pm 0.9$ & $1.9 \pm 0.3$ \\
\hline Octadecanol & 342 & 327 & 252 & 223 & $7.5 \pm 1.3$ & $4.4 \pm 0.9$ \\
\hline Nonadecanol & 356 & 341 & 266 & 237 & $3.4 \pm 0.8$ & $2.9 \pm 1.5$ \\
\hline Eicosanol & 370 & 355 & 280 & 251 & $4.9 \pm 1.0$ & $2.0 \pm 0.8$ \\
\hline Docosanol & 398 & 383 & 308 & 279 & $3.1 \pm 0.9$ & $2.2 \pm 0.3$ \\
\hline Tricosanol & 412 & 397 & 322 & 293 & $1.8 \pm 0.5$ & $1.3 \pm 0.3$ \\
\hline Tetracosanol & 426 & 411 & 336 & 307 & $3.6 \pm 0.5$ & $1.2 \pm 0.2$ \\
\hline Pentacosanol & 440 & 425 & 350 & 321 & $2.3 \pm 0.7$ & $1.5 \pm 0.9$ \\
\hline Total & & & & & 36.8 & 21.7 \\
\hline Triterpenic Alcohols & {$[\mathrm{M}]^{+}$} & {$[\mathrm{M}-15]^{+}$} & [M-90] $^{+}$ & [M-105] $^{+}$ & & \\
\hline Butyrospermol & 498 & 483 & 408 & 393 & $13.7 \pm 1.2$ & $8.1 \pm 2.1$ \\
\hline Obtusifoliol & 484 & 469 & 394 & 379 & $20.2 \pm 1.5$ & $11.9 \pm 1.1$ \\
\hline$\beta$-Amyrine & 498 & 483 & 408 & 393 & $16.1 \pm 1.1$ & $9.5 \pm 1.8$ \\
\hline $\begin{array}{c}\text { Cycloartenol } \\
\text { Total }\end{array}$ & 498 & 483 & 408 & 393 & $\begin{array}{c}13.3 \pm 1.0 \\
63.2\end{array}$ & $\begin{array}{c}7.8 \pm 1.5 \\
37.3\end{array}$ \\
\hline
\end{tabular}

$[\mathrm{M}]^{+}$indicates molecular ion. For aliphatic alcohols: $[\mathrm{M}-15]^{+},[\mathrm{M}-90]^{+}$, and $[\mathrm{M}-117]^{+}$correspond to loss of the methyl group $\left[-\mathrm{CH}_{3}\right]$, trimethylsilanol [-OSi $\left.\left(\mathrm{CH}_{3}\right)_{3}\right]$, and ethyl trimethylsilanol $\left[-\mathrm{CH}_{3} \mathrm{CH}_{2}-\mathrm{OSi}\left(\mathrm{CH}_{3}\right)_{3}\right]$. For triterpenic alcohols: $[\mathrm{M}-15]^{+},[\mathrm{M}-90]^{+}$, and $[\mathrm{M}-105]^{+}$correspond to loss of the methyl group $\left[-\mathrm{CH}_{3}\right]$, trimethylsilanol $\left[-\mathrm{OSi}\left(\mathrm{CH}_{3}\right)_{3}\right]$, and methyl group with trimethylsilanol $\left[-\mathrm{CH}_{3} \mathrm{OSi}\left(\mathrm{CH}_{3}\right)_{3}\right]$.

These minor compounds are also important constituents of edible oils and could be useful in distinguishing different pumpkin oil varieties.

\subsection{Carotenoid Analysis}

HPLC-DAD-MS analysis, performed directly on seed oils, detected two important carotenoids: lutein and $\beta$-carotene. Quantitative analysis showed a lutein concentration of $8 \mathrm{mg} / \mathrm{L}$ seed oil, while $\beta$-carotene concentration was $2.5 \mathrm{mg} / \mathrm{L}$ seed oil.

Carotenoids such as lycopene, lutein, $\beta$-carotene, and zeaxanthin have been studied by many researchers both analytically and biologically [49-51]. Carotenoids represent a significant added value for food: various health properties have been associated with these compounds, including antioxidant and anticancer activity, photoprotection, protection against cardiovascular diseases, and anti-inflammatory activity [52-54]. 


\section{Conclusions}

The results reported in this study confirm that pumpkin seed oils are interesting vegetable oils with important nutritional value, related to the presence of MUFA, PUFA, phytosterols, and carotenoids. A more extensive sampling for a better characterization of pumpkin seed oils and for authentication purposes is necessary. To the best of our knowledge, this is the first time stereospecific analysis data of pumpkin seed oil have been reported. Information obtained from this research could help to assess the potential of seed oil from this pumpkin cultivar to be commercially exploited for nutraceutical application, and incorporated into food formulations to benefit human health.

Author Contributions: Each author contributed equally to the manuscript setting up and preparation.

Conflicts of Interest: The authors declare no conflict of interest.

\section{References}

1. Adams, G.G.; Imran, S.; Wang, S.; Mohammad, A.; Kok, S.; Gray, D.A.; Channell, G.A.; Morris, G.A.; Harding, S.E. The hypoglycemic effect of pumpkins as anti-diabetic and functional medicines. Food Res. Int. 2011, 44, 862-867. [CrossRef]

2. Różyło, R.; Gawlik-Dziki, U.; Dziki, D.; Jakubczyk, A.; Karaś, M.; Różyło, K. Wheat bread with pumpkin (Cucurbita maxima L.) pulp as a functional food product. Food Technol. Biotechnol. 2014, 52, 430-438. [CrossRef] [PubMed]

3. AlJahani, A.; Cheikhousman, R. Nutritional and sensory evaluation of pumpkin-based (Cucurbita maxima) functional juice. Nutr. Food Sci. 2017, 47, 346-356. [CrossRef]

4. Patel, S. Pumpkin (Cucurbita sp.) seeds as nutraceutic: A review on status quo and scopes. Mediterr. J. Nutr. Metab. 2013, 6, 183-189. [CrossRef]

5. Bardaa, S.; Halima, N.B.; Aloui, F.; Mansour, R.B.; Jabeur, H.; Bouaziz, M.; Sahnoun, Z. Oil from pumpkin (Cucurbita pepo L.) seeds: Evaluation of its functional properties on wound healing in rats. Lipids Health Dis. 2016, 15, 73-84. [CrossRef] [PubMed]

6. Medjakovic, S.; Hobiger, S.; Ardjomand-Woelkart, K.; Bucar, F.; Jungbauer, A. Pumpkin seed extract: Cell growth inhibition of hyperplastic and cancer cells, independent of steroid hormone receptors. Fitoterapia 2016, 110, 150-156. [CrossRef] [PubMed]

7. Wang, S.; Lu, A.; Zhang, L.; Shen, M.; Xu, T.; Zhan, W.; Jin, H.; Zhang, Y.; Wang, W. Extraction and purification of pumpkin polysaccharides and their hypoglycemic effect. Int. J. Biol. Macromol. 2017, 98, 182-187. [CrossRef] [PubMed]

8. Yadav, M.; Jain, S.; Tomar, R.; Prasad, G.B.K.S.; Yadav, H. Medicinal and biological potential of pumpkin: An updated review. Nutr. Res. Rev. 2010, 23, 184-190. [CrossRef] [PubMed]

9. Gutierrez, R.M.P. Review of Cucurbita pepo (pumpkin) its phytochemistry and pharmacology. Med. Chem. 2016, 6, 12-21. [CrossRef]

10. Dyshlyuk, L.; Babich, O.; Prosekov, A.; Ivanova, S.; Pavskya, V.; Yang, Y. In vivo study of medical and biological properties of functional bakery products with the addition of pumpkin flour. Bioact. Carbohydr. Diet. Fibre 2017, 12, 20-24. [CrossRef]

11. Romano, R.; Santini, A.; Le Grottaglie, L.; Manzo, N.; Visconti, A.; Ritieni, A. Identification markers based on fatty acid composition to differentiate between roasted Arabica and Canephora (Robusta) coffee varieties in mixtures. J. Food Compos. Anal. 2014, 35, 1-9. [CrossRef]

12. Cimmino, A.; Andolfi, A.; Troise, C.; Zonno, M.C.; Santini, A.; Tuzi, A.; Vurro, M.; Ash, G.; Evidente, A. Phomentrioloxin: A Novel Phytotoxic Pentasubstituted Geranylcyclohexentriol Produced by Phomopsis sp., a Potential Mycoherbicide for Carthamus lanathus Biocontrol. J. Nat. Prod. 2012, 75, 1130-1137. [CrossRef] [PubMed]

13. Mikušová, P.; Šrobárová, A.; Sulyok, M.; Santini, A. Fusarium fungi and associated metabolites presence on grapes from Slovakia. Mycotoxin Res. 2013, 29, 97-102. [CrossRef] [PubMed]

14. Stevenson, D.G.; Eller, F.J.; Wang, L.; Jane, J.L.; Wang, T.; Inglett, G.E. Oil and tocopherol content and composition of pumpkin seed oil in 12 cultivars. J. Agric. Food Chem. 2007, 55, 4005-4013. [CrossRef] [PubMed] 
15. Rezig, L.; Chouaibi, M.; Msaada, K.; Hamdi, S. Chemical composition and profile characterization of pumpkin (Cucurbita maxima) seed oil. Ind. Crops Prod. 2012, 37, 82-87. [CrossRef]

16. Siano, F.; Straccia, M.C.; Paolucci, M.; Fasulo, G.; Boscaino, F.; Volpe, M.G. Physico-chemical properties and fatty acid composition of pomegranate, cherry and pumpkin seed oils. J. Sci. Food Agric. 2016, 96, 1730-1735. [CrossRef] [PubMed]

17. Habib, A.; Biswas, S.; Siddique, A.H.; Manirujjaman, M.; Uddin, B.; Hasan, S.; Khan, M.M.H.; Uddin, M.; Islam, M.; Hasan, M.; et al. Nutritional and lipid composition analysis of pumpkin seed (Cucurbita maxima Linn.). J. Nutr. Food Sci. 2015, 5, 374-379.

18. Younis, Y.M.H.; Ghirmay, S.; Al-Shihry, S.S. African Cucurbita pepo L.: Properties of seed and variability in fatty acid composition of seed oil. Phytochemistry 2000, 54, 71-75. [CrossRef]

19. Ardabili, G.; Farhoosh, R.; Haddad Khodaparast, M.H. Chemical composition and physicochemical properties of pumpkin seeds (Cucurbita pepo Subsp. pepo Var. Styriaka) grown in Iran. J. Agric. Sci. Technol. 2011, 13, 1053-1063.

20. Procida, G.; Stancher, B.; Catenia, F.; Zacchigna, M. Chemical composition and functional characterisation of commercial pumpkin seed oil. J. Sci. Food Agric. 2013, 93, 1035-1041. [CrossRef] [PubMed]

21. Hernández-Santos, B.; Rodríguez-Miranda, J.; Herman-Lara, E.; Torruco-Uco, J.G.; Carmona-García, R.; Juárez-Barrientos, J.M.; Chávez-Zamudio, R.; Martínez-Sánchez, C.E. Effect of oil extraction assisted by ultrasound on the physicochemical properties and fatty acid profile of pumpkin seed oil (Cucurbita pepo). Ultrason. Sonochem. 2016, 31, 429-436. [CrossRef] [PubMed]

22. Butinar, B.; Bučar-Miklavčič, M.; Valenčič, V.; Raspor, P. Stereospecific analysis of triacylglycerols as a useful means to evaluate genuineness of pumpkin seed oils: Lesson from virgin olive oil analyses. J. Agric. Food Chem. 2010, 58, 5227-5234. [CrossRef] [PubMed]

23. AOAC. Official Methods of Analysis, 18th ed.; Association of Official Analytical Chemists: Washington, DC, USA, 2010.

24. Cossignani, L.; Montesano, D.; Simonetti, M.S.; Blasi, F. Authentication of Coffea arabica according to triacylglycerol stereospecific composition. J. Anal. Meth. Chem. 2016, 2016, 7482620. [CrossRef] [PubMed]

25. Blasi, F.; Montesano, D.; De Angelis, M.; Maurizi, A.; Ventura, F.; Cossignani, L.; Simonetti, M.S.; Damiani, P. Results of stereospecific analysis of triacylglycerol fraction from donkey, cow, ewe, goat and buffalo milk. J. Food Comp. Anal. 2008, 21, 1-7. [CrossRef]

26. Commissione Tecnica Governativa per gli Oli Minerali i Grassi i Colori le Vernici e i Detersive. NGD: Norme Italiane per il Controllo dei Grassi e Derivati; Official Method C72; Stazione Sperimentale per le Industrie Degli Olii e Dei Grassi: Milano, Italy, 1989; pp. 1-5.

27. Cossignani, L.; Blasi, F.; Simonetti, M.S.; Montesano, D. Fatty acids and phytosterols to discriminate geographic origin of Lycium barbarum berry. Food Anal. Methods 2017. [CrossRef]

28. AOCS. AOCS Official Method Ch 6-91: Composition of the Sterol Fraction of Animal and Vegetable Oils and Fats by TLC and Capillary GLC; American Oil Chemists' Society: Urbana, IL, USA, 1997.

29. Lombardi, G.; Cossignani, L.; Giua, L.; Simonetti, M.S.; Maurizi, A.; Burini, G.; Coli, R.; Blasi, F. Phenol composition and antioxidant capacity of red wines produced in Central Italy changes after one-year storage. J. Appl. Bot. Food Qual. 2017, 90, 197-204.

30. Laakso, P. Analysis of sterols from various food matrices. Eur. J. Lipid Sci. Technol. 2005, 107, 402-410. [CrossRef]

31. Blasi, F.; Rocchetti, G.; Montesano, D.; Lucini, L.; Chiodelli, G.; Ghisoni, S.; Baccolo, G.; Simonetti, M.S.; Cossignani, L. Changes in extra-virgin olive oil added with Lycium barbarum L. carotenoids during frying: Chemical analyses and metabolomics approach. Food Res. Int. 2018, 105, 507-516. [CrossRef] [PubMed]

32. Kim, M.Y.; Kim, E.J.; Kim, Y.N.; Choi, C.; Lee, B.H. Comparison of the chemical compositions and nutritive values of various pumpkin (Cucurbitaceae) species and parts. Nutr. Res. Pract. 2012, 6, 21-27. [CrossRef] [PubMed]

33. Blessing, A.C.; Ifeanyi, U.M.; Chijioke, O.B. Nutritional evaluation of some Nigerian pumpkins (Cucurbita spp.). Fruit Veg. Cereal Sci. Biotechnol. 2012, 5, 64-71.

34. Sharma, S.; Ramana Rao, T.V. Nutritional quality characteristics of pumpkin fruit as revealed by its biochemical analysis. Int. Food Res. J. 2013, 20, 2309-2316.

35. BDA. Food Composition Database for Epidemiological Studies in Italy. Available online: http://www.bdaieo.it/ (accessed on 10 January 2018). 
36. US Department of Agriculture, Agricultural Research Service, Nutrient Data Laboratory. USDA National Nutrient Database for Standard Reference, Release 28. Version Current: September 2015, Slightly Revised May 2016. Available online: https:/ /ndb.nal.usda.gov/ndb/ (accessed on 10 January 2018).

37. Tsaknis, J.; Lalas, S.; Lazos, E.S. Characterization of crude and purified pumpkin seed oil. Grasas y Aceites 1997, 48, 267-272. [CrossRef]

38. Orsavova, J.; Misurcova, L.; Ambrozova, J.V.; Vicha, R.; Mlcek, J. Fatty acids composition of vegetable oils and its contribution to dietary energy intake and dependence of cardiovascular mortality on dietary intake of fatty acids. Int. J. Mol. Sci. 2015, 16, 12871-12890. [CrossRef] [PubMed]

39. Kaur, N.; Chugh, V.; Gupta, A.K. Essential fatty acids as functional components of foods-A review. J. Food Sci. Technol. 2014, 51, 2289-2303. [CrossRef] [PubMed]

40. Fruhwirth, G.O.; Hermetter, A. Seeds and oil of the Styrian oil pumpkin: Components and biological activities. Eur. J. Lipid Sci. Technol. 2007, 109, 1128-1140. [CrossRef]

41. Ulbricht, T.L.V.; Southgate, D.A.T. Coronary heart disease: Seven dietary factors. Lancet 1991, 338, $985-992$. [CrossRef]

42. Simonetti, M.S.; Blasi, F.; Bosi, A.; Maurizi, A.; Cossignani, L.; Damiani, P. Stereospecific analysis of triacylglycerol and phospholipid fractions of four freshwater fish species: Salmo trutta, Ictalurus punctatus, Ictalurus melas and Micropterus salmoides. Food Chem. 2008, 110, 199-206. [CrossRef] [PubMed]

43. D'Arco, G.; Blasi, F.; Cossignani, L.; Di Giacomo, F.; Ciavardelli, D.; Ventura, F.; Scipioni, S.; Simonetti, M.S.; Damiani, P. Composition of meat and offal from weaned and fattened rabbits and results of stereospecific analysis of triacylglycerols and phosphatidylcholines. J. Sci. Food Agric. 2011, 92, 952-959. [CrossRef] [PubMed]

44. Berger, A.; Jones, P.H.; Abumweis, S.S. Plant sterols: Factors affecting their efficacy and safety as functional food ingredients. Lipids Health Dis. 2004, 3, 1-19.

45. Wenzl, T.; Prettner, E.; Schweiger, K.; Wagner, F.S. An improved method to discover adulteration of Styrian pumpkin seed oil. J. Biochem. Biophys. Methods 2002, 53, 193-202. [CrossRef]

46. Tsai, Y.S.; Tong, Y.C.; Cheng, J.T.; Lee, C.H.; Yang, F.S.; Lee, H.Y. Pumpkin seed oil and phytosterol-F can block testosterone/prazosin-induced prostate growth in rats. Urol. Int. 2006, 77, 269-274. [CrossRef] [PubMed]

47. Naviglio, D.; Gallo, M.; Le Grottaglie, L.; Scala, C.; Ferrara, L.; Santini, A. Determination of cholesterol in Italian chicken eggs. Food Chem. 2013, 132, 701-708. [CrossRef]

48. Srbinoska, M.; Hrabovski, N.; Rafajlovska, V.; Sinadinović-Fišer, S. Characterization of the seed and seed extracts of the pumpkins Cucurbita maxima D. and Cucurbita pepo L. from Macedonia. Maced. J. Chem. Chem. Eng. 2012, 31, 65-78.

49. Montesano, D.; Gennari, O.; Seccia, S.; Albrizio, S. A simple and selective analytical procedure for the extraction and quantification of lutein from tomato by-products by HPLC-DAD. Food Anal. Methods 2012, 5, 710-715. [CrossRef]

50. Fattore, M.; Montesano, D.; Pagano, E.; Teta, R.; Borrelli, F.; Mangoni, A.; Seccia, S.; Albrizio, S. Carotenoid and flavonoid profile and antioxidant activity in "Pomodorino Vesuviano" tomatoes. J. Food Comp. Anal. 2016, 53, 61-68. [CrossRef]

51. Montesano, D.; Fallarino, F.; Cossignani, L.; Bosi, A.; Simonetti, M.S.; Puccetti, P.; Damiani, P. Innovative extraction procedure for obtaining high pure lycopene from tomato. Eur. Food Res. Technol. 2008, 226, 327-335. [CrossRef]

52. Stahl, W.; Sies, H. Bioactivity and protective effects of natural carotenoids. Biochim. Biophys. Acta 2005, 1740, 101-107. [CrossRef] [PubMed]

53. Rao, A.V.; Rao, L.G. Carotenoids and humane health. Pharmacol. Res. 2007, 55, 207-217. [CrossRef] [PubMed]

54. Wu, W.; Li, Y.; Wu, Y.; Zhang, Y.; Wang, Z.; Liu, X. Lutein suppresses inflammatory responses through Nrf2 activation and NF-B inactivation in lipopolysaccharide-stimulated BV-2 microglia. Mol. Nutr. Food Res. 2015, 59, 1663-1673. [CrossRef] [PubMed]

(C) 2018 by the authors. Licensee MDPI, Basel, Switzerland. This article is an open access article distributed under the terms and conditions of the Creative Commons Attribution (CC BY) license (http:/ / creativecommons.org/licenses/by/4.0/). 
Article

\title{
Italian Opuntia ficus-indica Cladodes as Rich Source of Bioactive Compounds with Health-Promoting Properties
}

\author{
Gabriele Rocchetti ${ }^{1}$, Marco Pellizzoni ${ }^{2}$, Domenico Montesano ${ }^{3, *}$ and Luigi Lucini ${ }^{2}$ \\ 1 Department of Animal Science, Food and Nutrition, Università Cattolica del Sacro Cuore, via Emilia \\ Parmense 84, 29122 Piacenza, Italy; gabriele.rocchetti@unicatt.it \\ 2 Department for Sustainable Food Process, Università Cattolica del Sacro Cuore, via Emilia Parmense 84, \\ 29122 Piacenza, Italy; marco.pellizzoni@unicatt.it (M.P.); luigi.lucini@unicatt.it (L.L.) \\ 3 Department of Pharmaceutical Sciences, Section of Food Science and Nutrition, University of Perugia, \\ Via San Costanzo 1, 06126 Perugia, Italy \\ * Correspondence: domenico.montesano@unipg.it; Tel.: +39-075-5857919; Fax: +39-075-5857921
}

Received: 13 January 2018; Accepted: 16 February 2018; Published: 18 February 2018

\begin{abstract}
Natural by-products, especially phenolic compounds, are in great demand by the nutra-pharmaceutical and biomedical industries. An analytical study was performed to investigate, for the first time, the presence of antioxidant constituents and the corresponding in vitro antioxidant activity in the extract of cladodes from Ficodindia di San Cono (Opuntia ficus-indica) protected designation of origin (PDO). The cladode extracts were analysed for target determination of selected constituents, i.e., $\beta$-polysaccharides and total phenolic content. Moreover, the antioxidant activity of hydro-alcoholic extracts was assessed by means of two different methods: $\alpha, \alpha$-diphenyl- $\beta$-picrylhydrazyl (DPPH) free radical scavenging method and ferric reducing antioxidant power (FRAP) assay. An untargeted UHPLC-ESI-QTOF-MS profiling approach was used to depict the phenolic profile of hydro-alcoholic cladode extracts. Interestingly, over $2 \mathrm{~g} / \mathrm{kg}$ of polyphenols were detected in this matrix, and these compounds were mainly responsible for the antioxidant properties, as shown by the strong correlation between phenolic classes and antioxidant scores. Finally, this study provides basic information on the presence of bioactive compounds and in vitro antioxidant activities in cladode extracts from cactus that might recommend their novel applications at the industrial level in the field of nutraceutical products.
\end{abstract}

Keywords: food profiling; polyphenols; $\beta$-polysaccharides; antioxidant activity; Opuntia ficus-indica; cladodes

\section{Introduction}

The cactus (genus Opuntia, family Cactaceae) is a native plant of the American continent and is commonly found at every latitude although it is better adapted to arid areas. Prickly pear cacti can be found all over the world, with a wide climatic tolerance, being able to proliferate in rainfall regimes of 250 to $1200 \mathrm{~mm}$ per annum with very hot summers of over $40^{\circ} \mathrm{C}$, and cold winters with temperatures frequently falling below $0{ }^{\circ} \mathrm{C}$ for brief durations [1].

Nowadays, there are more than 250 species, distributed in Mediterranean Europe, India, the Middle East and in the American and African countries [2]. More than $90 \%$ of cultivated crops of the Italian production are grown in Sicily (southern Italy), representing an important food source [3]. In this regard, "Ficodindia di San Cono" (Opuntia ficus-indica) is a protected designation of origin (PDO) product from Sicily characterized by a large-sized fruit, with a weight varying from 105 to $270 \mathrm{~g}$ (with $5 \%$ tolerance). From a botanical point of view, the fruit presents a green or yellowish-orange colored skin for the "Surfarina" cultivar, whilst the "Sanguigna" and "Muscaredda" cultivars range from green to ruby-red and green to straw-white, respectively. 
The main commercial exploitation of this plant remains the fruit, although the vegetative parts, i.e., cladodes, are generally used as animal feed [4,5], fodder or disposed in landfills, whilst in some countries they are also consumed as plants for human consumption [6]. In fact, not only the fruits but also young cladodes are used as a starting point to realize several consumer goods, such as candy, liqueurs, body lotions, creams, and shampoos [7]. Some authors [8] have calculated also the nutritional value of the Opuntia fruits, placing them between that of lettuce and spinach.

In recent years, the market has shown considerable interest in a variety of tissues of Opuntia ficus-indica since they can be used both in food and pharmaceutical areas [6]. In particular, attention is now focused on the difference between food/dietary supplements and nutraceuticals [9]. Nutraceuticals are closer to pharmaceuticals and can help in fighting some of the major health challenges of the century, such as metabolic syndrome, cardiovascular diseases and hypercholesterolemia [9]. In this regard, they are considered 'beyond the diet before the drugs', as pointed out in previous works [10].

Cactus cladodes contain high amounts of fiber, including pectin, mucilage, lignin, cellulose and hemicellulose, and generally these substances are able to bring wellbeing to the metabolism of lipids and sugars [11]. In particular, $\beta$-polysaccharides (i.e., glucose units linked $(1 \rightarrow 4)-\beta$ (as in cellulose) but interspersed with $(1 \rightarrow 3)$ - $\beta$-linkages), are characterized by an irregular linkage structure that prevents the formation of a crystalline structure leading to a water-soluble capacity [12]. These polysaccharides are generally classified as soluble dietary fiber, improving glucose control and modulate renal water and sodium handling in type 2 diabetes patients; therefore, the high dietary fiber content of cladodes has the capacity to absorb large amounts of water, forming viscous or gelatinous colloids, and determining the absorption of several kinds of organic molecules [13]. Opuntia ficus-indica cladodes can also be considered a rich source of bioactive and functional compounds, which make them an important candidate for the production of health-promoting and functional foods. In this regard, in recent years, the scientific world has paid particular attention to polyphenols as they have shown antioxidant properties in vitro, together with protective effects against cancer, and the ability to cure and prevent cardiovascular disorders, inflammatory and allergic diseases [14]. Cardiovascular disease is one of the major factors responsible for death in industrialized countries [15]; therefore, Opuntia ficus-indica cladodes could help in lowering cholesterol levels and in preventing hypercholesterolemia [16].

Several studies reported the potential of seeds and peels from Opuntia spp. as novel by-products with antioxidant activity and bioactive properties $[17,18]$. However, although traditionally used as a valuable health supporting nutrient, the vegetative parts of Opuntia spp. plants (i.e., the non-edible parts) have been scarcely studied, and nowadays there is a lack of information on their entire chemical and bioactive properties. Furthermore, antioxidant properties of Opuntia spp. genus have been described only for few species [19], and very little information is available about cultivars located in Italy, in particular about Ficodindia di San Cono PDO and its comprehensive screening of phenolic compounds.

Therefore, in this work, $\beta$-polysaccharides, total phenolic content, antioxidant activity (as FRAP reducing power and DPPH radical scavenging), and the untargeted phenolic profile of extracts from fully-grown cladodes from Ficodindia di San Cono PDO were deeply investigated. The use of an untargeted ultra-high-pressure liquid chromatography coupled to quadrupole-time-of-flight mass spectrometer (UHPLC-ESI-QTOF-MS) system is expected to provide a much deeper investigation of the actual phenolic composition of these cladodes, as compared to classical targeted approaches. Moreover, the obtained fingerprint may be useful to better understand the nutraceutical traits of this species, considering both products and by-products obtainable from the processing of cladodes.

\section{Materials and Methods}

\subsection{Cladodes Harvest and Preparation}

Opuntia ficus-indica cladodes with an approximate length of 25-30 cm were manually harvested from the PDO consortium area, comprising the municipalities of San Cono, San Michele di Ganzaria, Piazza Armerina and Mazzarino (Catania and Enna, Sicily, Italy-altitude: from 200 to $400 \mathrm{~m}$ a.s.l.). 
A sample per municipality (except the site of San Cono, where 2 samples were produced), was prepared by pooling 5 cladodes. In more detail, one apical, three central and one basal position fresh cactus cladodes were washed, and the thorns were removed manually. Then, they were individually cut into small pieces, peeled and homogenized by a mixer, obtaining five samples (replicates). The mean value for each target analyses has been obtained calculating the average among the five leaves. All samples were store at $-18^{\circ} \mathrm{C}$ in freezer until further analysis.

\subsection{Proximate Composition of Cladodes}

The proximate composition analyses were carried out according to AOAC [20] for dry matter (DM; method 930.15), protein (method 976.05), ash (method 942.05) and lipid (method 954.02 without acid hydrolysis), while total carbohydrates were calculated by difference. Samples were also analysed for contents of different fiber fractions, i.e., neutral detergent fiber (NDF), acid detergent fiber (ADF) and acid detergent lignin (ADL), according to the methods described by Van Soest et al. [21]. Finally, the results were expressed as grams of each compound per $100 \mathrm{~g}$ of cladodes.

\subsection{Determination of $\beta$-polysaccharides Content}

The $\beta$-polysaccharides content was determined colorimetrically, recording the absorbance at $540 \mathrm{~nm}$, after reaction with Congo red dye, according to Eberendu et al. [22]. The spectrophotometric measurements were performed using a Perkin Elmer lambda 12 UV/VIS spectrophotometer (Ontario, Canada). The samples were extracted by $4 \mathrm{~g}$ of inner parenchyma in $10 \mathrm{~mL}$ of double distilled sterile water, homogenized and finally shaken using a horizontal shaker for $2 \mathrm{~h}$. After that, $500 \mu \mathrm{L}$ of $15 \mathrm{~g} / \mathrm{L}$ $\mathrm{KOH}$ together with $2 \mathrm{~mL}$ of Congo red solutions (obtained by diluting a saturated aqueous solution 50 times) were added. The final reaction volume was left for $1 \mathrm{~h}$ prior the colorimetric reading at $\lambda=540 \mathrm{~nm}$. In order to perform quantitative determinations, a pure $\beta$-glucan standard was used, and the respective results were expressed as $\beta$-glucan equivalents. Finally, measurements on five different cladode extracts from Opuntia ficus-indica di San Cono were performed.

\subsection{Extraction and Profiling of Phenolic Compounds from Cladodes}

Each replicate (five) was extracted from $4 \mathrm{~g}$ of representative sample of inner parenchyma in $20 \mathrm{~mL}$ of $0.1 \%$ formic acid in 80:20 (v/v) methanol/water (LCMS grade, VWR, Milan, Italy) using an Ultra-turrax (Ika T25, Staufen, Germany) at 25,000 rpm for $3 \mathrm{~min}$. The extracts were then centrifuged at $313 \times g$ for $15 \mathrm{~min}$ at $4{ }^{\circ} \mathrm{C}$. The resulting solutions were filtered using $0.22 \mu \mathrm{m}$ cellulose syringe filters and collected in an amber vial for further use.

The total phenolic contents were investigated by using the Folin-Ciocalteu spectrophotometric assay, as previously reported [23], with small modifications. Aliquots of the sample $(1 \mathrm{~mL})$ were mixed with $2.5 \mathrm{~mL}$ of Folin-Ciocalteu reagent (Sigma, diluted five-fold) and $4 \mathrm{~mL}$ (75 g/L) sodium carbonate. Subsequently, the absorbance was recorded at $765 \mathrm{~nm}$, after $40 \mathrm{~min}$ at $20{ }^{\circ} \mathrm{C}$ in dark conditions. Finally, a calibration curve was prepared in order to express final results; in particular, aliquots of gallic acid methanolic solutions were prepared to his purpose, and the results expressed as gallic acid equivalents (GAE).

After that, phenolic compounds were profiled through ultra-high-pressure liquid chromatography (a 1290 liquid chromatographic system equipped with binary pump, from Agilent Technologies, Santa Clara, CA, USA) coupled to a hybrid quadrupole-time-of-flight mass spectrometer (a G6550 mass spectrometer detector, from Agilent Technologies, Santa Clara, CA, USA), by using a JetStream dual electrospray as ionization source (UHPLC-ESI-QTOF-MS). UHPLC-ESI-QTOF-MS analytical conditions were set up on the basis of a previous experiment [24]. Briefly, the acquisition range of mass spectrometer was set from 50 to $1000 \mathrm{~m} / \mathrm{z}$ with the instrument working in positive MS-only mode. In order to keep the mass axis calibrated, lock masses (121.0509 and $922.0098 \mathrm{~m} / \mathrm{z}$ ) were continuously infused during analyses using a separate electrospray. A reverse phase C18 column (Agilent Zorbax eclipse plus C18, $50 \times 2.1 \mathrm{~mm}, 1.8 \mu \mathrm{m}$ ) with a water/methanol gradient elution was 
used for chromatographic separation. In particular, the LC mobile phase A consisted of water (Milli-Q grade, Millipore, Bedford, MA, USA), while the mobile phase B was methanol (LCMS grade, VWR, Milan, Italy). Formic acid $0.1 \%(v / v)$ and ammonium formate $(5 \mathrm{mM})$ (both from Sigma) were added to both mobile phases. The gradient was initiated with $5 \% \mathrm{~B}$ and increased to $90 \% \mathrm{~B}$ within $15 \mathrm{~min}$, then held for $3 \mathrm{~min}$. The LC mobile phase temperature was set to $35^{\circ} \mathrm{C}$, with a flow rate of $220 \mu \mathrm{L} / \mathrm{min}$. Injection volume was $3 \mu \mathrm{L}$, and source conditions were the following: nitrogen was used as both sheath gas $\left(10 \mathrm{~L} / \mathrm{min}\right.$ and $\left.350{ }^{\circ} \mathrm{C}\right)$ and drying gas $\left(8 \mathrm{~L} / \mathrm{min}\right.$ and $\left.330{ }^{\circ} \mathrm{C}\right)$; nebulizer pressure was $60 \mathrm{psig}$, nozzle voltage was $300 \mathrm{~V}$, and capillary voltage was $3.5 \mathrm{kV}$. Mass spectrometry raw data were analysed using the Agilent Profinder B.07 software, by using the 'find-by-formula' algorithm. In particular, compound identification was realized based on the Phenol-Explorer 3.6 database [25], and using the entire isotopic profile (monoisotopic accurate mass, isotope spacing and ratio) to increase the accuracy. An overall identification score above $85 \%$ and a mass accuracy below 5 ppm were adopted as minimum identifications criteria. The mass and retention time alignment with the compounds filtering (post-acquisition data processing) were conducted in Profinder B.07: only those compounds identified within $100 \%$ of the replications in at least one cladode sample were considered.

Furthermore, after a classification of polyphenols into phenolic classes and subclasses, cumulative intensities were calculated, and then quantitative values were determined by using methanolic standard solutions of pure phenolics (provided from Extrasyntese, Lyon, France) in order to provide more information. Particularly, the standards used were: matairesinol and sesamin (for dibenzylbutyrolactone and dihydroxydibenzylbutane, and furan and furofuran lignans, respectively), ferulic acid (for hydroxycinnamic acids and other phenolic acids), cyanidin (as representative of anthocyanins subclass), catechin (flavanols), luteolin (flavones and other remaining flavonoids), resveratrol (stilbenes), pentadecylresorcinol or cardol (for alkylresorcinols) and tyrosol (as representative of tyrosols and other remaining phenolics). Therefore, a calibration curve (not weighed and not forced to origin) was built and used for the quantization of phenolic compounds, considering five concentrations of standard over 5 orders of magnitude.

\subsection{Assay of DPPH Radical Scavenging Activity}

The radical scavenging ability of polyphenols against the stable radical DPPH was investigated by using the DPPH spectrophotometric assay, as previously described [23]. Briefly, $2 \mathrm{~mL}$ of each phenolic extract solution was placed in a cuvette together with $2 \mathrm{~mL}$ of a $1.0 \times 10^{-4} \mathrm{~mol} / \mathrm{L}$ daily-prepared ethanol solution of DPPH. The absorbance measurements were performed at $517 \mathrm{~nm}$ using a Perkin Elmer lambda 12 UV/VIS spectrophotometer (Ontario, Canada). The decrease in absorbance was determined continuously after the addition of the DPPH radical at five minute intervals. DPPH radical scavenging activity coefficients were calculated using gallic acid as reference compound, and results were finally expressed as gallic acid equivalents (GAE).

\subsection{Assay of FRAP Reducing Antioxidant Power}

The FRAP assay was carried out on the basis of the colorimetric method previously described by Benzie and Strain [26], with minor modification. In particular, the clinical auto-analyzer ILAB 600 (Instrumentation Laboratory, Lexington, MA, USA) was used to carry out the measurements. The FRAP working reagent was prepared daily by mixing a pH 3.6 acetate buffer $300 \mathrm{mM}$, a TPTZ (2,4,6-tripyridyl-s-triazine) $10 \mathrm{mM}$ in $40 \mathrm{mM} \mathrm{HCl}$ solution and $\mathrm{FeCl}_{3} 20 \mathrm{mM}$, in the ratio of 10:1:1. The phenolic extracts $(100 \mu \mathrm{L})$ were mixed with $3000 \mu \mathrm{L}$ of FRAP working reagent and the absorbance was measured at $600 \mathrm{~nm}$, after $343 \mathrm{~s}$ of incubation at $37^{\circ} \mathrm{C}$. A calibration curve was built using gallic acid in ethanol before any session of analysis. Finally, the results were expressed as gallic acid equivalents (GAE).

\subsection{Statistical Analysis}

Data analysis were carried out with PASW Statistics 25.0 (SPSS Inc.: Chicago, IL, USA). Correlations among $\beta$-polysaccharides, total phenolic content, antioxidant activities and phenolic classes equivalents 
of Opuntia cladode samples were obtained through Pearson's correlation coefficient $(p<0.01$, two tailed). The elaboration of UHPLC-ESI-QTOF-MS data on phenolic profile of cladodes phenolic extracts were made using Agilent Mass Profiler Professional B.12.06 (Agilent Technologies, Santa Clara, CA, USA). Compounds' abundance was normalized at the 75th percentile and baselined to their median across all replicates.

\section{Results and Discussion}

\subsection{Nutritional Composition, Total Phenolics and $\beta$-polysaccharides Contents}

The nutritional composition of Ficodindia di San Cono cladodes is presented in Table 1.

Table 1. Chemical composition (on a fresh weight basis) of Ficodindia di San Cono cladodes. Data are presented as mean values \pm standard deviation $(n=5) . \mathrm{NDF}=$ neutral detergent fiber; $\mathrm{ADF}=$ acid detergent fiber; $\mathrm{ADL}=$ acid detergent lignin. ${ }^{*}=$ obtained by difference.

\begin{tabular}{cc}
\hline Parameters & San Cono cladodes \\
\hline Moisture (g water $/ 100$ g cladodes) & $92.33 \pm 1.36$ \\
Protein (\%) & $0.58 \pm 0.02$ \\
Ash (\%) & $0.50 \pm 0.01$ \\
Lipid (\%) & $0.12 \pm 0.02$ \\
Carbohydrates (\%) * & 3.05 \\
NDF (\%) & $3.42 \pm 0.63$ \\
ADF (\%) & $0.83 \pm 0.14$ \\
ADL (\%) & $0.12 \pm 0.02$ \\
\hline
\end{tabular}

These results showed that San Cono cladodes possessed low protein and lipid content, being 0.58 and $0.12 \mathrm{~g} / 100 \mathrm{~g}$, respectively. De Santiago et al. [27] reported a higher protein content $(1.1 \mathrm{~g} / 100 \mathrm{~g})$ and a similar lipid content $(<0.1 \mathrm{~g} / 100 \mathrm{~g})$ in fresh cactus cladodes (Opuntia ficus-indica) from Spain. San Cono cladodes were particularly abundant in fiber, being the NDF content of $3.42 \mathrm{~g} / 100$, and this finding fitted with results obtained by De Santiago et al. [27] and Guevara-Figueroa et al. [28]. Stintzing and Carle [7] reviewed the chemistry and technological use of Opuntia cladodes, showed that, on a fresh weight basis, the typical chemical composition of these matrices is characterized by $3-7 \mathrm{~g}$ carbohydrates, 1-2 $\mathrm{g}$ minerals, $0.5-1 \mathrm{~g}$ proteins, $0.2 \mathrm{~g}$ lipids and $1 \mathrm{~g}$ of fiber. However, the fact that cladode composition varies according to edaphic factors at the cultivation site, the season and the age of the plant should be taken into account; at this regard, young cladodes show higher carbohydrate, protein and water contents [7].

As regards polyphenols, these compounds are widely distributed in the plant kingdom and in recent years they have attracted much attention, due to their in vitro antioxidant capacity with potential beneficial implications in human health [29]. The total phenolic content (TPC), as assayed through the Folin-Ciocalteu approach, along with $\beta$-polysaccharides content and in vitro antioxidant activity (DPPH radical scavenging and FRAP reducing power) are reported in Table 2.

Overall, present findings showed that cladodes from Ficodindia di San Condo PDO possessed considerable nutritional value with health-promoting properties. It has been well studied that the phenolic content of plant materials is strongly correlated with their antioxidant activity [30]. Normally, lipophilic and hydrophilic compounds, such as carotenoids and polyphenols, contribute to the total in vitro antioxidant activity of fruits and vegetables [31,32]. In particular, phenolic compounds are the principal plant constituents with antioxidant properties, which exhibit an important function in neutralizing free radicals [33]. In the present study, the TPC in cladodes of Ficodindia di San Cono PDO was found around $2600 \mathrm{mg} \mathrm{GAE} / \mathrm{kg}$ fresh weight (FW). This value was comparable to findings reported by De Santiago et al. [27] which obtained a GAE value of $1700 \mathrm{mg} / \mathrm{kg}$ FW for cactus cladodes (Opuntia ficus-indica) collected from Spain. Other works reported definitely lower TPC values; for example, Santos-Zea et al. [34] reported GAE values of $318 \mathrm{mg} / \mathrm{kg}$ DM for cladode 
flours, considering the variety 'Jalpa' of Opuntia ficus-indica, whilst other varieties of Opuntia spp. showed on average GAE values around $700 \mathrm{mg} / \mathrm{kg}$ DM. Furthermore, Ramirez-Moreno et al. [35] determined the levels of polyphenols in cladodes of two species (Opuntia ficus-indica, cultivars 'Milpa' and 'Atlixco'), showing GAE values of 5710 and $3820 \mathrm{mg} / \mathrm{kg}$ DM, respectively. However, it is important to underline that these differences in TPC could arise above all from different climatic conditions [36]. In particular, looking at Opuntia spp. plants, all parts of the cactus are particularly rich in polyphenolic classes, such as various flavonoids and phenolic acids, as reviewed by El-Mostafa et al. [37]. However, the secondary metabolite accumulation in the plant depends on both biotic and abiotic factors. Since the Opuntia species used in this study were cultivated under the same environmental conditions (according to PDO product specifications), the amount and profile of polyphenols were characteristics of Opuntia spp. grown in this geographic area.

Table 2. Total $\beta$-polysaccharides, total phenolic content (TPC), and antioxidant activities (DPPH radical scavenging and FRAP reducing power) in cladodes extracts. The data are presented as mean values \pm standard deviation $(n=5)$. Results for TPC, DPPH and FRAP are expressed as gallic acid equivalents (GAE), whilst results for $\beta$-polysaccharides are expressed as $\beta$-glucan equivalents. $\mathrm{FW}=$ fresh weight.

\begin{tabular}{ccccc}
\hline & $\begin{array}{c}\beta \text {-Polysaccharides } \\
(m g \beta \text {-Glucan Equivalents } / \mathrm{kg} \text { FW })\end{array}$ & $\begin{array}{c}\text { TPC } \\
(m g \text { GAE/kg FW })\end{array}$ & $\begin{array}{c}\text { DPPH } \\
(m g \text { GAE/kg FW })\end{array}$ & $\begin{array}{c}\text { FRAP } \\
(m g \text { GAE/kg FW })\end{array}$ \\
\hline Cladodes & $2617.39 \pm 225.58$ & $2633.10 \pm 214.78$ & $1040.03 \pm 112.42$ & $1638.17 \pm 41.30$ \\
\hline
\end{tabular}

Dietary fiber (DF) is considered a combination of chemically heterogeneous substances. Nowadays, the soluble/insoluble DF ratio is an important nutritional parameter, like TDF content, because of the different physiological and beneficial effects [38]. In particular, soluble dietary fiber (SDF) is characterized by compounds with high water holding activity, which can be considered health promoting substrates of intestinal and colonic microbiota. Some studies outlined that the majority component of cladode samples was DF [13]. In this study, the SDF content in cladodes was investigated colorimetrically, showing a value of $2617.39 \mathrm{mg} \beta$-glucan equivalents $/ \mathrm{kg}$ FW. This value was even higher than the $\beta$-polysaccharides content of inner gel parenchyma from leaves of two different Aloe species, being on average $828 \mathrm{mg}$ $\beta$-glucan equivalents $/ \mathrm{kg}$ FW [39]. $\beta$-glucans, like some other $\beta$-polysaccharides, are considered the principal component of the soluble fiber in whole oats and barley, and their biological activities are strongly influenced by the molecular weight. Among cereals, the highest content of $\beta$-glucans (as $g$ per $100 \mathrm{~g}$ dry weight) has been reported for barley $2-20 \mathrm{~g}$ and oats $3-8 \mathrm{~g}$. The other cereals contain these compounds in much lower amounts, with the following values: sorghum 1.1-6.2 g, rye 1.3-2.7 g, maize $0.8-1.7 \mathrm{~g}$, triticale $0.3-1.2 \mathrm{~g}$, wheat $0.5-1.0 \mathrm{~g}$, durum wheat $0.5-0.6 \mathrm{~g}$, and rice $0.13 \mathrm{~g}$ [40]. Other studied sources of $\beta$-glucans include some types of seaweed and different species of mushrooms [40]. Cladodes from Ficodindia di San Cono PDO were then characterized by approximately $0.3 \mathrm{~g} / 100 \mathrm{~g}$ DM of $\beta$-glucan equivalents, a value comparable to triticale, rice, and wheat. Therefore, the combination of high DF and associated phytochemicals (such as phenolic compounds) in a single matrix (such as cladodes) results in a food system with specific health related properties, suitable for different uses.

\subsection{In vitro Antioxidant Activity of Cladodes}

The in vitro antioxidant activity should not be determined based on a single antioxidant test [41]. Therefore, in the current work, the in vitro antioxidant activity of samples was evaluated by employing FRAP and DPPH assays, since the aforementioned methods are based on two different reaction mechanisms and kinetics [41]. Furthermore, the DPPH assay is currently considered a valid colorimetric method for the evaluation of antioxidant potential of plant extracts [42]. Furthermore, the literature presents a lack of uniformity in the standards used for calibration or regarding the best antioxidant assay performed; therefore, sometimes the comparison of spectrophotometric results with literature data becomes difficult. 
Antioxidants are a group of compounds very different in chemistries and properties, therefore. the choice of assay could have a great effect upon the results obtained [43]. These antioxidant compounds may help to reduce the oxidative stress, preventing free radicals from damaging biomolecules such as proteins, DNA and lipids [44]. As shown in Table 2, San Cono Opuntia cladodes possessed GAE values of $1040 \mathrm{mg} / \mathrm{kg}$ FW considering DPPH radical scavenging, and $1638 \mathrm{mg} / \mathrm{kg}$ FW for FRAP reducing power. De Santiago et al. [27] obtained DPPH values in Opuntia spp. cladode extracts of $45.05 \mathrm{mg}$ Trolox Equivalents $/ \mathrm{kg} \mathrm{FW}$, while Astello-Garcia et al. [45] reported on average a DPPH value of 127,000 Trolox Equivalents/ $\mathrm{kg}$ DW considering three different cultivars of the same species (Opuntia ficus-indica). However, these data regarding DPPH were not properly comparable due to the different expression of results. Considering FRAP reducing power of San Cono cladodes, the value obtained ( $962 \mu \mathrm{mol} \mathrm{GAE} / 100 \mathrm{~g}$ ) is higher than those reported by Rocchetti et al. [24], evaluating the antioxidant potential of common gluten-free flours containing polyphenols. Furthermore, cladode extracts also showed higher DPPH radical scavenging values than pumpkin and poppy seeds, being respectively 620 and $860 \mathrm{mg} \mathrm{GAE} / \mathrm{kg}$, as reported by Ghisoni et al. [46].

\subsection{Evaluation of Phenolic Profile by UHPLC-ESI-QTOF-MS}

An untargeted UHPLC-ESI/QTOF-MS approach was used to investigate the entire phenolic profile in cladodes extracts. Flavonoids were definitely the most frequent class of polyphenols detected, with 89 compounds annotated, followed by phenolic acids (54 compounds), tyrosols equivalents (27 compounds), and few other phenolics (lignans, alkylphenols and stilbenes derivatives). The phenolic profile of cladode extracts is shown in Figure 1 considering the cumulative intensity per phenolic class (as gained from UHPLC-ESI/QTOF-MS screening).

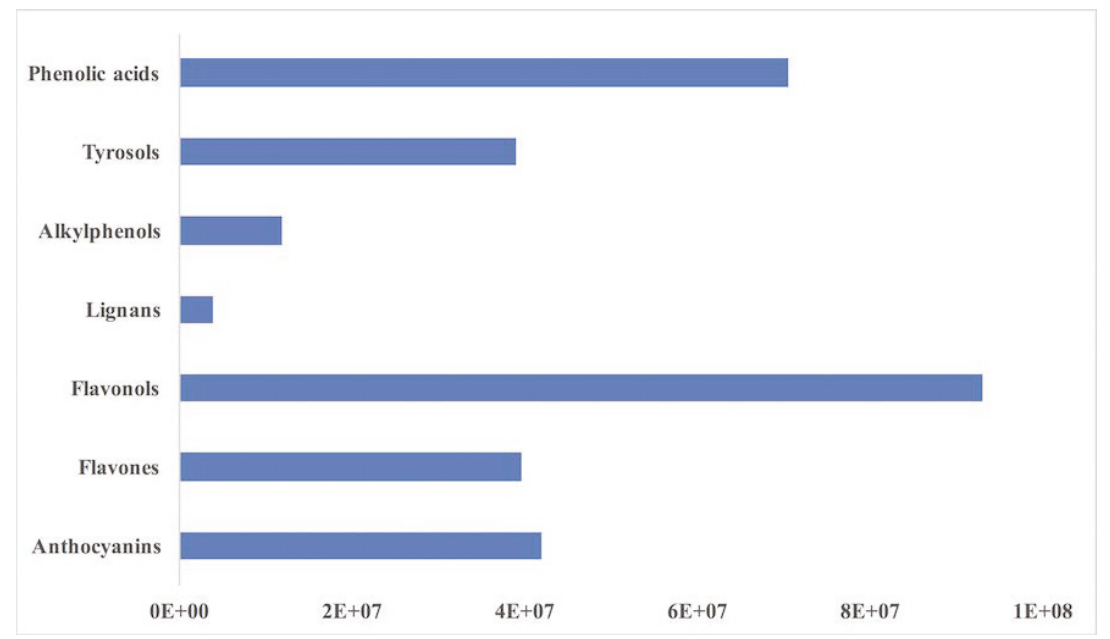

Figure 1. Abundance of different chemical classes of polyphenols in Ficodindia di San Cono PDO cladodes analysed (cumulative intensities as gained from UHPLC-ESI-QTOF-MS profiling).

Flavonols showed the highest intensity when compared to other phenolic subclasses, with approximately a difference of one order of magnitude. The entire list of phenolic compounds identified in cladodes extracts, together with annotations (raw formula, identification score, composite mass spectrum), is provided as supplementary material. Even though each compound possessed a different response factor at the electrospray ionization (ESI), the cumulative intensity of phenolic compounds in cladode extracts (when referred to semi-quantitative values) is generally in agreement with the Folin-Ciocalteu assay [24]. Nonetheless, results were elaborated and expressed as equivalents for 
the main phenolic classes. In particular, as shown in Table 3, cladodes from San Cono PDO were very abundant in anthocyanins ( $1443.76 \mathrm{mg} / \mathrm{kg}$ cyanidin equivalents) and phenolic acids, expressed as ferulic acid equivalents, being $1453.84 \mathrm{mg} / \mathrm{kg}$ when referring to the sum of hydroxybenzoic, hydroxyphenylpropanoic and hydroxycinnamic acids. Glycosidic forms of kaempferol (a flavonol) were very abundant, being $241 \mathrm{mg} / \mathrm{kg}$ equivalents, together with alkylphenols equivalents which were strongly represented in this matrix being $65.04 \mathrm{mg} / \mathrm{kg}$, followed by flavones equivalents (in particular glycosidic forms of apigenin). Lower values were obtained for both subclasses of lignans (furofurans and dibenzylbutyrolactones), being 6.52 and $3.47 \mathrm{mg} / \mathrm{kg}$ equivalents, respectively.

Table 3. Quantifications per classes of phenolics identified from untargeted UHPLC-ESI-QTOF-MS in Ficodindia di San Cono PDO cladodes. Results are expressed in $\mathrm{mg} / \mathrm{kg}$ of phenolic equivalents. The data are presented as mean values \pm standard deviation $(n=3)$. Glu = glucoside.

\begin{tabular}{|c|c|c|}
\hline Phenolic Class & Phenolic Derivatives & $\mathrm{mg} / \mathrm{kg}$ Equivalents \\
\hline \multirow[t]{5}{*}{ Flavonoids-Anthocyanins } & Cyanidin-Glu & $1058.55 \pm 10.49$ \\
\hline & Pelargonidin-Glu & $187.97 \pm 10.42$ \\
\hline & Petunidin-Glu & $186.55 \pm 3.11$ \\
\hline & Delphinidin-Glu & $2.81 \pm 0.31$ \\
\hline & Malvidin-Glu & $4.31 \pm 0.08$ \\
\hline \multirow[t]{3}{*}{ Flavonoids-Flavones } & Luteolin-Glu & $5.14 \pm 1.59$ \\
\hline & Apigenin-Glu & $40.69 \pm 0.58$ \\
\hline & Isoflavonoids & $6.81 \pm 0.52$ \\
\hline \multirow[t]{4}{*}{ Flavonoids_Flavonols } & Myricetin-Glu & $8.52 \pm 0.55$ \\
\hline & Quercetin-Glu & $8.97 \pm 0.69$ \\
\hline & Kaempferol-Glu & $241.68 \pm 3.39$ \\
\hline & Isorhamnetin-Glu & $98.42 \pm 8.52$ \\
\hline \multirow[t]{2}{*}{ Lignans } & Furofurans & $6.52 \pm 2.24$ \\
\hline & Dibenzylbutyrolactone & $3.47 \pm 0.02$ \\
\hline \multirow[t]{4}{*}{ Other phenolics } & Alkylphenols & $65.04 \pm 10.43$ \\
\hline & Hydroxybenzaldehydes & $0.43 \pm 0.06$ \\
\hline & Hydroxycoumarins & $7.81 \pm 0.52$ \\
\hline & Tyrosols & $12.89 \pm 1.02$ \\
\hline \multirow[t]{3}{*}{ Phenolic acids } & Hydroxybenzoics & $114.01 \pm 3.34$ \\
\hline & Hydroxyphenylpropanoics & $91.58 \pm 5.98$ \\
\hline & Hydroxycinnamics & $1248.24 \pm 103.15$ \\
\hline
\end{tabular}

Looking at the great abundance in anthocyanins and phenolic acids, the health benefits of these two classes of compounds must be emphasized. In particular, anthocyanins are natural pigments in the plant kingdom, mainly responsible for the blue, purple, red, and orange colors of many fruits and vegetables. In the last year, the interest towards their absorption, metabolism, bioavailability and pharmacokinetics, has increased along with methods for their analytical determination. The interest to deepen the knowledge of the health benefits of anthocyanins has also strongly increased thanks to their anticancer, anti-inflammatory, antidiabetic, and neuroprotective activities together with prevention of cardiovascular diseases [47]. Concerning phenolic acids, they are usually divided into two classes: equivalents of benzoic acid and equivalents of cinnamic acid. The hydroxybenzoic acid content of plants is generally low when compared to hydroxycinnamic acids, with the exception of certain red fruits, black radish and onions [48]. The free form of hydroxycinnamic acids is rapidly absorbed by the small intestine after ingestion. Nevertheless, these compounds are naturally esterified in plant matrices, establishing chemical bonds with this latter, and esterification is able to reduce their absorption due to the lack of enzymes (esterases) able to hydrolyse phenolic acids in the intestinal mucosa, liver and plasma. The hydrolysis can be performed only by the microflora present into the colon; therefore, the polyphenols reaching the colon could promote an antioxidant environment after their hydrolysis 
into aglycones by bacterial microflora [47]. Regarding San Cono PDO cladodes, phenolic extracts from this plant matrix could provide relevant quantities of these antioxidant and functional compounds.

Overall, present findings fitted with Astello-Garcia et al. [45], which identified phenolic compounds in cladode extracts considering Opuntia spp. cultivars with different domestication gradient. In particular, the phenolic profile showed major and minor compounds that were present only in wild or domesticated species. Among polyphenols, the most represented were conjugated forms of isorhamnetin, kaempferol, and quercetin, all belonging to the phenolic class of flavonoids. In another work, Guevara-Figueroa et al. [28] investigated the phenolic composition of commercial and wild leaves from Opuntia spp., showing that phenolic acids and flavonoids were the most represented compounds. In particular, these authors identified among phenolic acids ferulic, caffeic, gallic, coumaric, and 2-hydroxybenozoic (also known as salicylic acid) acids. Considering the flavonoids class, conjugated forms of quercetin (rutin and iso-quercitrin), kampferol-3-O-rutinoside (nicotiflorin) and two different forms of narcissin (isorhamnetin derivatives) were detected and quantified in different commercial and wild cladodes. The same findings were shown by El-Mostafa et al. [37], reviewing the possible use of cactus leaves as a source of bioactive compounds. Looking at semi-quantitative values, this work could be considered one of the first identifying anthocyanins as representative phenolic compounds in cladodes extracts from Opuntia spp. In particular, our findings showed that conjugated forms of cyanidin, pelargonidin and petunidin were very abundant in cladodes extracts with average values of 428.27, 161.39 and $114.08 \mathrm{mg} / \mathrm{kg}$ equivalents for cyanidin 3,5-O-diglucoside, pelargonidin 3-O-(6"-malonyl-glucoside) and petunidin 3-O-rutinoside, respectively (supplementary material). Finally, looking at Pearson's correlations, there were highly significant correlations between TPC and DPPH $(p<0.01)$, whilst flavones (luteolin equivalents) were well correlated to phenolic acids (ferulate equivalents) and flavanols (catechin equivalents) $(p<0.05)$. Interestingly, ferulate and luteolin equivalents were those phenolic compounds better explaining the DPPH radical scavenging activity $(p<0.01)$. However, all the correlation values recorded are shown in Table 4.

Table 4. Pearson's correlations coefficients between total phenolic content (TPC), DPPH radical scavenging, FRAP reducing power and phenolic subclasses equivalents. ${ }^{* *}=p<0.01 ;{ }^{*}=p<0.05$; n.s. = not significant.

\begin{tabular}{|c|c|c|c|c|c|c|c|c|c|c|}
\hline & DPPH & FRAP & TPC & Cyanidin Eq. & $\begin{array}{l}\text { Luteolin } \\
\text { Eq. }\end{array}$ & $\begin{array}{l}\text { Catechin } \\
\text { Eq. }\end{array}$ & $\begin{array}{l}\text { Ferulate } \\
\text { Eq. }\end{array}$ & $\begin{array}{c}\text { Matairesinol } \\
\text { Eq. }\end{array}$ & $\begin{array}{c}\text { Tyrosol } \\
\text { Eq. }\end{array}$ & $\begin{array}{c}\text { Cardol } \\
\text { Eq. }\end{array}$ \\
\hline DPPH & 1 & n.s. & $1^{* *}$ & $0.84^{*}$ & $0.95^{* *}$ & $0.92^{*}$ & $0.96^{* *}$ & n.s. & n.s. & 0.59 \\
\hline FRAP & n.s. & 1 & n.s. & -0.74 & n.s. & n.s. & n.s. & 0.90 & -0.84 & -0.61 \\
\hline TPC & $1^{* *}$ & n.s. & 1 & -0.84 & 0.95 & -0.92 & $0.96^{* *}$ & n.s. & n.s. & 0.59 \\
\hline Cyanidin Eq. & $0.84^{*}$ & -0.74 & -0.84 & 1 & -0.64 & 0.56 & -0.65 & n.s. & n.s. & n.s. \\
\hline Luteolin Eq. & $0.95^{* *}$ & n.s. & 0.95 & -0.64 & 1 & $-0.99^{*}$ & $1^{*}$ & -0.45 & 0.56 & 0.80 \\
\hline Catechin Eq. & $0.92^{*}$ & n.s. & -0.92 & 0.56 & $-0.99^{*}$ & 1 & -0.99 & 0.54 & -0.64 & -0.86 \\
\hline Ferulate Eq. & $0.96^{* *}$ & n.s. & $0.96^{* *}$ & -0.65 & $1^{*}$ & -0.99 & 1 & -0.44 & 0.54 & 0.79 \\
\hline Matairesinol Eq. & n.s. & 0.90 & n.s. & n.s. & -0.45 & 0.54 & -0.44 & 1 & -0.99 & -0.89 \\
\hline Tyrosol Eq. & n.s. & -0.84 & n.s. & n.s. & 0.56 & -0.64 & 0.54 & -0.99 & 1 & 0.94 \\
\hline Cardol Eq. & 0.59 & -0.61 & 0.59 & n.s. & 0.80 & -0.86 & 0.79 & -0.89 & 0.94 & 1 \\
\hline
\end{tabular}

This work can be considered as the first assessing the entire phenolic profile and composition in cladodes of Ficondindia di San Cono PDO thanks to an untargeted UHPLC-ESI/QTOF mass spectrometry approach. The further study on the comparison of phenolic profile of different Opuntia species using a metabolomics-based approach (UHPLC-ESI/QTOF-MS) appears to be worthwhile, in order to select the best source of antioxidant compounds within this plant genus for industrial applications.

\section{Conclusions}

The demand for natural antioxidants, to be used for applications such as nutraceuticals, biopharmaceuticals, as well as food additives, is increasing due to consumers' preference. In this work, a new source of antioxidant compounds from Ficodindia di San Cono PDO cladodes extracts has been deeply investigated describing its entire phenolic profile. Very high antioxidant activity values have been observed in the hydro-alcoholic extracts of Ficodindia di San Cono cladodes. A high 
correlation between total phenolic content and DPPH radical scavenging was observed $(p<0.01)$. Moreover, an elevated quantity of $\beta$-polysaccharides, included in the group of water-soluble fiber, was accounted. The UHPLC-ESI/QTOF-MS phenolic profiling allowed for the identification of the main phenolic classes and subclasses in cladode extracts, showing that they are good source of equivalent for anthocyanins and phenolic acids, followed by other phenolics. Overall, considering the results obtained, it would seem possible to use cactus cladodes as a source of natural and antioxidant compounds, possibly incorporating them into foods, cosmetics or pharmaceutical products. From a health-promoting perspective, these cladode extracts could be considered as new and very promising sources of natural antioxidants. Our findings provide a basis for developing a valuable food additive, based on Opuntia ficus-indica cladodes from San Cono (Sicily, Italy), thanks to their water-soluble fiber, phenolic composition and the related antioxidant activity.

Supplementary Materials: The following are available online at http://www.mdpi.com/2304-8158/7/2/24/s1. Table S1: Whole dataset of phenolic compounds identified in cladode extracts, together with relative abundances and annotations (raw formula, identification score, composite spectrum).

Acknowledgments: G.R. was recipient of a fellowship from the Doctoral School on the Agro-Food System (AgriSystem) of the Università Cattolica del Sacro Cuore (UCSC, Piacenza, Italy).

Author Contributions: L. Lucini designed the study and interpreted the results. D. Montesano assisted interpretations and revised the manuscript. G. Rocchetti and M. Pellizzoni carried out the experimental work and drafted the manuscript.

Conflicts of Interest: The authors declare no conflict of interest.

\section{References}

1. Le Houérou, H.N. Cacti (Opuntia spp.) as a fodder crop for marginal lands in the Mediterranean basin. Proceedings of the 4th International Congress on cactus pear and cochineal. Acta Hortic. 2002, 581, 21-46. [CrossRef]

2. Fernandez-Lopez, J.A.; Almela, L.; Obón, J.M.; Castellar, M.R. Determination of antioxidant constituents in cactus pear fruits. Plant Foods Hum. Nutr. 2010, 65, 253-259. [CrossRef] [PubMed]

3. Lee, J.C.; Kim, H.R.; Kim, J.; Jang, Y.S. Antioxidant property of an ethanol extract of the stem of Opuntia ficus-indica var. saboten. J. Agric. Food. Chem. 2002, 50, 6490-6496. [CrossRef] [PubMed]

4. Reynolds, S.G.; Arias, E. Introduction in: Cactus (Opuntia spp.) as Forage; Mondragon-Jacobo, C., Ed.; Food and Agriculture Organization (FAO): Rome, Italy, 2001; pp. 1-4.

5. Gutierrez, M.A. Medicinal use of the latin food staple nopales: The rickly pear cactus. Nutr. Bytes 1998, 4, 1-3.

6. Feugang, J.M.; Konarski, P.; Zou, D.; Stintzing, F.C.; Zou, C. Nutritional and medicinal use of cactus pear (Opuntia spp.) cladodes and fruits. Front. Biosci. 2006, 11, 2574-2589. [CrossRef] [PubMed]

7. Stintzing, F.C.; Carle, R. Cactus stems (Opuntia spp.): A review on their chemistry, technology, and uses. Mol. Nutr. Food Res. 2005, 49, 175-194. [CrossRef] [PubMed]

8. Galati, E.M.; Mondello, M.R.; Monforte, M.T.; Galluzzo, M.; Miceli, N.; Tripodo, M.M. Effect of Opuntia ficus-indica (L.) Mill. cladodes in wound-healing process. J. Prof. Assoc. Cactus. 2003, 5, 1-16.

9. Santini, A.; Novellino, E. Nutraceuticals in hypercholesterolaemia: An overview. Br. J. Pharmacol. 2017, 174, 1450-1463. [CrossRef] [PubMed]

10. Santini, A. Nutraceuticals: An healthy bet for the future. J. Food Res. 2014, 3, 1-2. [CrossRef]

11. Ayadi, M.A.; Abdelmaksoud, W.; Ennour, M.; Attia, H. Cladodes from Opuntia ficus-indica as a source of dietary fiber. Effect on dough characteristic and cake making. Ind. Crops Prod. 2009, 30, 40-47. [CrossRef]

12. Lovergrove, A.; Edwards, C.H.; De Noni, I.; Patel, H.; El, S.N.; Grassby, T.; Zielke, C.; Ulmius, M.; Nilsson, L.; Butterworth, P.J.; et al. Role of polysaccharides in food, digestion, and health. Crit. Rev. Food Sci. Nutr. 2017, 57, 237-253. [CrossRef] [PubMed]

13. Bensadón, S.; Hervert-Hernández, D.; Sáyago-Ayerdi, S.G.; Goni, I. By-products of Opuntia ficus-indica as a source of antioxidant dietary fiber. Plant Foods Hum. Nutr. 2010, 65, 210-216. [CrossRef] [PubMed]

14. Rothwell, J.A.; Knaze, V.; Zamora-Rosa, R. Polyphenols: Dietary assessment and role in the prevention of cancers. Curr. Opin. Clin. Nutr. Metab. Care. 2017, 20, 512-521. [CrossRef] [PubMed] 
15. Naviglio, D.; Gallo, M.; Le Grottaglie, L.; Scala, C.; Ferrara, L.; Santini, A. Determination of cholesterol in Italian chicken eggs. Food Chem. 2012, 132, 701-708. [CrossRef]

16. Del Socorro Santos Díaz, M.; Barba de la Rosa, A.-P.; Héliès-Toussaint, C.; Guéraud, F.; Nègre-Salvayre, A. Opuntia spp.: Characterization and benefits in chronic diseases. Oxid. Med. Cell. Longev. 2017. [CrossRef] [PubMed]

17. Chahdoura, H.; Barreira, J.C.M.; Barros, L.; Santos-Buelga, C.; Ferreira, I.C.R.; Achour, L. Seeds of Opuntia spp. as a novel high potential by-product: Phytochemical characterization and antioxidant activity. Ind. Crops Prod. 2017, 65, 383-389. [CrossRef]

18. Melgar, B.; Dias, M.I.; Ciric, A.; Sokovic, M.; Garcia-Castello, E.M.; Rodriguez-Lopez, A.D.; Barros, L.; Ferreira, I. By-product recovery of Opuntia spp. peels: Betalainic and phenolic profile and bioactive properties. Ind. Crops Prod. 2017, 107, 353-359. [CrossRef]

19. Dok-Go, H.; Lee, K.H.; Kim, H.J.; Lee, E.H.; Lee, J.; Song, Y.S.; Lee, Y.H.; Jin, C.; Lee, Y.S.; Cho, J. Neuroprotective effects of antioxidative flavonoids quercetin, $\beta$-dihydroquercetin and quercetin 3-methyl ether, isolated from Opuntia ficus-indica var. Saboten. Brain Res. 2003, 965, 130-136. [CrossRef]

20. AOAC. Official Methods of Analysis, 17th ed.; Association of Official Analytical Chemists: Gaithersburg, MD, USA, 2000.

21. Van Soest, P.J.; Robertson, J.B.; Lewis, B.A. Methods for dietary fiber, neutral detergent fiber, and non-starch polysaccharides in relation to animal nutrition. J. Diary Sci. 1991, 74, 3583-3597. [CrossRef]

22. Eberendu, A.R.; Luta, G.; Edwards, J.A.; Mcanalley, B.H.; Davis, B.; Rodriguez, S.; Ray Henry, C. Quantitative colorimetric analysis of Aloe polysaccharides as a measure of Aloe Vera quanlity in commercial products. J. AOAC Int. 2005, 88, 684-691. [PubMed]

23. Lucini, L.; Pellizzoni, M.; Pellegrino, R.; Molinari, G.P.; Colla, G. Phytochemical constituents and in vitro eadical scavening activity of different Aloe species. Food Chem. 2015, 170, 501-507. [CrossRef] [PubMed]

24. Rocchetti, G.; Chiodelli, G.; Giuberti, G.; Masoero, F.; Trevisan, M.; Lucini, L. Evaluation of phenolic profile and antioxidant capacity in gluten-free flours. Food Chem. 2017, 228, 367-373. [CrossRef] [PubMed]

25. Rothwell, J.A.; Perez-Jimenez, J.; Neveu, V.; Medina-Remón, A.; M'Hiri, N.; García-Lobato, P.; Manach, C.; Knox, C.; Eisner, R.; Wishart, D.S.; et al. Phenol-Explorer 3.0: A major update of the Phenol-Explorer database to incorporate data on the effects of food processing on polyphenol content. Database 2013, 2013, bat070. [CrossRef] [PubMed]

26. Benzie, I.F.F.; Strain, J.J. The ferric reducing ability of plasma (FRAP) as a measure of "antioxidant power": The FRAP assay. Anal Biochem. 1996, 239, 70-76. [CrossRef] [PubMed]

27. De Santiago, E.; Domínguez-Fernández, M.; Cid, C.; De Pena, M.-P. Impact of cooking process on nutritional composition and antioxidants of cactus cladodes (Opuntia ficus-indica). Food Chem. 2018, 240, 1055-1062. [CrossRef] [PubMed]

28. Guevara-Figueroa, T.; Jiménez-Islas, H.; Reyes-Escogido, M.L.; Mortensen, A.G.; Laursen, B.B.; Lin, L.W.; De León-Rodríguez, A.; Fomsgaard, I.S.; Barba de la Rosa, A.P. Proximate composition, penolic acids, and flavonoids characterization of commercial and wild nopal (Opuntia spp.). J. Food Comp. Anal. 2010, 23, 525-532. [CrossRef]

29. Ross, J.A.; Kasum, C.M. Dietary flavonoids: Bioavailability, metabolic effects, and safety. Annu. Rev. Nutr. 2002, 22, 19-34. [CrossRef] [PubMed]

30. Skerget, M.; Kotnik, P.; Hadolin, M.; Hras, A.; Simonic, M.; Knez, Z. Phenols, proanthocyanidins, flavones and flavonols in some plant materials and their antioxidant activities. Food Chem. 2005, 89, 191-198. [CrossRef]

31. Montesano, D.; Gennari, O.; Seccia, S.; Albrizio, S. A simple and selective analytical procedure for the extraction and quantification of lutein from tomato by-products by HPLC-DAD. Food Anal. Methods. 2012, 5, 710-715. [CrossRef]

32. Fattore, M.; Montesano, D.; Pagano, E.; Teta, R.; Borrelli, F.; Mangoni, A.; Seccia, S.; Albrizio, S. Carotenoid and flavonoid profile and antioxidant activity in "Pomodorino Vesuviano" tomatoes. J. Food Comp. Anal. 2016, 53, 61-68. [CrossRef]

33. Zheng, W.; Wang, S.Y. Antioxidant activity and phenolic compounds in selected herbs. J. Agric. Food Chem. 2001, 49, 5165-5170. [CrossRef] [PubMed]

34. Santos-Zea, L.; Gutierrez-Uribe, J.A.; Serna-Saldivar, S.O. Comparative analyses of total phenols, antioxidant activity, and flavonol glycoside profile of cladode flours from different varieties of Opuntia spp. J. Agric. Food Chem. 2011, 59, 7054-7061. [CrossRef] [PubMed] 
35. Ramírez-Moreno, E.; Córdoba-Díaz, D.; de Cortes Sánchez-Mata, M.; Díez-Marqués, C.; Honi, I. Effect of boiling on nutritional, antioxidant and physicochemical characteristics in cladodes (Opuntia ficus-indica). LWT Food Sci. Technol. 2013, 51, 296-302. [CrossRef]

36. Reyes-Agüero, J.A.; Aguirre-Rivera, J.R.; Hernández, H.M. Systematic notes and a detailed description of Opuntia ficus-indica (L.) Mill. (CACTACEAE). Agrociencia. 2005, 39, 395-408.

37. El-Mostafa, K.; El Kharrassi, Y.; Badreddine, A.; Andreoletti, P.; Vamecq, J.; El Kebbaj, M.S.; Latruffe, N.; Lizard, G.; Nasser, B.; Cherkaoui-Malki, M. Nopal cactus (Opuntia ficus-indica) as a source of bioactive compounds for nutrition, health and disease. Molecules 2014, 19, 14879-14901. [CrossRef] [PubMed]

38. McClearly, B.V.; Prosky, L. Advanced Dietary Fiber Technology; Blackwell Science: Ames, IW, USA, 2001.

39. Cardarelli, M.; Rouphael, Y.; Rea, E.; Lucini, L.; Pellizzoni, M.; Colla, G. Effects of fertilization, arbuscolar myxorrhiza, and salinity on growth, yield, and bioactive compounds of two Alow species. HortScience 2013, 48, 568-575.

40. El Khoury, D.; Cuda, C.; Luhovyy, B.L.; Anderson, G.H. Beta glucan: Health benefits in obesity and metabolic syndrome. J. Nutr. Metab. 2012. [CrossRef] [PubMed]

41. Alam, M.N.; Bristi, N.J.; Rafiquzzaman, M. Review on in vivo and in vitro methods evaluation of antioxidant activity. Saudi Pharm. J. 2013, 21, 143-152. [CrossRef] [PubMed]

42. Cheng, Z.; Moore, J.; Yu, L. High-throughput relative DPPH radical scavenging capacity assay. J. Agric. Food Chem. 2006, 54, 7429-7436. [CrossRef] [PubMed]

43. Craft, B.D.; Kerrihard, A.L.; Amarowicz, R.; Pegg, R.B. Phenol-based antioxidants and the in vitro methods used for their assessment. Compr. Rev. Food Sci. Food Saf. 2012, 11, 148-173. [CrossRef]

44. Shahidi, F.; Naczk, M. Phenolics in Food and Nutraceuticals; CRC Press: Boca Raton, FL, USA, 2004.

45. Astello-García, M.; Cervantes, I.; Nair, V.; del Socorro Santos-Díaz, M.; Reyes-Agüero, A.; Guéraud, F.; Negre-Salvayre, A.; Rossignol, M.; Cisneros-Zevallos, L.; Barba de la Rosa, A.P. Chemical composition and phenolic compounds profile of cladodes from Opuntia spp. cultivars with different domestication gradient. J. Food Comp. Anal. 2015, 43, 119-130.

46. Ghisoni, S.; Chiodelli, G.; Rocchetti, G.; Kane, D.; Lucini, L. UHPLC-ESI-QTOF-MS screening of lignans and other phenolics in dry seeds for human consumption. J. Funct. Foods. 2017, 34, 229-236. [CrossRef]

47. Li, D.; Wang, P.; Luo, Y.; Zhao, M.; Chen, F. Health benefits of anthocyanins and molecular mechanism: Update from recent decade. Crit. Rev. Food Sci. Nutr. 2017, 57, 1729-1741. [CrossRef] [PubMed]

48. Pandey, K.B.; Rizvi, S.I. Plant polyphenols as dietary antioxidants in human health and disease. Oxid. Med. Cell Longev. 2009, 2, 270-278. [CrossRef] [PubMed]

(C) 2018 by the authors. Licensee MDPI, Basel, Switzerland. This article is an open access article distributed under the terms and conditions of the Creative Commons Attribution (CC BY) license (http:/ / creativecommons.org/licenses/by/4.0/). 


\title{
Article \\ A Comparative Study of Phenols in Apulian Italian Wines
}

\author{
Andrea Ragusa ${ }^{1, *}$, Carla Centonze ${ }^{2}$, Maria E. Grasso ${ }^{2}$, Maria F. Latronico ${ }^{2}$, Pier F. Mastrangelo ${ }^{2}$, \\ Federica Sparascio ${ }^{2}$, Francesco P. Fanizzi ${ }^{2}$ and Michele Maffia ${ }^{2, *}$ \\ 1 Department of Engineering for Innovation, University of Salento, via Monteroni, 73100 Lecce, Italy \\ 2 Department of Biological and Environmental Sciences and Technologies, University of Salento, \\ via Monteroni, 73100 Lecce, Italy; carla_centonze@libero.it (C.C.); nutrizionegrasso@gmail.com (M.E.G.); \\ latronico-francesca@libero.it (M.F.L.); mastrangelo.pf@hotmail.it (P.F.M.); federicasparascio@alice.it (F.S.); \\ fp.fanizzi@unisalento.it (F.P.F.) \\ * Correspondence: andrea.ragusa@unisalento.it (A.R.); michele.maffia@unisalento.it (M.M.); \\ Tel.: +39-0832-319208 (A.R.); +39-0832-298685 (M.M.); Fax: +39-0832-661995 (M.M.)
}

Academic Editor: Antonello Santini

Received: 27 February 2017; Accepted: 21 March 2017; Published: 24 March 2017

\begin{abstract}
Nutraceutics is a growing research field in which researchers study and attempt to improve the biological properties of metabolites in food. Wine is one of the most consumed products in the world and contains a plethora of molecules biologically relevant to human health. In this article, several polyphenols with potential antioxidant activity were measured in wines from Apulia, in Southeast Italy. Hydroxytyrosol, gallic and syringic acids, luteolin, quercetin, and trans-resveratrol were identified and quantified by HPLC. The amount of the analyzed metabolites in wines were largely dependent on their color, with red ones being the richest compared to white and rose wines. Gallic acid was the most abundant polyphenol, followed by syringic acid and luteolin. Nevertheless, significant amounts of hydroxytyrosol, quercetin, and trans-resveratrol were also found. The average concentration of polyphenols found in these wines could have potential health-promoting effects, especially if consumed in moderate quantities on a regular basis.
\end{abstract}

Keywords: HPLC; wine; polyphenols; antioxidants; hydroxytyrosol; trans-resveratrol

\section{Introduction}

Wine is not only one of the most ancient and consumed beverages, but it is also an important product from the nutritional point of view [1]. Among the variety of compounds which determine the overall quality of the final product, polyphenols contribute to several organoleptic properties, such as color, astringency, and flavor [2]. Furthermore, the healthy effect of polyphenols is well-known due to their antioxidant activity and contribute to a variety of biological processes, such as (a) inhibition of the oxidation of low-density lipoprotein (LDL) with a significant effect on atherosclerosis; (b) DNA protection from oxidative stress, with important consequences on the development of some age-related cancers; (c) protection of the vascular system by strengthening capillaries which carry oxygen and other essential nutrients to cells; (d) anti-thrombotic and anti-inflammatory effects; and (e) anti-microbial activity against viruses, bacteria, and hepatotoxins [3-6]. Polyphenols are produced by the shikimic pathway [7]. However, this path can be found in fungi and bacteria, but it is absent in animals; that is why humans have to introduce phenolic products and aromatic amino acids they need through diet. Phenolic compounds represent, after carbohydrates and acids, the most abundant species in grapes. Nevertheless, the amount and type of polyphenols in wine vary considerably depending on the grape type, environmental factors, production techniques, and conditions [8,9]. The total amount of polyphenols in red wine is usually about $1.5 \mathrm{~g} / \mathrm{L}$ ( $80 \%-90 \%$ of which are flavonoids) [6]. Rose wine 
contains about $400-800 \mathrm{mg} / \mathrm{L}$ of polyphenols ( $40 \%-60 \%$ of which are flavonoids); white wine has only $100-400 \mathrm{mg} / \mathrm{L}$. Depending on the molecular structure and the number of carbon atoms, polyphenols can be roughly grouped into flavonoids, non-flavonoids, and hydroxystilbenes [1]. Flavonoids are found in the peel, seed, and petiole, while non-flavonoid compounds, such as hydroxybenzoic and cinnamic acid derivatives, can be found especially in the pulp. Gallic and syringic acids belong to the hydroxybenzoic acid class and have been shown to induce significant effects on neurodegenerative pathologies, such as Parkinson's and Alzheimer's diseases [10-12]. Quercetin, part of a subclass of flavonoids called flavonols, has received considerable attention because of its overwhelming presence in foods and its antioxidant activity and is believed to protect against several degenerative diseases by preventing lipid peroxidation [13]. Luteolin, another flavonoid derivative of the flavone subclass, was shown to possess a variety of pharmacological activities, including antioxidant, anti-inflammatory, antimicrobial, and anticancer activities [14]. Hydroxytyrosol is one of the most powerful antioxidants in nature, and extensive research has been carried out trying to exploit its therapeutic effects on the cardiovascular system, neurodegenerative diseases, cancer treatment, osteoporosis, and diabetic neuropathy, to name a few [15-20]. The stilbene trans-resveratrol has been one of the most extensively studied non-flavonoids due to its well-known health benefits, such as cardioprotective and chemopreventive effects (by inhibiting LDL oxidation) and anti-inflammatory, antibacterial, antifungal, antiviral, neuroprotective, antiproliferative, and anti-angiogenic activities [21-25].

In this article, we measured the above-mentioned polyphenols in several red, white, and rose wines from Apulia and the results were associated with grape type. To the best of our knowledge, few characterization data have been reported in the literature regarding Apulian wines. In pioneering work from the groups of Fanizzi and Sacco, the authors determined several analytes by chemical, chromatographic, and ${ }^{1} \mathrm{H}$ NMR techniques in red wines and then managed to identify the origin of the unknown samples by multivariate statistical analysis [26-28]. Later, Crupi and colleagues identified and quantified several carotenoid and flavonoid compounds in red and white seedless grape varieties [29-31]; Siciliano and co-workers analyzed the volatile components of Negroamaro and Primitivo Apulian red wines [32,33]. Very recently, Barnaba et al. determined the profile of 61 phenols in two of the most common red grapes from Apulia, Primitivo di Manduria and Negroamaro [34]. Nevertheless, to date, quantification and comparison of some of these and other polyphenols in a much wider variety of local red, white, and rose wines has not been reported in the literature.

\section{Materials and Methods}

\subsection{Chemicals}

HPLC-grade reference standard of trans-resveratrol was purchased from Dr. Ehrenstorfer GmbH (Augsburg, Germany). Analytical grade gallic acid, hydroxytyrosol, luteolin, quercetin, and syringic acid were purchased from Sigma-Aldrich (Milan, Italy). Acetic acid and HPLC-grade ethanol and methanol were purchased from J.T. Baker (Deventer, The Netherlands). HPLC-grade water was purchased from Carlo Erba Reagenti (Milan, Italy).

\subsection{Samples}

Analysis was conducted on a total of 72 commercially available wine bottles ( $27 \mathrm{red}, 23 \mathrm{rose}$, and 22 white wines) from Apulia, a region in Southeast Italy (Figure 1). The most characteristic Vitis vinifera red grape (Negramaro, Primitivo, and Susumaniello), rose grape (Negramaro, Black Malvasia, and Primitivo), white grape (Bianco d'Alessano, Chardonnay, Falanghina, Fiano, Malvasia, Moscato, and Verdeca), and some combination of these varieties (blend samples) were studied. Details of number of samples, production year, and alcoholic grade for each grape type are given in Table 1. All samples had a denomination of origin (DOC) certification mark, which guarantees the quality and the geographical origin of the wines produced in the Apulia region in Italy. 


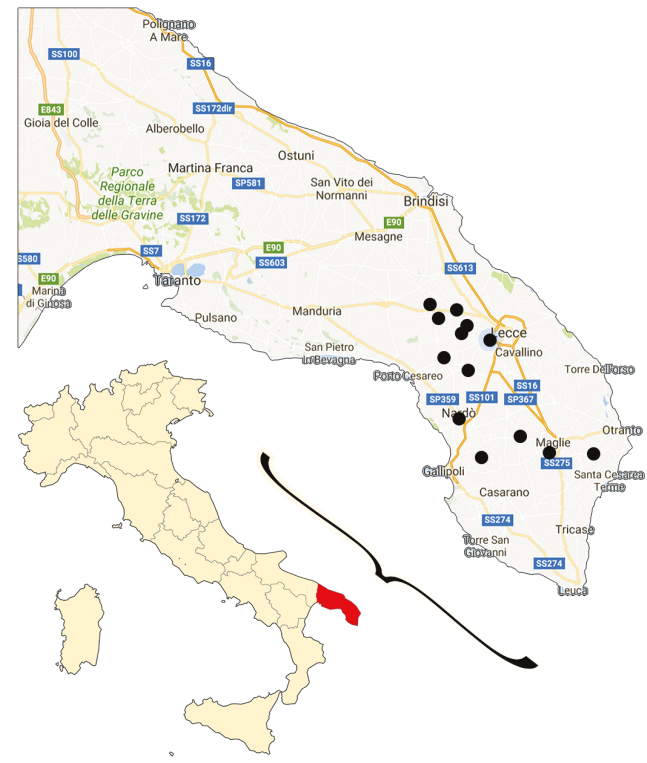

Figure 1. Map of Italy with a zoom on a southern Apulia region (Salento, in red). The black dots represent the sites of production of the wines.

\subsection{HPLC Analysis}

Separation and identification of phenolic compounds were carried out using an HPLC 1220 Infinity (Agilent Technologies, Palo Alto, CA, USA) interfaced with a diode array detector (model G1315B DAD system; Agilent). A calibration curve was prepared using a standard solution at increasing concentrations of the analytes in ethanol. Fitting of the data was performed through a linear equation with zero intercept $\left(R^{2}>0.98\right.$ for all samples). The concentration in $\mathrm{mg} / \mathrm{kg}$ of the biomolecules in the analyzed samples was calculated through interpolation of the corresponding peak areas. Samples were collected directly from the bottle by a syringe injection through the cork cap. After filtration through a $0.45 \mu \mathrm{m}$ pore size regenerated cellulose filters (VWR International, Milano, Italy), wine samples were directly injected into an Eclipse Plus C18 (particle size $5 \mu \mathrm{m} ; 4.6 \times 250 \mathrm{~mm}$, Agilent) stationary phase column. For the detection of trans-resveratrol, quercetin, and luteolin, a gradient system of water/methanol/acetic acid (75:20:5, v:v:v) (Solvent A) and water/methanol/acetic acid (50:45:5, v:v:v) (Solvent B) was used. The gradient parameters were: $0 \% \mathrm{~B}$ at $0 \mathrm{~min}, 100 \% \mathrm{~B}$ at $30 \mathrm{~min}, 0 \% \mathrm{~B}$ at $50 \mathrm{~min}$. The solvent flow was maintained at $1.0 \mathrm{~mL} / \mathrm{min}$, the column temperature was set $25^{\circ} \mathrm{C}$, and the UV-Vis detection wavelength was set at $309 \mathrm{~nm}$. Obtained retention times were: trans-resveratrol at Min 24.8, quercetin at Min 34.8, and luteolin at Min 42.3. For the detection of gallic acid, hydroxytyrosol, and syringic acid a gradient system of water/methanol/acetic acid (75:20:5, v:v:v) (Solvent A) and water/methanol/acetic acid (50:45:5, v:v:v) (Solvent B) was used. The gradient parameters were as follows: $0 \%$ B at $0 \mathrm{~min}, 100 \% \mathrm{~B}$ at $40 \mathrm{~min}$, and $0 \% \mathrm{~B}$ at $50 \mathrm{~min}$. The flow was maintained at $1.0 \mathrm{~mL} / \mathrm{min}$, the column temperature was set $25^{\circ} \mathrm{C}$, and the UV-Vis detection wavelength was set at $280 \mathrm{~nm}$. Obtained retention times were as follows: gallic acid at Min 3.3, hydroxytyrosol at Min 4.3, and syringic acid at Min 10.1 (The original raw data are available from the Multilab-Chamber of Commerce of Lecce-upon request at multilab@le.camcom.it.). 


\section{Foods 2017, 6, 24}

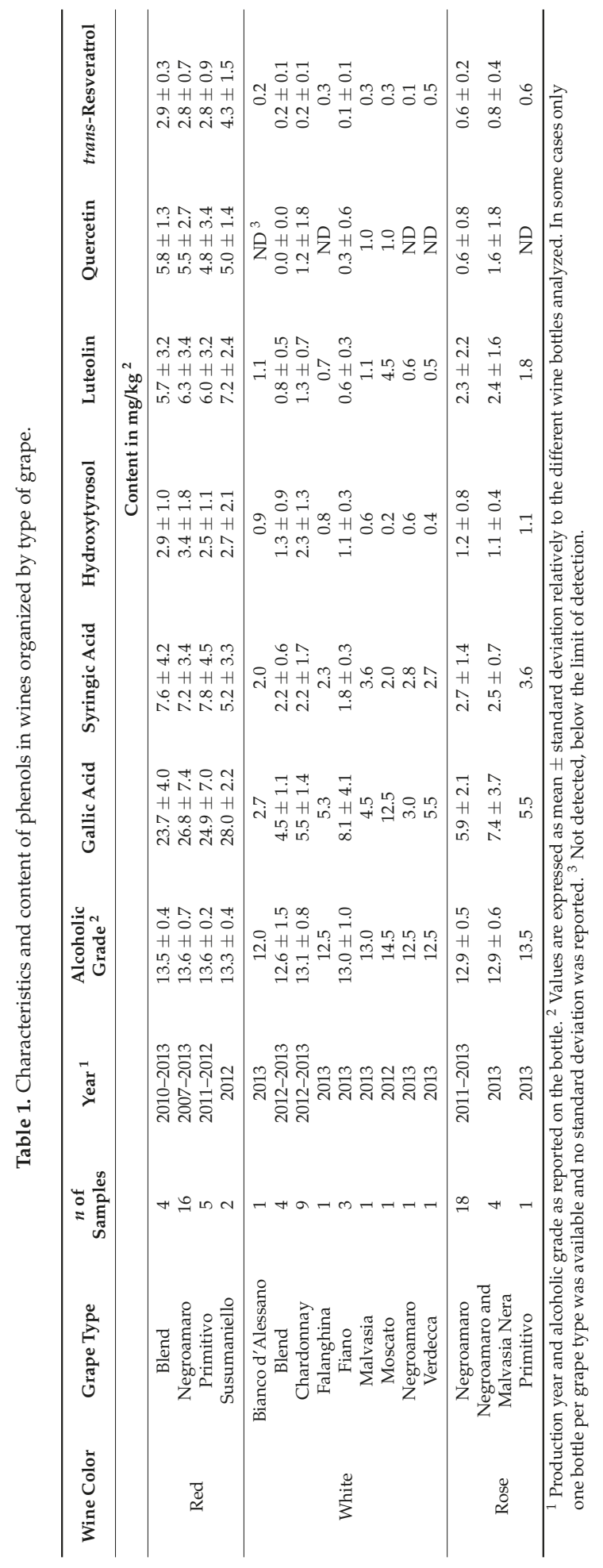




\subsection{Statistical Analysis}

The amounts of polyphenols reported represent the mean values for a specific wine color and grape type. The reported standard deviation represents the difference among different samples from the same category. If just one sample for a specific grape type was available, no standard deviation has been reported. Standard deviation relatively to replicates of the same sample was always $<5 \%$. Obtained polyphenolic values were rounded to one decimal place. Multivariate statistical analysis was performed using STATISTICA 12.5 software (State-Ease Inc., Minneapolis, MN, USA). Principal component analysis (PCA) was performed using the detected polyphenols as variables $(n=6)$ and the wine samples as cases $(n=72)$, yielding a matrix of 432 data points. The analysis was based on correlation and the variances were computed as $S S /(N-1)$, where $S S$ is the Sum of the Squares and $N$ is the number of items in the list. In the $2 \mathrm{D}$ score plot, cases with sum of $\operatorname{cosine} \mathrm{e}^{2} \geq 0$ were reported. General discriminant analysis (GDA) was performed using the type of grape as a dependent variable, the wine color as a categorical predictor variable, and the analyzed polyphenols as continuous predictors.

\section{Results and Discussion}

The content of several polyphenols, namely gallic acid, hydroxytyrosol, luteolin, quercetin, trans-resveratrol, and syringic acid, was quantified in different types of commercially available Apulian wines, in Southeast Italy (Figure 1), and the results are shown in Figure 2. The data represent the mean values of the detected polyphenols grouped for wine color. In general, standard deviations are quite high for each data series because of the variability of the samples. In fact, each sample represents a commercially available bottle of a different brand, and even though some of them have the same grape composition, the high variability of all the production parameters led to a quite broad range of data. Nevertheless, all wines were prepared from grapes grown locally and from pure autochthonous varieties, although they were mixed in blend wines, as detailed later in the text. Average production year was about 2012 for red wines and about 2013 for white and rose wines. As expected, alcoholic grade was slightly higher for red wines (average 13.6\% $\pm 0.6 \%$ ), while white and rose ones presented almost the same value (about 13\%).

All the 72 commercially available samples (27 red, 22 white, and 23 rose wine bottles) showed significant amounts of the investigated polyphenols. As expected, red wines contained the highest concentrations, while white and rose wines had less, with rose wines generally presenting slightly higher values compared to white ones.

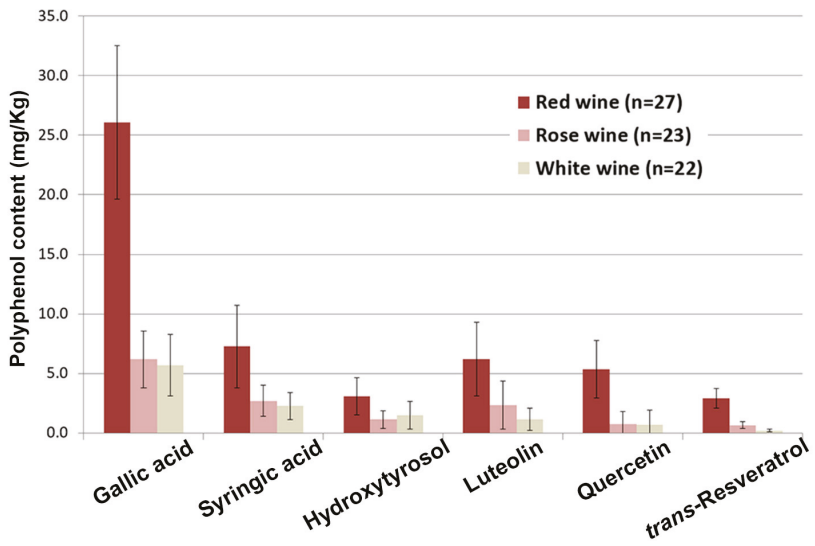

Figure 2. Histogram of the analyzed phenols grouped for wine color. 
The results clearly indicate that gallic acid is the most abundant polyphenol in all wines, although there is quite a large difference when comparing their color. In fact, red wines averaged $26 \mathrm{mg} / \mathrm{kg}$, about four times the quantity found in white and rose ones (around $6 \mathrm{mg} / \mathrm{kg}$ in both varieties). Considerable amounts of syringic acid, luteolin, and quercetin were also found in the red varieties (about 7, 6, and $5 \mathrm{mg} / \mathrm{kg}$, respectively). Lower quantities of the same phenols were detected in white and rose wines (about 2-3 mg/ $\mathrm{kg}$ of syringic acid and about $1-2 \mathrm{mg} / \mathrm{kg}$ of luteolin for white and rose wines, respectively). Finally, red wines also contained good amounts of hydroxytyrosol and trans-resveratrol (about $3 \mathrm{mg} / \mathrm{kg}$ each). On the other hand, half that amount of hydroxytyrosol was found in white and rose wines, and even less of trans-resveratrol. The results of a more detailed analysis of the quantified polyphenols grouped by type of grape are shown in Table 1.

\subsection{Red Wines}

A total of 27 red wines were analyzed, most of which were Negroamaro (16 samples), followed by Primitivo, blend, and Susumaniello grapes (5, 4, and 2 samples, respectively). The most abundant polyphenol observed was found to be gallic acid (between about 24 and $28 \mathrm{mg} / \mathrm{kg}$ in all samples). Lower amounts of syringic acid, luteolin, and quercetin were detected in all wines, with averages of about 7,6 , and $5 \mathrm{mg} / \mathrm{kg}$, respectively (see Table 1 for details). The highest content of hydroxytyrosol was found in Negroamaro grapes, with an average content of $3.4 \pm 1.8 \mathrm{mg} / \mathrm{kg}$. Soon after, blend wines were shown to have $2.9 \pm 1.0 \mathrm{mg} / \mathrm{kg}$ of hydroxytyrosol, not surprising if we consider that these wines were obtained mainly from Negroamaro grapes (percentages from 50\% to 80\%), and lower amounts were obtained from Malvasia Nera, Primitivo, and Monte Pulciano grapes. Similar concentrations were observed in Susumaniello and Primitivo grapes (about $2-3 \mathrm{mg} / \mathrm{kg}$ ).

Finally, Susumaniello wines had the highest concentration of trans-resveratrol $(4.3 \pm 1.5 \mathrm{mg} / \mathrm{kg})$, while Negroamaro, Primitivo, and blend wines averaged about $3 \mathrm{mg} / \mathrm{kg}$, respectable amounts considering the antioxidant strength of this molecule. The results found are in line with values reported in the literature for this grape variety, although Barnaba and colleagues very recently found somewhat higher concentrations of gallic acid and slightly lower ones of hydroxytyrosol in Negroamaro and Primitivo wines from Apulia [34]. Nevertheless, these variations might be related to different cultivation areas and different production years and parameters.

\subsection{White Wines}

White wines were the ones with most grape varieties, with 8 monocultivar samples and 4 blends, mainly composed of different ratios of Malvasia Bianca with Chardonnay, Verdeca, and Trebbiano grapes. Surprisingly, Chardonnay yielded quite high values of hydroxytyrosol $(2.3 \pm 1.3 \mathrm{mg} / \mathrm{kg})$, almost comparable to those found in red wines. Much lower amounts were found in Fiano, Bianco d'Alessano, Falanghina, Malvasia, and Negroamaro (from about 1.1 to $0.6 \mathrm{mg} / \mathrm{kg}$ ). Blend wines contained about $1.3 \pm 0.9 \mathrm{mg} / \mathrm{kg}$, quite high values although quite variable too, probably because of the different type of grapes and the different mixing percentages used. Gallic acid was the most abundant analyte found. In particular, Moscato grapes yielded $12.5 \mathrm{mg} / \mathrm{kg}$ of gallic acid and Fiano about $8 \mathrm{mg} / \mathrm{kg}$, while the remaining varieties yielded between about 3 and $6 \mathrm{mg} / \mathrm{kg}$. Most notably, Moscato grapes were also shown to have the highest alcoholic grade $(14.5 \%)$, quite high compared to average values in the analyzed white wines (between $12 \%$ and $13 \%$ ). Malvasia grapes yielded the highest content of syringic acid (about $4 \mathrm{mg} / \mathrm{kg}$ ), although not much higher than the other wines (about $2-3 \mathrm{mg} / \mathrm{kg}$ ). Even smaller amounts of luteolin were generally detected (about $1 \mathrm{mg} / \mathrm{kg}$ if we exclude the only Moscato sample with $4.5 \mathrm{mg} / \mathrm{kg}$ ). Verdecca showed to have the highest value of trans-resveratrol $(0.5 \mathrm{mg} / \mathrm{kg})$ among white wines, while the other grapes yielded about $0.1-0.3 \mathrm{mg} / \mathrm{kg}$. Quercetin was detected only in Chardonnay, Malvasia, and Moscato (about $1 \mathrm{mg} / \mathrm{kg}$ ), while it was present only in traces of the other white grapes. 


\subsection{Rose Wines}

Most rose wines were composed of Negroamaro grape, with 18 monocultivar samples and 4 blends in which it was mixed in different percentages with Malvasia Nera. One sample of Primitivo was also present among rose wines. Nevertheless, all rose wines yielded similar results. Gallic acid was again the most abundant polyphenol found (about 6-7 mg/kg). Much smaller amounts of syringic acid were obtained (about $3 \mathrm{mg} / \mathrm{kg}$ ), and even less of luteolin and hydroxytyrosol (about 2 and $1 \mathrm{mg} / \mathrm{kg}$, respectively). Rose wines also contained higher values of trans-resveratrol compared to white wines (about $0.6-0.8 \mathrm{mg} / \mathrm{kg}$ in all samples), although still about a fourth of the average concentration found in red ones.

\subsection{Statistical Multivariate Analysis}

Principal component analysis (PCA) was performed using polyphenols data as active variables and wine samples as active cases. Two PCs were extracted: the first one describing $67.1 \%$ and the second one $13.4 \%$ of the sample variability, respectively. The first two PCs account for $80.5 \%$ of the total sample variability. At first glance, it can be seen from the scores plot that red samples spread from about -1 to -4 of PC1, while covering the entire PC2 axis (Figure 3a).
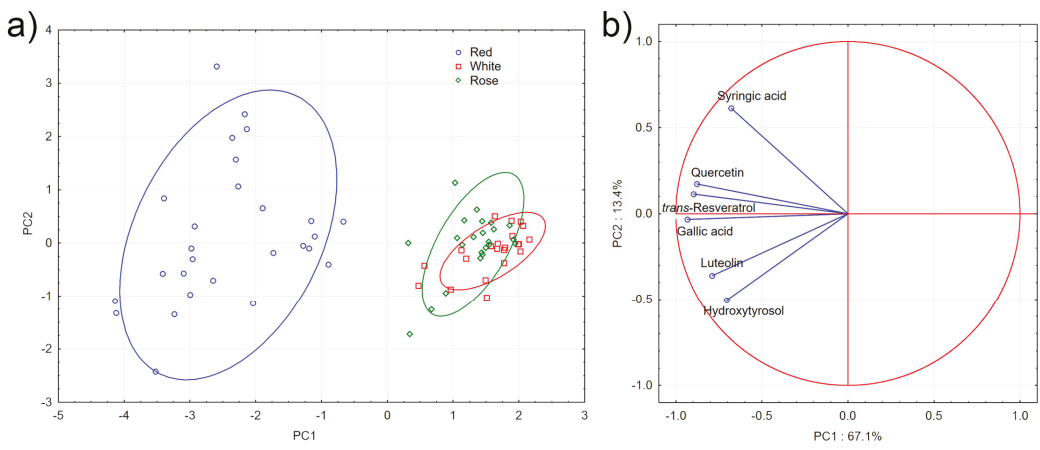

Figure 3. (a) Principal component analysis (PCA) scoreplot (PC1 vs. PC2) for red (blue circles), white (red squares), and rose (green diamonds) wines. Ellipses represent the density space of each group with a correlation coefficient of 0.95 . (b) Loadings plot of PC1 vs. PC2.

By plotting the loadings of the variables, it can be seen that gallic acid, trans-resveratrol, and quercetin contribute the most to PC1, although not much difference was noted with respect to the contribution (on PC1) of the other variables. Syringic acid, hydroxytyrosol, and luteolin was shown to have a major influence on PC2 (Figure 3b). On the other hand, white and rose wines form two significantly merging groups with positive values along PC1 and average neutral ones along PC2, confirming that these wines in general contain much lower amounts of the detected polyphenols compared to red ones (Figure 3a). The two groups overlap significantly although minor differences can be noted through their density space, drawn by an ellipse with a correlation coefficient of 0.95. The three samples corresponding to the markers at the bottom of the rose wines' ellipse represent three Negroamaro characterized by a higher hydroxytyrosol concentration. The sample on top of the rose wines' ellipse corresponds to a Negroamaro sample with a higher concentration of syringic acid. White wines showed even lower variability than rose wines, meaning all samples were quite close to each other in the PCA score plot.

A further investigation was performed using a supervised general discriminant analysis (GDA) in order to determine the variables, allowing a better discrimination between rose and white wines. Complete separation between the two groups was obtained, as can be seen in the scatterplot of the correlation scores for Factors 1 and 2 in Figure 4a. trans-Resveratrol and, to a minor extent, luteolin 
was shown to contribute the most to Factor 1, while gallic acid and hydroxytyrosol the most to Factor 2, as suggested by the respective coefficients. Nonetheless, appreciable separation of white and rose wines had already been noticed during the PCA in the scatter matrix plots for all the pairs of variables, in particular when plotting trans-resveratrol versus the other variables (data not shown). The discriminatory power of the model toward the two groups was also observed in the Mahalanobis distances scatter plot, as shown in Figure $4 b$.

a)

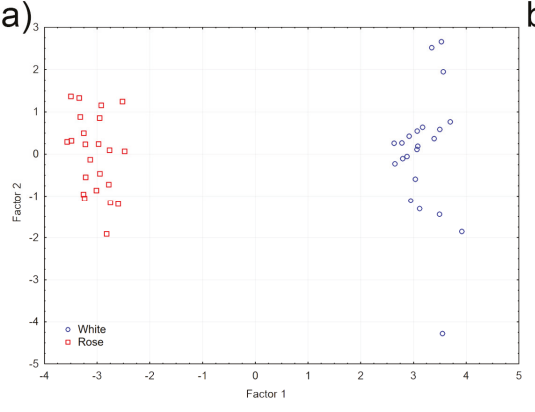

b)

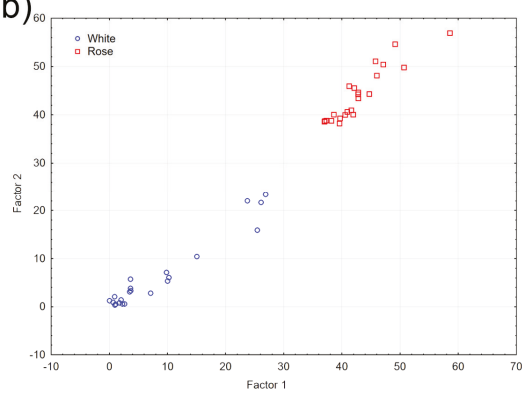

Figure 4. (a) GDA scoreplot; (b) Mahalanobis distances scatter plot for white (blue circles) and rose (red squares) wines.

\section{Conclusions}

Quantification of biomolecules with nutraceutical properties is of paramount importance, especially nowadays that food quality is being considered more and more. Wine is an aliment with important antioxidant activity due to the presence of a variety of biomolecules, some of which were here characterized by means of HPLC analysis in several commercially available red, white, and rose wines from Apulia, in Southeast Italy. Red grapes were shown to yield the healthiest wines, at least based on the analyzed polyphenols. Gallic acid was found to be the most abundant polyphenol. Nevertheless, red wines also contained high amounts of hydroxytyrosol, especially in those with Negroamaro grapes. High concentrations of hydroxytyrosol were also found in Chardonnay white wines, while the other white and rose grapes analyzed generally contained half those values or even less. Red grapes also produced significant amounts of syringic acid, luteolin, and quercetin. Much lower values of these polyphenols were found in white and rose wines. Red wines yielded good concentrations of trans-resveratrol, about 10 times those found in white wines, while rose wines showed an almost intermediate behavior. In general, the amounts of polyphenols found in this study are much lower compared to values used in research studies for curing, e.g., cardiovascular or cancer diseases; nevertheless, ingesting similar amounts of these biomolecules (especially trans-resveratrol) on a regular basis is at the origin of the French paradox assumption [35-37]. The results here reported were part of a study aiming at characterizing the nutraceutical properties of local Apulian wines, but they can be also exploited to modify the production parameters of these wines to improve their already beneficial properties. Furthermore, these data can be used to determine a metabolic profile of these grapes and can be exploited, in combination with other parameters, to guarantee their traceability and safety when analyzed by multivariate statistical analysis [26-28].

Acknowledgments: This research was supported by the project "Negramaro e Qualità" funded by the Fondazione Caripuglia to the MultiLab-Chamber of Commerce of Lecce (Italy). We would like to thank Giuseppe Potenza for his technical assistance and fruitful discussion.

Author Contributions: A.R. and M.M. conceived and designed the experiments; A.R., C.C., M.E.G., M.F.L., P.F.M., and F.S. performed the experiments; A.R., F.P.F., and M.M. analyzed the data; A.R., F.P.F., and M.M. wrote the paper.

Conflicts of Interest: The authors declare no conflict of interest. 


\section{References}

1. Georgiev, V.; Ananga, A.; Tsolova, V. Recent advances and uses of grape flavonoids as nutraceuticals. Nutrients 2014, 6, 391-415. [CrossRef] [PubMed]

2. De Quiros, A.R.B.; Lage-Yusty, M.A.; Lopez-Hernandez, J. Hplc-analysis of polyphenolic compounds in spanish white wines and determination of their antioxidant activity by radical scavenging assay. Food Res. Int. 2009, 42, 1018-1022. [CrossRef]

3. Duthie, G.G.; Duthie, S.J.; Kyle, J.A.M. Plant polyphenols in cancer and heart disease: Implications as nutritional antioxidants. Nutr. Res. Rev. 2000, 13, 79-106. [CrossRef] [PubMed]

4. Giovinazzo, G.; Grieco, F. Functional properties of grape and wine polyphenols. Plant Food Hum. Nutr. 2015, 70, 454-462. [CrossRef] [PubMed]

5. Pandey, K.B.; Rizvi, S.I. Plant polyphenols as dietary antioxidants in human health and disease. Oxid. Med. Cell. Longev. 2009, 2, 270-278. [CrossRef] [PubMed]

6. Arranz, S.; Chiva-Blanch, G.; Valderas-Martinez, P.; Medina-Remon, A.; Lamuela-Raventos, R.M.; Estruch, R. Wine, beer, alcohol and polyphenols on cardiovascular disease and cancer. Nutrients 2012, 4, 759-781. [CrossRef] [PubMed]

7. Tsao, R. Chemistry and biochemistry of dietary polyphenols. Nutrients 2010, 2, 1231-1246. [CrossRef] [PubMed]

8. Lachman, J.; Sulc, M.; Schilla, M. Comparison of the total antioxidant status of bohemian wines during the wine-making process. Food Chem. 2007, 103, 802-807. [CrossRef]

9. Peri, P.; Kamiloglu, S.; Capanoglu, E.; Ozcelik, B. Investigating the effect of aging on the phenolic content, antioxidant activity and anthocyanins in turkish wines. J. Food Process. Preserv. 2015, 39, 1845-1853. [CrossRef]

10. Liu, Y.Q.; Pukala, T.L.; Musgrave, I.F.; Williams, D.M.; Dehle, F.C.; Carver, J.A. Gallic acid is the major component of grape seed extract that inhibits amyloid fibril formation. Bioorg. Med. Chem. Lett. 2013, 23, 6336-6340. [CrossRef] [PubMed]

11. Liu, Y.Q.; Carver, J.A.; Calabrese, A.N.; Pukala, T.L. Gallic acid interacts with alpha-synuclein to prevent the structural collapse necessary for its aggregation. Biochim. Biophys. Acta-Proteins Proteom. 2014, 1844, 1481-1485. [CrossRef] [PubMed]

12. Wang, Y.J.; Thomas, P.; Zhong, J.H.; Bi, F.F.; Kosaraju, S.; Pollard, A.; Fenech, M.; Zhou, X.F. Consumption of grape seed extract prevents amyloid-beta deposition and attenuates inflammation in brain of an Alzheimer's disease mouse. Neurotox. Res. 2009, 15, 3-14. [CrossRef] [PubMed]

13. Hollman, P.C.H.; Katan, M.B. Absorption, metabolism and health effects of dietary flavonoids in man. Biomed. Pharmacother. 1997, 51, 305-310. [CrossRef]

14. Lopez-Lazaro, M. Distribution and biological activities of the flavonoid luteolin. Mini-Rev. Med. Chem. 2009, 9, 31-59. [CrossRef] [PubMed]

15. Hagiwara, K.; Goto, T.; Araki, M.; Miyazaki, H.; Hagiwara, H. Olive polyphenol hydroxytyrosol prevents bone loss. Eur. J. Pharmacol. 2011, 662, 78-84. [CrossRef] [PubMed]

16. Gonzalez-Santiago, M.; Martin-Bautista, E.; Carrero, J.J.; Fonolla, J.; Baro, L.; Bartolome, M.V.; Gil-Loyzaga, P.; Lopez-Huertas, E. One-month administration of hydroxytyrosol, a phenolic antioxidant present in olive oil, to hyperlipemic rabbits improves blood lipid profile, antioxidant status and reduces atherosclerosis development. Atherosclerosis 2006, 188, 35-42. [CrossRef] [PubMed]

17. Vazquez-Velasco, M.; Diaz, L.E.; Lucas, R.; Gomez-Martinez, S.; Bastida, S.; Marcos, A.; Sanchez-Muniz, F.J. Effects of hydroxytyrosol-enriched sunflower oil consumption on cvd risk factors. Br. J. Nutr. 2011, 105, 1448-1452. [CrossRef] [PubMed]

18. Schaffer, S.; Podstawa, M.; Visioli, F.; Bogani, P.; Muller, W.E.; Eckert, G.P. Hydroxytyrosol-rich olive mill wastewater extract protects brain cells in vitro and ex vivo. J. Agric. Food Chem. 2007, 55, 5043-5049. [CrossRef] [PubMed]

19. Warleta, F.; Quesada, C.S.; Campos, M.; Allouche, Y.; Beltran, G.; Gaforio, J.J. Hydroxytyrosol protects against oxidative DNA damage in human breast cells. Nutrients 2011, 3, 839-857. [CrossRef] [PubMed]

20. Ristagno, G.; Fumagalli, F.; Porretta-Serapiglia, C.; Orru, A.; Cassina, C.; Pesaresi, M.; Masson, S.; Villanova, L.; Merendino, A.; Villanova, A.; et al. Hydroxytyrosol attenuates peripheral neuropathy in streptozotocin-induced diabetes in rats. J. Agric. Food Chem. 2012, 60, 5859-5865. [CrossRef] [PubMed] 
21. Brown, L.; Kroon, P.A.; Das, D.K.; Das, S.; Tosaki, A.; Chan, V.; Singer, M.V.; Feick, P. The biological responses to resveratrol and other polyphenols from alcoholic beverages. Alcohol.-Clin. Exp. Res. 2009, 33, 1513-1523. [CrossRef] [PubMed]

22. Nassiri-Asl, M.; Hosseinzadeh, H. Review of the pharmacological effects of vitis vinifera (grape) and its bioactive compounds. Phytother. Res. 2009, 23, 1197-1204. [CrossRef] [PubMed]

23. Neves, A.R.; Lucio, M.; Lima, J.L.C.; Reis, S. Resveratrol in medicinal chemistry: A critical review of its pharmacokinetics, drug-delivery, and membrane interactions. Curr. Med. Chem. 2012, 19, 1663-1681. [CrossRef] [PubMed]

24. Vergara, D.; Valente, C.M.; Tinelli, A.; Siciliano, C.; Lorusso, V.; Acierno, R.; Giovinazzo, G.; Santino, A.; Storelli, C.; Maffia, M. Resveratrol inhibits the epidermal growth factor-induced epithelial mesenchymal transition in mcf-7 cells. Cancer Lett. 2011, 310, 1-8. [CrossRef] [PubMed]

25. Toaldo, I.M.; Van Camp, J.; Gonzales, G.B.; Kamiloglu, S.; Bordignon-Luiz, M.T.; Smagghe, G.; Raes, K.; Capanoglu, E.; Grootaert, C. Resveratrol improves tnf-alpha-induced endothelial dysfunction in a coculture model of a caco-2 with an endothelial cell line. J. Nutr. Biochem. 2016, 36, 21-30. [CrossRef] [PubMed]

26. Brescia, M.A.; Caldarola, V.; De Giglio, A.; Benedetti, D.; Fanizzi, F.P.; Sacco, A. Characterization of the geographical origin of italian red wines based on traditional and nuclear magnetic resonance spectrometric determinations. Anal. Chim. Acta 2002, 458, 177-186. [CrossRef]

27. De Pascali, S.A.; Coletta, A.; Del Coco, L.; Basile, T.; Gambacorta, G.; Fanizzi, F.P. Viticultural practice and winemaking effects on metabolic profile of negroamaro. Food Chem. 2014, 161, 112-119. [CrossRef] [PubMed]

28. Ragone, R.; Crupi, P.; Piccinonna, S.; Bergamini, C.; Mazzone, F.; Fanizzi, F.P.; Schena, F.P.; Antonacci, D. Classification and chemometric study of southern italy monovarietal wines based on NMR and HPLC-DAD-MS. Food Sci. Biotechnol. 2015, 24, 817-826. [CrossRef]

29. Crupi, P.; Coletta, A.; Antonacci, D. Analysis of carotenoids in grapes to predict norisoprenoid varietal aroma of wines from apulia. J. Agric. Food Chem. 2010, 58, 9647-9656. [CrossRef] [PubMed]

30. Crupi, P.; Coletta, A.; Milella, R.A.; Palmisano, G.; Baiano, A.; La Notte, E.; Antonacci, D. Carotenoid and chlorophyll-derived compounds in some wine grapes grown in Apulian region. J. Food Sci. 2010, 75, S191-S198. [CrossRef] [PubMed]

31. Crupi, P.; Coletta, A.; Milella, R.A.; Perniola, R.; Gasparro, M.; Genghi, R.; Antonacci, D. HPLC-DAD-ESI-MS analysis of flavonoid compounds in 5 seedless table grapes grown in Apulian region. J. Food Sci. 2012, 77, C174-C181. [CrossRef] [PubMed]

32. Capone, S.; Tufariello, M.; Francioso, L.; Montagna, G.; Casino, F.; Leone, A.; Siciliano, P. Aroma analysis by GC/MS and electronic nose dedicated to negroamaro and primitivo typical Italian Apulian wines. Sens. Actuators B-Chem. 2013, 179, 259-269. [CrossRef]

33. Tufariello, M.; Capone, S.; Siciliano, P. Volatile components of negroamaro red wines produced in Apulian Salento area. Food Chem. 2012, 132, 2155-2164. [CrossRef]

34. Barnaba, C.; Dellacassa, E.; Nicolini, G.; Nardin, T.; Malacarne, M.; Larcher, R. Free and glycosylated simple phenol profiling in Apulian Italian wines. Food Chem. 2016, 206, 260-266. [CrossRef] [PubMed]

35. Weiskirchen, S.; Weiskirchen, R. Resveratrol: How much wine do you have to drink to stay healthy? Adv. Nutr. 2016, 7, 706-718. [CrossRef] [PubMed]

36. Bonnefont-Rousselot, D. Resveratrol and cardiovascular diseases. Nutrients 2016, 8, 24. [CrossRef] [PubMed]

37. Artero, A.; Artero, A.; Tarin, J.J.; Cano, A. The impact of moderate wine consumption on health. Maturitas 2015, 80, 3-13. [CrossRef] [PubMed]

(C) 2017 by the authors. Licensee MDPI, Basel, Switzerland. This article is an open access article distributed under the terms and conditions of the Creative Commons Attribution (CC BY) license (http:/ / creativecommons.org/licenses/by/4.0/). 


\title{
Composition and Statistical Analysis of Biophenols in Apulian Italian EVOOs
}

\author{
Andrea Ragusa ${ }^{1,2, *}$, Carla Centonze ${ }^{3}$, Maria Elena Grasso ${ }^{3}$, Maria Francesca Latronico ${ }^{3}$, \\ Pier Francesco Mastrangelo ${ }^{3}$, Francesco Paolo Fanizzi ${ }^{3}$ and Michele Maffia ${ }^{3, *}$ \\ 1 Department of Engineering for Innovation, University of Salento, via Monteroni, 73100 Lecce, Italy \\ 2 CNR Nanotec, Institute of Nanotechnology, via Monteroni, 73100 Lecce, Italy \\ 3 Department of Biological and Environmental Sciences and Technologies, University of Salento, via \\ Monteroni, 73100 Lecce, Italy; carla_centonze@libero.it (C.C.); nutrizionegrasso@gmail.com (M.E.G.); \\ latronico-francesca@libero.it (M.F.L.); mastrangelo.pf@hotmail.it (P.F.M.); fp.fanizzi@unisalento.it (F.P.F.) \\ * Correspondence: andrea.ragusa@unisalento.it (A.R.); michele.maffia@unisalento.it (M.M.); \\ Tel.: +39-0832-319208 (A.R.); +39-0832-298685 (M.M.); Fax: +39-0832-661995 (M.M.)
}

Received: 26 September 2017; Accepted: 16 October 2017; Published: 18 October 2017

\begin{abstract}
Extra-virgin olive oil (EVOO) is among the basic constituents of the Mediterranean diet. Its nutraceutical properties are due mainly, but not only, to a plethora of molecules with antioxidant activity known as biophenols. In this article, several biophenols were measured in EVOOs from South Apulia, Italy. Hydroxytyrosol, tyrosol and their conjugated structures to elenolic acid in different forms were identified and quantified by high performance liquid chromatography (HPLC) together with lignans, luteolin and $\alpha$-tocopherol. The concentration of the analyzed metabolites was quite high in all the cultivars studied, but it was still possible to discriminate them through multivariate statistical analysis (MVA). Furthermore, principal component analysis (PCA) and orthogonal partial least-squares discriminant analysis (OPLS-DA) were also exploited for determining variances among samples depending on the interval time between harvesting and milling, on the age of the olive trees, and on the area where the olive trees were grown.
\end{abstract}

Keywords: HPLC; EVOO; biophenols; antioxidants; hydroxytyrosol; oleuropein; multivariate statistical analysis; OPLS-DA

\section{Introduction}

The nutritional and health-promoting properties of extra-virgin olive oils (EVOOs) are well-known and they have been extensively studied over recent decades. In particular, it has been demonstrated that phenolic derivatives in olive oils, also known as biophenols, have strong antioxidant activity which, apart from being responsible of the product shelf life, it also confers on EVOOs anti-inflammatory, chemopreventive, and anti-cancer effects, among others, yielding a product with very important nutraceutical properties [1].

Antioxidants in EVOOs can be mainly grouped in two categories depending on the solubility of the phenolic compounds in either organic or aqueous solvents [2]. Lipophilic phenols in EVOOs are mainly constituted by tocopherols, and in particular, their $\alpha$-homologue, the most biologically active form of vitamin E, which represents over $90 \%$ of their total composition [3]. On the other hand, lignans and secoiridoids represent the mayor constituents of hydrophilic phenols in EVOOs, with the latter being only found in plants belonging to the family of Oleaceae. Among secoiridoids, o-diphenols, such as 3,4-DHPEA and its derivatives 3,4-DHPEA-EDA and 3,4-DHPEA-EA, were reported to have a higher antioxidant activity compared to $p$-HPEA and $\alpha$-tocopherol (see Figure 1 for names and structures of these compounds) [4]. Nevertheless, all these molecules, together with other minor 
compounds, such as carotenoids, and thanks to a well-balanced unsaturated-to-saturated fatty acid ratio, contribute to the high quality of EVOOs and its fundamental role in the Mediterranean diet.
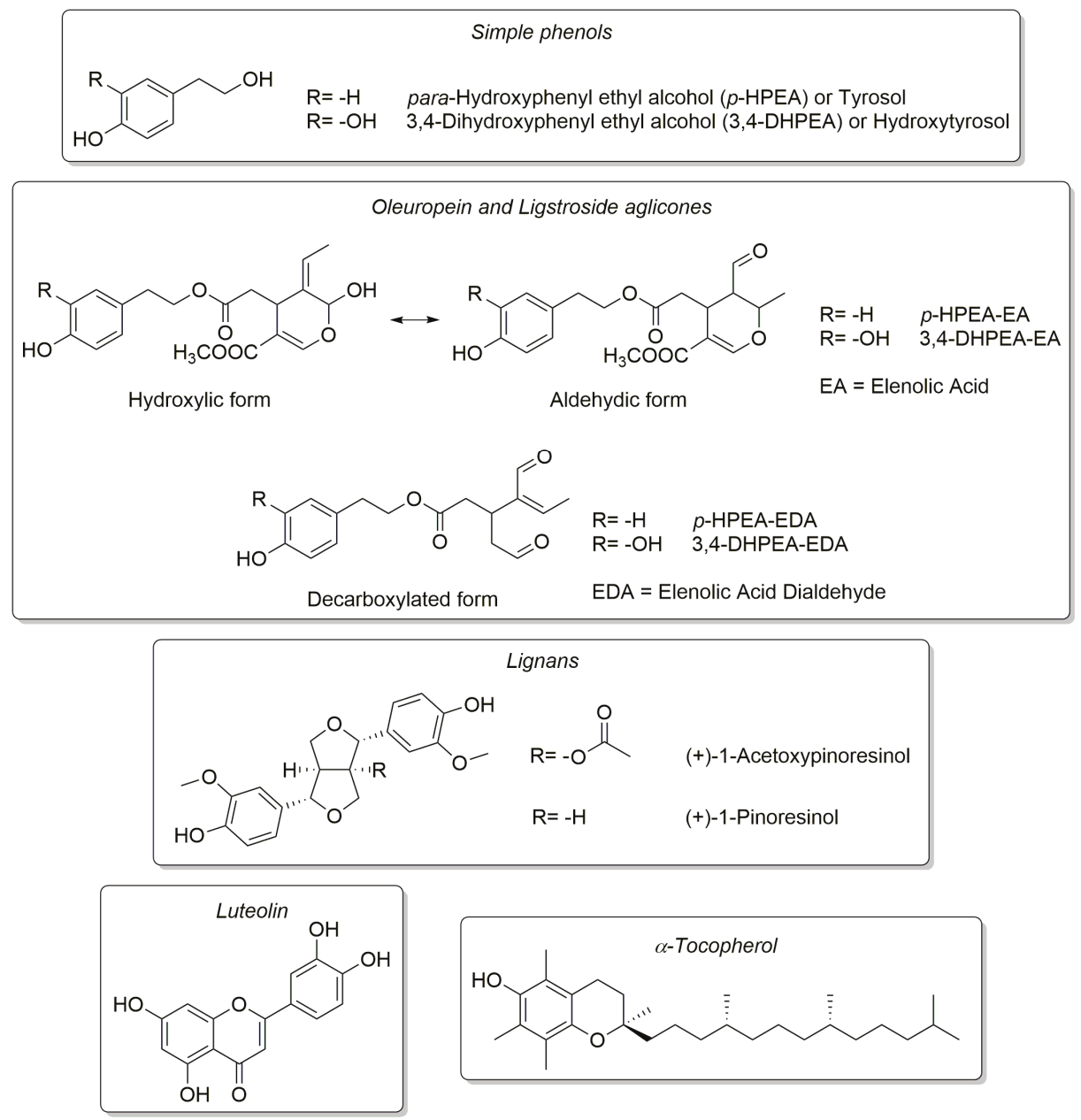

Figure 1. Chemical structures of the antioxidant molecules studied.

EVOOs from Apulia have been already studied in quite significant detail over recent years, also because they represent almost $40 \%$ of the total Italian production [5]. However, most of the studies examine cultivar from the central area of Apulia and only few investigate the southern part, that is, Salento. Back in 1999, Caponio et al., studied the phenolic composition of Ogliarola and Coratina EVOOs and correlated its variation to different technological variables [6]. They later investigated the influence of decanter working parameters on the quality of the oils [7]. Longobardi and colleagues classified Apulian olive oils based on their chemical composition, i.e., free acidity, peroxide value, spectrophotometric indexes, chlorophyll content, sterol, fatty acid, and triacylglycerol, and on the NMR profile combined with multivariate statistical analysis [8,9]. Gambacorta et al., also inspected the phenolic composition and the antioxidant activity of Collina di Brindisi oils and found out that the maturity degree of olives had a major influence on the phenol composition, followed by the extraction 
system and the place of growth [10]. Over recent years Fanizzi and colleagues explored, in detail, the use of nuclear magnetic resonance (NMR) and used multivariate statistical analysis (MVA) to investigate various aspects of EVOOs from Apulia. They managed to correlate NMR spectra to genetic profile of the cultivars, to the characteristics of the soil where the trees were grown, to the age of the olive trees, as well as the production parameters employed and the weather influence over the years [11-14]. The NMR-based metabolomics was exploited to generate a comparable data set for fingerprinting olive oil cultivars from Apulia, thus allowing identification and traceability of commercial EVOOs [5,15-18]. They also applied the same technique to EVOOs from Salento, in particular to Ogliarola, Cellina, and blend samples [19]. Nevertheless, a detailed study regarding the phenolic composition in EVOOs from Salento has not been reported so far despite the commercial importance of these products.

We already reported the phenolic profile of several grape types from Salento and we now extend this study, by examining similar antioxidant molecules in local olive oils [20]. In this article, the total amount of biophenols, as well as the concentration of hydroxytyrosol and tyrosol and their derivatives conjugated to elenolic acid, lignans, luteolin, and $\alpha$-tocopherol were quantified in several monovarietal cultivars and blend EVOOs. Furthermore, their concentrations were correlated to the type of cultivar and other agronomical parameters, such as the age of the trees and the areas they were located, as well as more technical variables, such as the interval time between harvesting and milling.

\section{Materials and Methods}

\subsection{Chemicals}

High performance liquid chromatography (HPLC)-grade orto-phosphoric acid ( $85 \% v / v)$ and reference standard of tyrosol, hydroxytyrosol, syringic acid, luteolin, and $\alpha$-tocopherol were purchased from Sigma-Aldrich (Milan, Italy). HPLC-grade methanol, acetonitrile, isopropanol, and hexane were purchased from J.T. Baker (Deventer, The Netherlands). HPLC-grade water was purchased from Carlo Erba Reagenti (Milan, Italy).

\subsection{Samples}

Analysis was conducted on a total of 68 EVOO samples collected and produced between October and December 2013 by enterprises from Salento, a geographic region at the southern end of the region of Apulia, in South Italy (see Figure 2 for details). All samples were produced from olive trees grown locally and representing typical cultivars from Apulia, such as Ogliarola salentina $(n=25)$, Cellina di Nardò $(n=20)$, Leccino $(n=4)$, Frantoio $(n=2)$, Picholine $(n=2)$, and Cima di Melfi $(n=1)$. Furthermore, 14 blend samples, 9 of which composed of mixtures of Ogliarola and Cellina in different ratios (from 30 to $70 \%$ ), and the other 5 same as the former with also a minor percentage (from 10 to $20 \%$ ) of either Leccino, Frantoio, or Coratina, were also analyzed. The Protected Designation of Origin (PDO) cultivars were certified by the Chamber of Commerce of Lecce (IT), the competent Public Authority Control, while the non-PDO cultivars were assessed and certified based on the growers' declaration. Other technical info and production details were provided by the farmers and are reported in Table 1. When the sum of the number of samples in each category is lower to the total number of samples it means that not all the producers provided the corresponding information. All producers employed the same technical details additionally provided, such as the use of continuous crushers, malaxation at low temperatures (about $25^{\circ} \mathrm{C}$ ), and two-phases decanters, and as such they were not treated as variables. Samples were stored directly in dark glass bottles soon after production, and were kept as such in a cool, dark place until analyzed. All analyses were completed within 2014. 


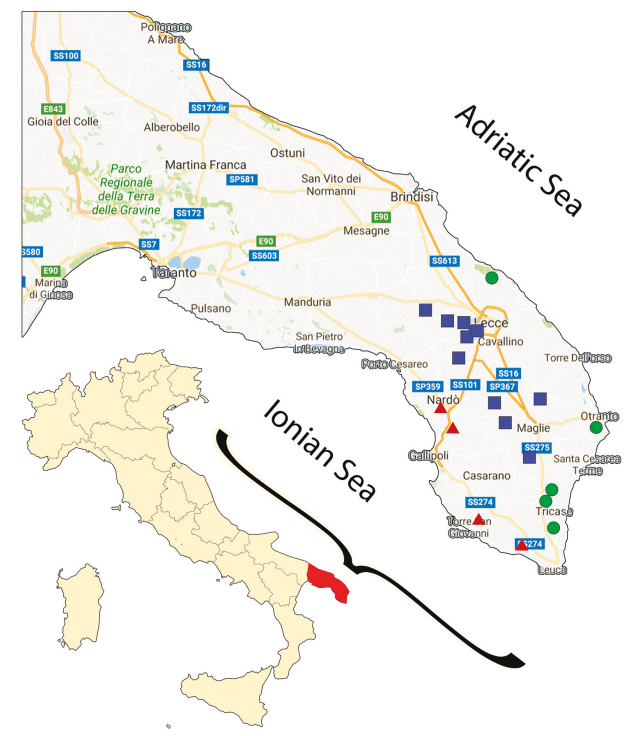

Figure 2. Map of Italy with a zoom on a southern Apulia region (Salento, in red). The colored shapes represent the sites of production of the extra-virgin olive oils (EVOOs) categorized according to their proximity either to the Adriatic (green circles) or Ionian Sea (red triangles), or to neither of them (blue squares).

Table 1. Technical info and production details about EVOO samples organized by type of cultivar. ${ }^{1}$

\begin{tabular}{|c|c|c|c|c|c|c|c|c|c|c|}
\hline \multirow[t]{2}{*}{ Cultivar } & \multirow{2}{*}{$\begin{array}{c}n \text { of } \\
\text { Samples }\end{array}$} & \multicolumn{2}{|c|}{$\begin{array}{l}\text { PDO “Terra d'Otranto" } \\
\text { Certification }{ }^{2}\end{array}$} & \multicolumn{3}{|c|}{ Cultivation Area ${ }^{3}$} & \multicolumn{2}{|c|}{$\begin{array}{c}\text { Interval Time between } \\
\text { Harvesting and Milling (h) }\end{array}$} & \multicolumn{2}{|c|}{$\begin{array}{l}\text { Age of Olive } \\
\text { Trees (year) }\end{array}$} \\
\hline & & Yes & No & Ionian & Center & Adriatic & $\leq 12$ & $>12$ & $\leq 100$ & $>100$ \\
\hline Ogliarola salentina & 25 & 19 & 2 & 10 & 13 & 2 & 25 & - & 2 & 15 \\
\hline Cellina di Nardò & 20 & 17 & 1 & 5 & 8 & 6 & 13 & 7 & 7 & 11 \\
\hline Leccino & 4 & - & - & 2 & 2 & - & 3 & 1 & 1 & - \\
\hline Picholine & 2 & - & - & 2 & - & - & 2 & - & - & - \\
\hline Frantoio & 2 & - & - & 2 & - & - & 2 & - & - & - \\
\hline Cima di Melfi & 1 & - & - & 1 & - & - & 1 & - & - & - \\
\hline Blend & 14 & 8 & 6 & 5 & 5 & 2 & 9 & 4 & 2 & 7 \\
\hline Total & 68 & 44 & 9 & 27 & 28 & 10 & 55 & 12 & 12 & 33 \\
\hline
\end{tabular}

${ }^{1}$ Extra-virgin olive oils (EVOOs) data were provided by the farmers. When the sum of the number of samples for each category is lower than the total it means that not all the producers provided the corresponding information. 2 Protected Designation of Origin (PDO) "Terra d'Otranto" certification is valid only for EVOOs from Ogliarola salentina and Cellina di Nardò cultivars, present alone or in combination, in varying percentages and not less than $60 \%$. The remaining $40 \%$ can consist of other minor cultivars present in the olive grove of the production area [21].

${ }^{3}$ Location of the olive trees according to their proximity either to the Ionian or Adriatic Sea, or to neither of them.

4 Samples in the "> 12 " category were milled between 12 and $24 \mathrm{~h}$ from harvesting.

\subsection{HPLC Analysis}

Separation and identification of phenolic compounds were carried out using an HPLC 1220 Infinity (Agilent Technologies, Palo Alto, CA, USA) equipped with an Eclipse Plus C18 (particle size $5 \mu \mathrm{m} ; 4.6 \times 250 \mathrm{~mm}$, Agilent) stationary phase column interfaced with a diode array detector (model G1315B DAD system; Agilent).

\subsubsection{Analysis of the Phenolic Compounds}

Extraction and quantification of the phenolic compounds was carried out following an official methodology from the International Olive Council, see the original document for details and a representative spectrum [22]. Tyrosol and syringic acid in a methanol/water $80 / 20(v / v)$ solution at a 
concentration of 0.030 and $0.015 \mathrm{mg} / \mathrm{mL}$, respectively, were used as external standards. Syringic acid in a methanol/water $80 / 20(v / v)$ solution at a concentration of $0.015 \mathrm{mg} / \mathrm{mL}$ was used as internal standard. The concentration of the biomolecules in the analyzed samples was expressed as $\mathrm{mg} / \mathrm{kg}$ of tyrosol.

Before analysis, $2.0 \mathrm{~g}$ of olive oil were put into a $10 \mathrm{~mL}$ vial and $1 \mathrm{~mL}$ of the internal standard solution was added. The vial was shaken on an orbital shaker (New Brunswick Innova 2050, Eppendorf, Germany) for $30 \mathrm{~s}$ and then $5 \mathrm{~mL}$ of a methanol/water 80/20 (v/v) solution were added. The sample was shaken for $1 \mathrm{~min}$ and then sonicated for $15 \mathrm{~min}$ at room temperature. The sample was centrifuged (Eppendorf 5804R Centrifuge, Eppendorf, Germany) at $5000 \mathrm{rpm}$ for $25 \mathrm{~min}$ and an aliquot was extracted from the upper layer and filtered over polyvinylidene fluoride (PVDF) membrane filters with $0.45 \mu \mathrm{m}$ pore size (VWR International, Milano, Italy). The solution obtained was ready for HPLC analysis.

A ternary gradient system with solvents (A) $0.2 \% \mathrm{H}_{3} \mathrm{PO}_{4} / \mathrm{H}_{2} \mathrm{O}(\mathrm{v} / \mathrm{v})$, (B) methanol, and (C) acetonitrile was used. The gradient parameters were: $96 \%(\mathrm{~A}), 2 \%(\mathrm{~B}), 2 \%(\mathrm{C})$ at $0 \mathrm{~min} ; 50 \%(\mathrm{~A}), 25 \%$ (B), $25 \%$ (C) at $40 \mathrm{~min} ; 40 \%(\mathrm{~A}), 30 \%(\mathrm{~B}), 30 \%$ (C) at $45 \mathrm{~min} ; 0 \%(\mathrm{~A}), 50 \%(\mathrm{~B}), 50 \%(\mathrm{C})$ at $60 \mathrm{~min} ; 0 \%$ (A), $50 \%(\mathrm{~B}), 50 \%(\mathrm{C})$ at $70 \mathrm{~min} ; 96 \%(\mathrm{~A}), 2 \%(\mathrm{~B}), 2 \%(\mathrm{C})$ at $72 \mathrm{~min} ; 96 \%(\mathrm{~A}), 2 \%(\mathrm{~B}), 2 \%(\mathrm{C})$ at $82 \mathrm{~min}$. The solvent flow was maintained at $1.0 \mathrm{~mL} / \mathrm{min}$, the column temperature was set $25{ }^{\circ} \mathrm{C}$, and the ultraviolet-visible (UV-Vis) detection wavelength was set at $280 \mathrm{~nm}$. The ratio of the response factors between syringic acid and tyrosol, $R R F_{\text {syr } / \text { tyr }}$, was calculated before sample analyses to be sure that it was in the range $5.1 \pm 0.4$. The concentration of the phenol $X$ was calculated according to the equation:

$$
\mathrm{X}(\mathrm{mg} / \mathrm{kg})=\left(\left(\mathrm{A}_{x}\right) \times 1000 \times R R F_{\text {syr } / \mathrm{tyr}} \times \mathrm{P}_{\text {syr }}\right) /\left(\mathrm{A}_{\text {syr }} \times \mathrm{P}_{\text {oil }}\right),
$$

where $\mathrm{A}_{x}$ is the area of the corresponding phenol $X, \mathrm{P}_{s y r}$ is the weight in $\mathrm{mg}$ of the syringic acid utilized as internal standard, $\mathrm{A}_{\text {syr }}$ is the area of the peak of syringic acid, and $\mathrm{P}_{\text {oil }}$ is the exact weighted amount of oil utilized for the extraction. Obtained retention time for the identified phenols were: hydroxytyrosol, min 10.6; tyrosol, min 15.1; syringic acid, min 20.6; 3,4-DHPEA-EDA, min 31.7; 3,4-DHPEA-EA, min 34.4; $p$-HPEA-EDA, min 36.6; lignans, min 37.8; -HPEA-EA, min 39.8; luteolin, min 40.9; 3,4-DHPEA-EA aldehydic and hydroxylic isomer, min 54.8; $p$-HPEA-EA aldehydic and hydroxylic isomer, min 57.7. The total amount of biophenols was calculated by integrating all the peaks in the spectrum in the range 9-59 $\mathrm{min}$, i.e., those of the identified phenols plus other unidentified. The original raw data are available from the Multilab-Chamber of Commerce of Lecce-upon request at multilab@le.camcom.it.

\subsubsection{Analysis of $\alpha$-Tocopherol}

Before analysis, $0.1 \mathrm{~g}$ of olive oil was put into a $10 \mathrm{~mL}$ vial and $5 \mathrm{~mL}$ of methanol were added. The vial was shaken on an orbital shaker for $2 \mathrm{~min}$ and then centrifuged at $3000 \mathrm{rpm}$ for $5 \mathrm{~min}$. An aliquot was extracted from the upper layer and filtered over PVDF filters with $0.45 \mu \mathrm{m}$ pore size (VWR International, Milano, Italy). The solution obtained was ready for HPLC analysis.

A calibration curve was prepared using standard solutions at increasing concentration of $\alpha$-tocopherol in methanol and recording the corresponding peak area. Fitting of the data was performed through a linear equation with zero intercept $\left(R^{2}>0.99\right)$. The concentration in $\mathrm{mg} / \mathrm{kg}$ of $\alpha$-tocopherol in the analyzed sample was then calculated through interpolation of the corresponding peak area.

A binary gradient system with solvents (A) 0.5\% isopropanol/hexane $(v / v)$, (B) $10 \%$ isopropanol/hexane was used. The gradient parameters were: $100 \%$ (A), $0 \%$ (B) at $0 \mathrm{~min} ; 100 \%$ (A), $0 \%$ (B) at $4 \mathrm{~min} ; 60 \%(\mathrm{~A}), 40 \%(\mathrm{~B})$ at $14 \mathrm{~min} ; 40 \%(\mathrm{~A}), 60 \%$ (B) at $18 \mathrm{~min} ; 100 \%(\mathrm{~A}), 0 \%$ (B) at $21 \mathrm{~min} ; 100 \%$ (A), $0 \%$ (B) at $25 \mathrm{~min}$. The solvent flow was maintained at $1.0 \mathrm{~mL} / \mathrm{min}$, the column temperature was set $25^{\circ} \mathrm{C}$, and the UV-Vis detection wavelength was set at $288 \mathrm{~nm}$. Obtained retention time was $11.2 \mathrm{~min}$.

\subsection{Statistical Analysis}

The amounts of phenols reported represent the mean values for a specific type of cultivar. The reported standard deviation represents the difference among different samples from the same 
category. When just one sample for a specific type of cultivar was available, no standard deviation has been reported. Standard deviation relatively to replicates of the same sample was always $<5 \%$. Obtained values were rounded to one decimal place. Statistical analysis was performed using SIMCA 14.1 software (MKS Umetrics, Malmö, Sweden). Principal component analysis (PCA) and orthogonal partial least-squares discriminant analysis (OPLS-DA) were performed using the detected biophenols, their total amount, and $\alpha$-tocopherol as variables $(n=12)$ while the qualitative information, such as cultivar, interval time between harvesting and milling, age of the trees, location of the trees, and PDO certification, as classes according to the data reported in Table 1. Strong outliers were removed from the computation to obtain a better fit. $R^{2} X(\mathrm{cum})$ and $R^{2} Y(\mathrm{cum})$ are the cumulative Sum of Squares (SS) of the variation of the $\mathrm{X}$ or $\mathrm{Y}$ variables, respectively, explained by the extracted components of the model. $Q^{2}$ (cum) is the cumulative variation of the $X$ and $Y$ variables predicted by the extracted components of the model. $R^{2} X$ (cum) and $R^{2} Y$ (cum) are parameters utilized for describing the goodness of the fit and their values are always between 0 and 1 , the higher the better. $Q^{2}(\mathrm{cum})$ is a parameter used to describe the predictive ability of the model and its value is usually between 0 and 1 , the higher the better.

\section{Results and Discussion}

The content of several biophenols and their total amount was quantified in several EVOOs from Salento, in Southeast Italy (Figure 2). All EVOOs were prepared from olive trees grown locally from monovarietal species of Ogliarola, Cellina, Leccino, Picholine, Frantoio, and Cima di Melfi. Furthermore, Ogliarola and Cellina were mixed in blend samples, in percentages from 30 to $70 \%$, plus a few samples wherein small amounts of other cultivar were added (see Section 2.2 for details). Oils were produced in late 2013, between October and December, and additional agronomical and technical information are reported in Table 1.

All samples showed significant amounts of the investigated biophenols, as well as very high quantities of $\alpha$-tocopherol, as shown in Figure 3. orto-Diphenols conjugated to the elenolic acid in various forms, i.e., the dialdehydic 3,4-DHPEA-EA, the decarboxylated dialdehydic 3,4-DHPEA-EDA, and 3,4-DHPEA-EA in the mixed aldehydic and hydroxylic form, were found to be the most abundant compounds, followed by their mono-hydroxy homologous (the $p$-HPEA derivatives). Nevertheless, significant amounts of their simple phenols hydroxytyrosol and tyrosol (3,4-DHPEA and p-HPEA, respectively) as well as lignans and luteolin were also found.

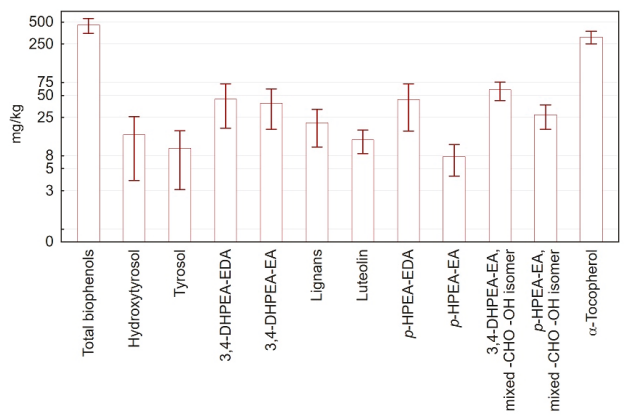

Figure 3. Histograms of the analyzed biophenols averaged for all samples. Bars represent standard deviations. A logarithmic scale was used on the $\mathrm{Y}$ axis.

\subsection{Analysis by Cultivar}

The average total amount of biophenols was about $452 \mathrm{mg} / \mathrm{kg}$, with Frantoio being the cultivar with lowest quantity, as detailed in Table 2. On the other hand, Frantoio EVOOs had the highest concentration of hydroxytysosol and tyrosol (about 23 and $20 \mathrm{mg} / \mathrm{kg}$, respectively), and lignans 
(about $43 \mathrm{mg} / \mathrm{kg}$ ). Nevertheless, all the other biophenols were present in modest quantities compared to the other cultivars. Ogliarola showed quite high concentrations of total biophenols and $p$-HPEA-EDA, all other values being on average. Cellina also had quantities of phenols analogous to average values, with the only exception being the amount of $\alpha$-tocopherol, the highest among all cultivars. As expected, blend samples showed a trend similar to that of Ogliarola and Cellina, being they constituted completely by mixtures in different percentages of those two cultivars, or at least for $80 \%$ by them also when mixed with other varieties, such as Leccino, Frantoio, or Coratina. The only significant difference was the concentration of $\alpha$-tocopherol, much lower than that in the pure parent varieties. Small amounts of $p$-HPEA-EDA and $p$-HPEA-EA were detected in Leccino EVOOs, while Picholine had a low concentration of hydroxytyrosol but very high quantities of $p$-HPEA-EA in the aldehydic and hydroxylic form. Finally, Cima di Melfi EVOOs showed quite high concentrations of biophenols compared to average, especially of 3,4-DHPEA-EDA, 3,4-DHPEA-EA, and lignans, while lower quantities of $\alpha$-tocopherol were detected. However, it must be considered that only two samples each of Frantoio and Picholine and one of Cima di Melfi were analyzed, hence those average values might be quite variable on a broader pattern.

In order to check the presence of dominant constituents among the cultivars, principal component analysis (PCA) was carried out on the Cellina and Ogliarola samples, for a total of 45 observations, using the 10 detected phenols, $\alpha$-tocopherol, and the total amount of biophenols as variables. Blend samples were initially excluded from the analysis because of their intrinsic variability being mixtures of Cellina and Ogliarola in various ratios and, in some cases, also with other cultivars, as already stated. On the other hand, Leccino, Picholine, Frantoio, and Cima di Melfi EVOOs were omitted due to low number of available samples for each category $(4,2,2$, and 1 , respectively). The first two components of the model could explain $50.3 \%$ of the total population, however the resulting score plot did not show any dominant variable but the samples were quite spread with a high degree of overlap among them, as shown in Figure 4.

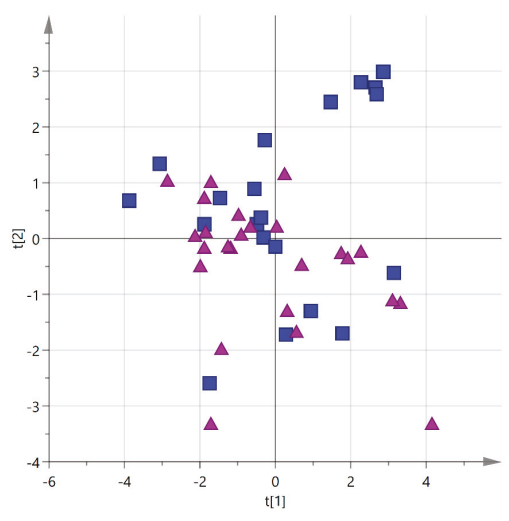

Figure 4. PCA score plot (PC1 vs. PC2) for EVOO samples from Salento categorized by cultivar (blue squares $=$ Cellina; purple triangles $=$ Ogliarola $)$.

Much better results were obtained when a supervised multivariate method was used. Partial least-squares discriminant analysis (OPLS-DA) improved significantly separation of the cultivars, as shown in Figure 5, with cumulative $R^{2} X$ and $R^{2} Y$ of 0.60 and 0.83 , respectively, and a respectable $Q^{2}$ of 0.66 . The two groups were perfectly separated along the mayor component, while the variability among samples is probably responsible for their dispersion along the orthogonal component. According to the loadings, $\alpha$-tocopherol and 3,4-DHPEA-EA contributed the most to the discrimination of Cellina EVOOs, while $p$-HPEA-EDA and $p$-HPEA-EA to that of Ogliarola samples. 

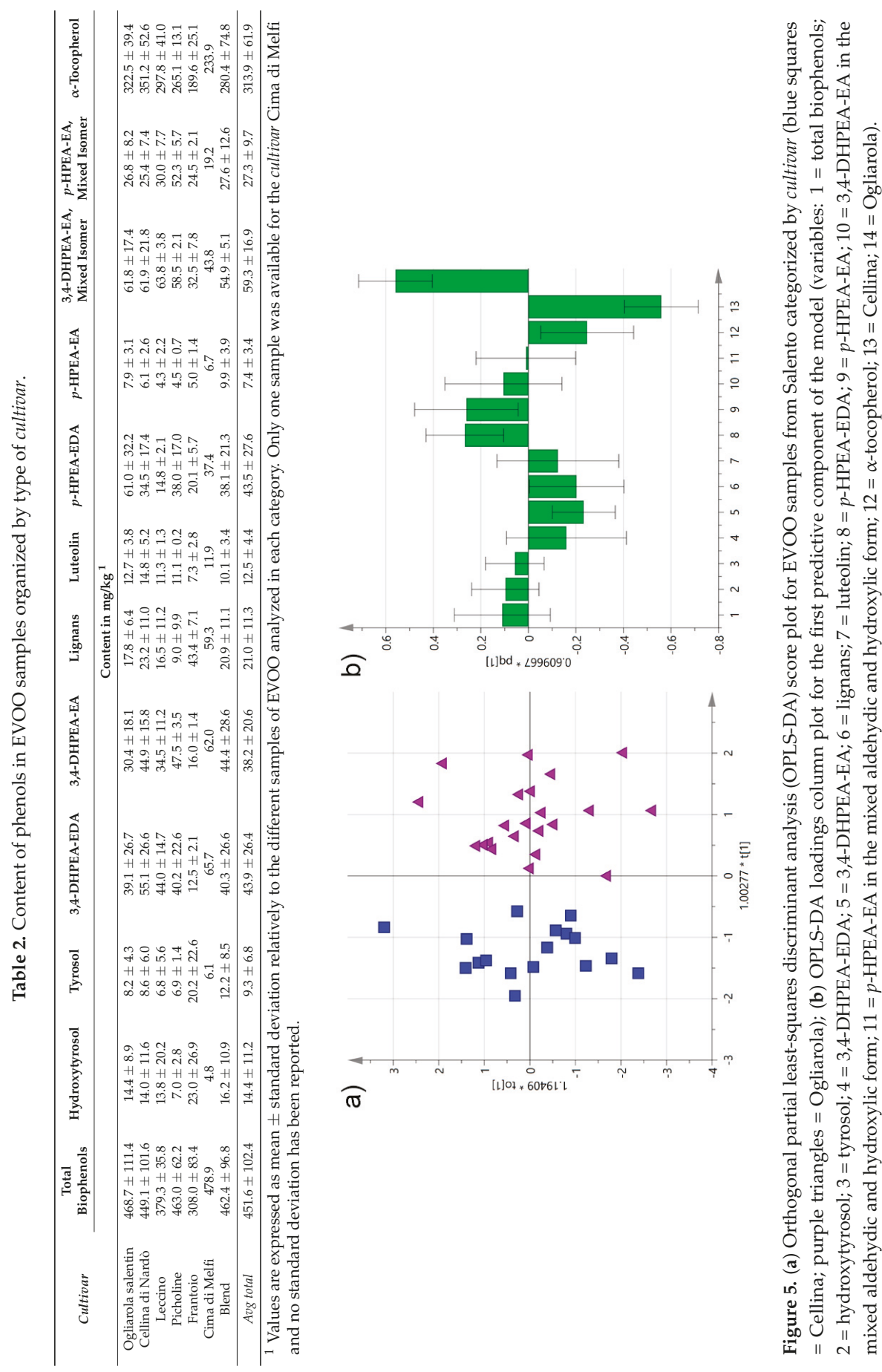
In order to check the predictive ability of the model, blend EVOOs were used as prediction dataset. As expected, samples did not aggregate in any region of the plot but they spread along PC1 between the two extremes marked by the pure cultivars, probably according to the different percentages of Cellina and Ogliarola in their composition, as shown in Figure 6.

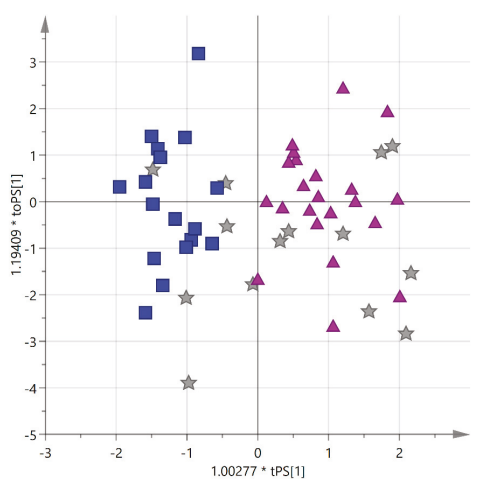

Figure 6. Predicted OPLS-DA score plot for blend EVOO samples from Salento with unknown percentages of Cellina/Ogliarola (blue squares = Cellina; purple triangles = Ogliarola, gray stars = blend predictions).

\subsection{Analysis by Interval Time between Harvesting and Milling}

It is well recognized that the amount of antioxidants in EVOOs is influenced, together with other factors, also by the interval time between harvesting and milling. In fact, it has been shown that the shorter this interval time the higher the concentration of biophenols and it is also the reason why, for example, PDO EVOOs are required to be processed by $48 \mathrm{~h}$ at the latest after being collected [21]. Samples were grouped in two classes, those which were milled by $12 \mathrm{~h}$ from harvesting and those for which that interval time was longer, and OPLS-DA was performed. Initially only Cellina EVOOs were considered to reduce the potential variability introduced by other cultivars, and the resulting score scatter plot is reported in Figure 7.
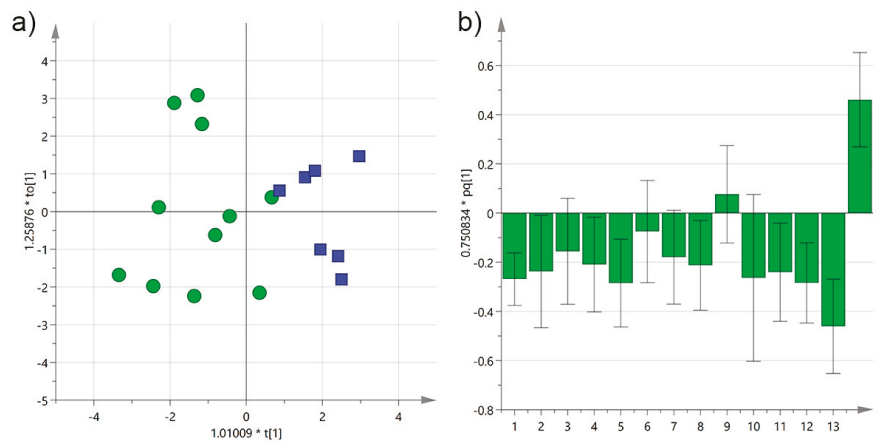

Figure 7. (a) OPLS-DA score plot for Cellina EVOO samples from Salento categorized by the interval time between harvesting and milling of the olives (green circles $\leq 12 \mathrm{~h}$; blue squares $>12 \mathrm{~h}$ ); (b) OPLS-DA loadings column plot for the first predictive component of the model (variables: $1=$ total biophenols; 2 = hydroxytyrosol; 3 = tyrosol; 4 = 3,4-DHPEA-EDA; 5 = 3,4-DHPEA-EA; 6 = lignans; 7 = luteolin; $8=p$-HPEA-EDA; $9=p$-HPEA-EA; $10=3,4$-DHPEA-EA in the mixed aldehydic and hydroxylic form; $11=p$-HPEA-EA in the mixed aldehydic and hydroxylic form; $12=\alpha$-tocopherol; $13 \leq 12 \mathrm{~h} ; 14>12 \mathrm{~h}$ ). 
Discrimination was substantial and it could be observed from the loading plot that most variables contributed significantly to the separation of EVOOs with shorter interval time, especially the total concentration of biophenols, 3,4-DHPEA-EA, and $\alpha$-tocopherol. On the other hand, only $p$-HPEA-EA appeared to give a slightly positive contribution to samples with an interval time longer than $12 \mathrm{~h}$. However, this result is not surprising because it is known that degradation of antioxidant molecules starts soon after harvesting, and that is why a short interval time between harvesting and milling is a prerequisite for producing high quality EVOOs.

Performing the OPLS-DA on all EVOOs yielded a much worse model $\left(R^{2} X(\mathrm{cum})=0.38\right.$, $\left.R^{2} \mathrm{Y}(\mathrm{cum})=0.45, Q^{2} \mathrm{X}(\mathrm{cum})=0.28\right)$ compared to that obtained with only Cellina samples $\left(R^{2} \mathrm{X}(\mathrm{cum})=0.56, R^{2} \mathrm{Y}(\mathrm{cum})=0.73, Q^{2} \mathrm{X}(\mathrm{cum})=0.54\right)$. This was expected given the randomness introduced by other variables, nevertheless a similar trend could be observed in the score scatter plot and in the loading column plot (Figure 8).
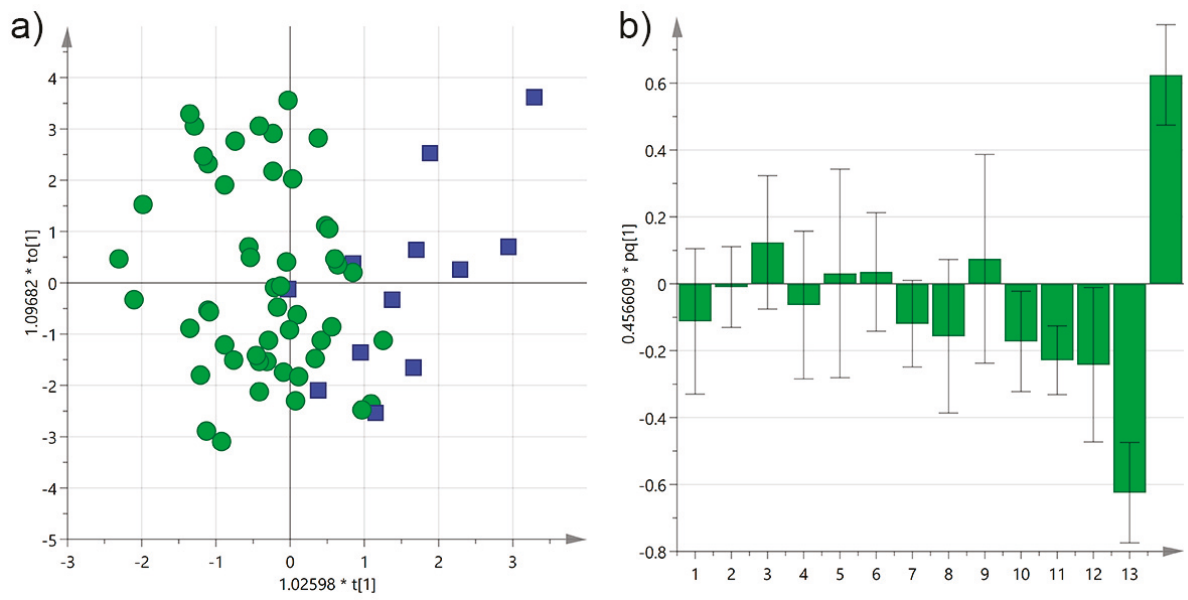

Figure 8. (a) OPLS-DA score plot for EVOO samples from Salento categorized by the interval time between harvesting and milling of the olives (green circles $\leq 12 \mathrm{~h}$; blue squares $\geq 12 \mathrm{~h}$ ); (b) OPLS-DA loadings column plot for the first predictive component of the model (variables: $1=$ total biophenols; 2 = hydroxytyrosol; 3 = tyrosol; 4 = 3,4-DHPEA-EDA; 5 = 3,4-DHPEA-EA; 6 = lignans; 7 = luteolin; $8=p$-HPEA-EDA; $9=p$-HPEA-EA; $10=3,4$-DHPEA-EA in the mixed aldehydic and hydroxylic form; $11=p$-HPEA-EA in the mixed aldehydic and hydroxylic form; $12=\alpha$-tocopherol; $13 \leq 12 \mathrm{~h} ; 14>12 \mathrm{~h}$ ).

\subsection{Analysis by the Age of the Olive Trees}

Salento is well-known for having a high number of secular olive trees, which have recently been regulated and surveyed because of their high historical value [23]. Furthermore, EVOOs from secular olive trees have been already studied and categorized by NMR due to their commercial importance [12]. We now tested if any statistical difference in the amount of biophenols could be detected between secular and younger olive trees. EVOOs were grouped depending on the age of their trees in $>100$ and $<100$-year-old classes and OPLS-DA was performed on Cellina samples. A quite good descriptive but not predictive model was obtained, as shown by the correlation coefficients $\left(R^{2} \mathrm{X}(\mathrm{cum})=0.48, R^{2} Y(\mathrm{cum})=0.70, Q^{2}(\mathrm{cum})=0.02\right)$. According to the loadings, EVOOs from younger trees were significantly discriminated by the total amount of biophenols and $p$-HPEA-EDA, although many other variables also contributed to the separation, as shown in Figure 9. On the other hand, only tyrosol gave a slightly positive contribution to the discrimination of secular trees. 

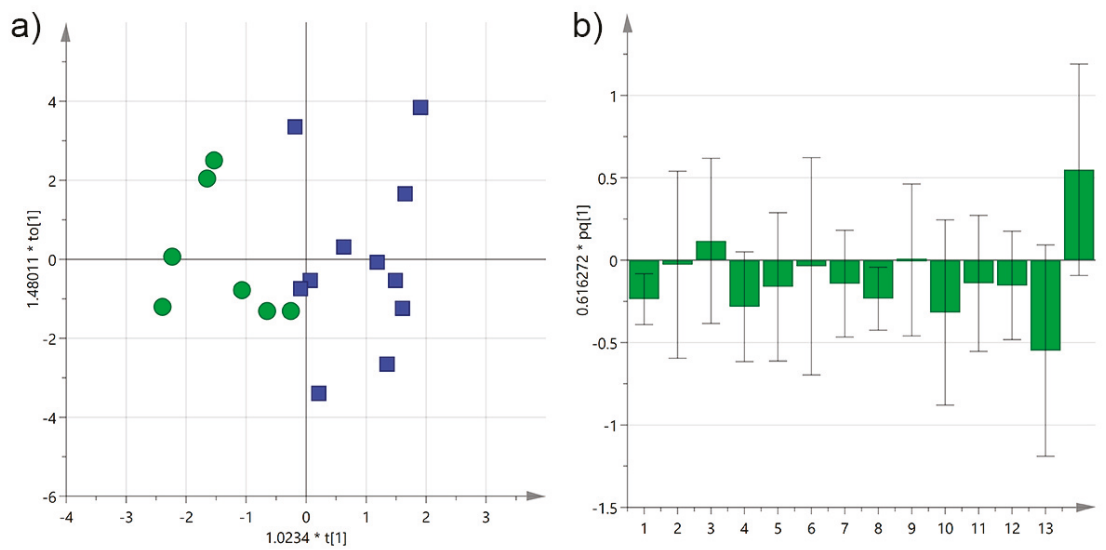

Figure 9. (a) OPLS-DA score plot for Cellina EVOO samples from Salento categorized by the age of the olive trees (green circles $\leq 100$ years; blue squares $>100$ years); (b) OPLS-DA loadings column plot for the first predictive component of the model (variables: 1 = total biophenols; 2 =hydroxytyrosol; 3 = tyrosol; 4 = 3,4-DHPEA-EDA; 5 = 3,4-DHPEA-EA; 6 = lignans; 7 = luteolin; $8=p$-HPEA-EDA; $9=p$-HPEA-EA; $10=3,4$-DHPEA-EA in the mixed aldehydic and hydroxylic form; $11=p$-HPEA-EA in the mixed aldehydic and hydroxylic form; $12=\alpha$-tocopherol; $13 \leq 100$ years; $14>100$ years).

The OPLSA-DA was repeated on all EVOOs yielding, despite the different cultivars utilized, a model with very good both descriptive $\left(R^{2} X(\mathrm{cum})=0.74, R^{2} Y(\mathrm{cum})=0.79\right)$ and predictive $\left(Q^{2}(\mathrm{cum})=0.65\right)$ ability, as shown in Figure 10. The reported loadings again confirmed that younger trees were richer of biophenols compared to secular ones, also emphasizing the role of 3,4-DHPEA derivatives and luteolin, while older ones were discriminated thanks to tyrosol and its derivatives conjugated to elenolic acid.
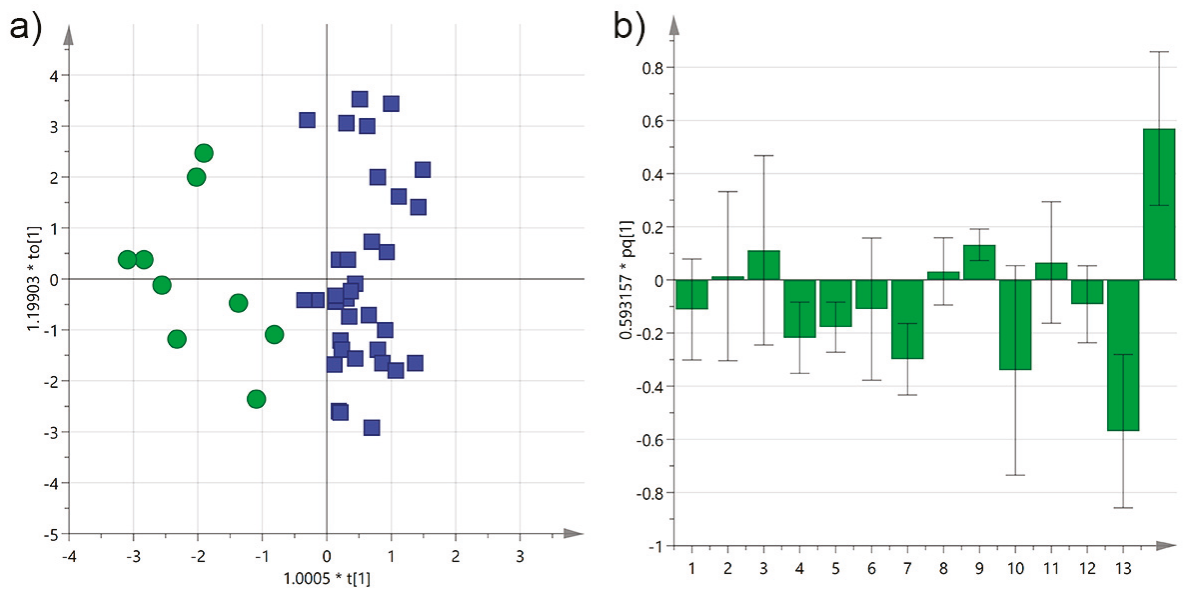

Figure 10. (a) OPLS-DA score plot for EVOO samples from Salento categorized by the age of the olive trees (green circles $\leq 100$ years; blue squares $>100$ years); (b) OPLS-DA loadings column plot for the first predictive component of the model (variables: 1 = total biophenols; 2 =hydroxytyrosol; 3 = tyrosol; 4 = 3,4-DHPEA-EDA; 5 = 3,4-DHPEA-EA; 6 = lignans; 7 = luteolin; $8=p$-HPEA-EDA; $9=p$-HPEA-EA; $10=3,4$-DHPEA-EA in the mixed aldehydic and hydroxylic form; $11=p$-HPEA-EA in the mixed aldehydic and hydroxylic form; $12=\alpha$-tocopherol; $13 \leq 100$ years; $14>100$ years). 


\subsection{Analysis by the Cultivation Area}

Climate and agronomical features are very important variables that influence noteworthy the final characteristics of olives and vegetables in general. Gambacorta et al., reported that olive maturity index and technology used had a greater influence with respect to the place of growth on the total amount of phenols [10]. Nevertheless, they found a variability of about $40 \%$ depending on the cultivation area. Similarly, we looked for any correlation between the area where the olive trees were grown and the concentration of the analyzed biophenols. OPLS-DA was performed on Cellina EVOOs grouped into 3 categories depending on the proximity of the trees either to the Adriatic or Ionian Sea, or to neither of them if in the central mainland. The EVOOs clustered quite nicely $\left(R^{2} X(\right.$ cum $)=0.85, R^{2} Y($ cum $\left.)=0.73\right)$ with samples from trees close to the Adriatic Sea being well separated on the positive axis because of most variables, especially luteolin, $p$-HPEA-EDA, lignans, and the total amount of biophenols, as shown in Figure 11. On the other hand, samples from the Ionian area and the central mainland reported both similar negative values along PC1, but were completely separated along PC2 mainly because of $p$-HPEA-EA the former and 3,4-DHPEA-EA in the mixed aldehydic and hydroxylic form the latter.
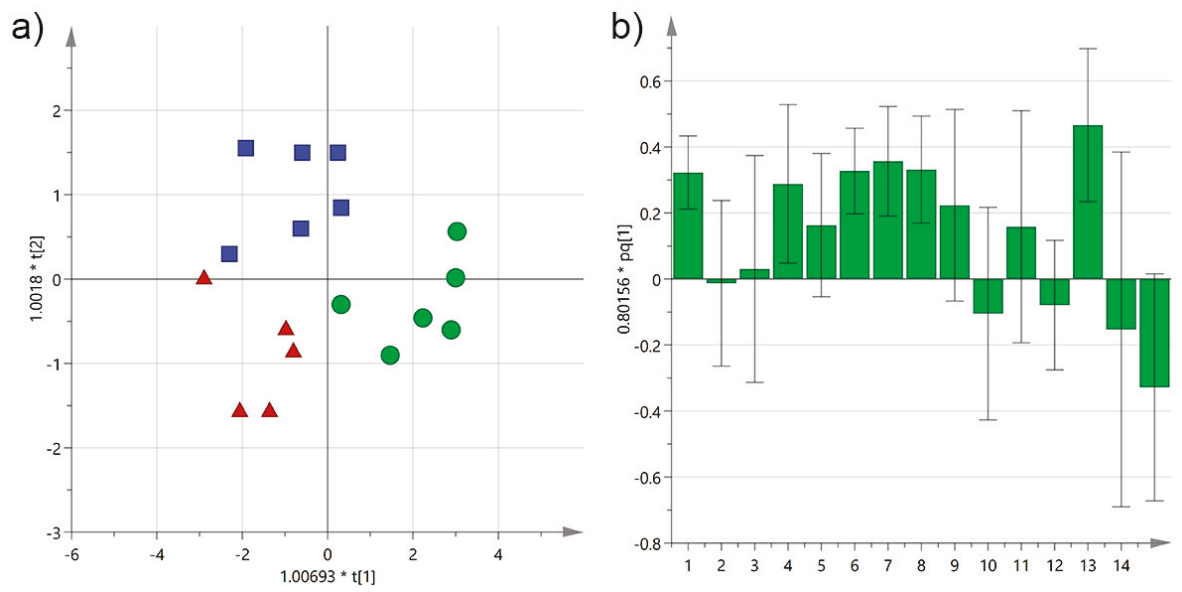

Figure 11. (a) OPLS-DA score plot for Cellina EVOO samples from Salento categorized by their proximity either to the Adriatic (green circles) or Ionian Sea (red triangles), or to neither of them (blue squares); (b) OPLS-DA loadings column plot for the first predictive component of the model (variables: 1 = total biophenols; 2 = hydroxytyrosol; 3 = tyrosol; 4 = 3,4-DHPEA-EDA; 5 = 3,4-DHPEA-EA; $6=$ lignans; $7=$ luteolin; $8=p$-HPEA-EDA; $9=p$-HPEA-EA; $10=3,4$-DHPEA-EA in the mixed aldehydic and hydroxylic form; $11=p$-HPEA-EA in the mixed aldehydic and hydroxylic form; $12=\alpha$-tocopherol; $13=$ Adriatic area; $14=$ central mainland; $15=$ Ionian area).

OPLS-DA was also performed on Ogliarola EVOOs, but only samples from the Ionian Sea and the central mainland were considered, being only two those close the Adriatic area. A very good both descriptive $\left(R^{2} \mathrm{X}(\mathrm{cum})=0.65, R^{2} Y(\mathrm{cum})=0.89\right)$ and predictive $\left(Q^{2}(\mathrm{cum})=0.75\right)$ model was obtained, with samples close to the Ionian Sea being richer of $p$-HPEA-EDA and $p$-HPEA-EA, while those from the central mainland of 3,4-DHPEA-EA and $\alpha$-tocopherol, quite in agreement with Cellina EVOOs from similar cultivation areas (Figure 12). 

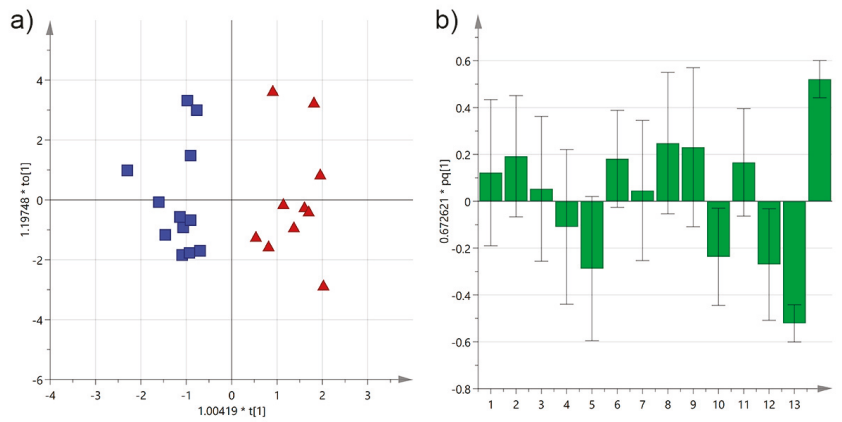

Figure 12. (a) OPLS-DA score plot for Ogliarola EVOO samples from Salento categorized by their proximity either to the Ionian Sea (red triangles), or to the central mainland (blue squares); (b) OPLS-DA loadings column plot for the first predictive component of the model (variables: $1=$ total biophenols; 2 = hydroxytyrosol; 3 = tyrosol; 4 = 3,4-DHPEA-EDA; 5 = 3,4-DHPEA-EA; 6 = lignans; 7 = luteolin; $8=p$-HPEA-EDA; $9=p$-HPEA-EA; $10=3,4$-DHPEA-EA in the mixed aldehydic and hydroxylic form; $11=p$-HPEA-EA in the mixed aldehydic and hydroxylic form; $12=\alpha$-tocopherol; $13=$ central mainland; $14=$ Ionian area).

\subsection{Analysis by PDO Certification}

Protected Designation of Origin (PDO) "Terra d'Otranto" accreditation is a certificate given to EVOOs from the province of Lecce and part of the provinces of Brindisi and Taranto which satisfy determined agronomic and production characteristics which should guarantee healthful properties, among which a high content of antioxidants. Ogliarola and Cellina are the most popular cultivars in Salento and they are the mayor components of PDO EVOOs [21,24].

Most of the analyzed EVOOs in this study were PDO certified, however none of the pure cultivars studied contained a significant number of both $\mathrm{PDO}$ and non-PDO samples to perform a multivariate statistical analysis. Nevertheless, OPLS-DA analysis conducted on all EVOOs could descript ( $R^{2} X$ (cum) $\left.=0.54, R^{2} Y(\mathrm{cum})=0.77\right)$ and predict $\left(Q^{2} \mathrm{X}(\mathrm{cum})=0.68\right)$ quite satisfactorily the two groups (Figure 13). The PDO samples were separated mainly because of a higher content of $\alpha$-tocopherol and $p$-HPEA-EA in the mixed aldehydic and hydroxylic form, while smaller phenols, such as tyrosol and hydroxytyrosol, and $p$-HPEA-EA influenced the most the discrimination of samples without certification.
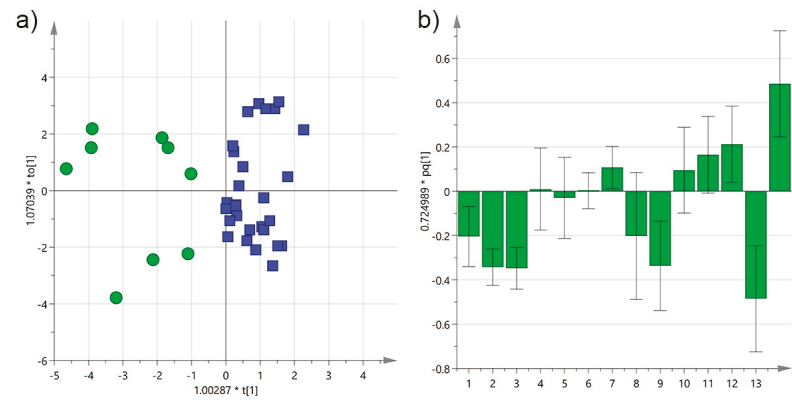

Figure 13. (a) OPLS-DA score plot for EVOO samples from Salento categorized by PDO certification (green circles = non-PDO; blue squares = PDO); (b) OPLS-DA loadings column plot for the first predictive component of the model (variables: 1 = total biophenols; 2 = hydroxytyrosol; $3=$ tyrosol; 4 =3,4-DHPEA-EDA; 5 = 3,4-DHPEA-EA; 6 = lignans; 7 = luteolin; $8=p$-HPEA-EDA; $9=p$-HPEA-EA; $10=3,4$-DHPEA-EA in the mixed aldehydic and hydroxylic form; $11=p$-HPEA-EA in the mixed aldehydic and hydroxylic form; $12=\alpha$-tocopherol; $13=$ non-PDO; $14=\mathrm{PDO}$ ). 


\section{Conclusions}

Quantification of antioxidant molecules in EVOOs is of paramount importance because of their nutraceutical value, even though biophenols represent only minor constituents in olive oil. In this article, we quantified, by HPLC, the total amount of biophenols, several individual biophenols (i.e., tyrosol, hydroxytyrosol, and several more complex derivatives conjugated to elenolic acid in various forms), and $\alpha$-tocopherol in a variety of pure cultivars and blend EVOOs from Salento, in South Apulia. Remarkable differences in the phenolic profile were evident among samples and a high variability was found within the cultivars, probably because of the influence of genotyping and other agro-climatic parameters. Nevertheless, all cultivars showed significant amounts of biophenols and supervised multivariate statistical analysis could detect differences between Cellina and Ogliarola EVOOs, and predict blend samples. Furthermore, the content of biophenols was correlated to production parameters, such the interval time between harvesting and milling, and to agronomical variables, such as the age of the olive trees and the area they were grown. OPLS-DA showed that shorter interval times lead to an increase in the total concentration of biophenols. Furthermore, it could distinguish between EVOOs from secular and from younger trees, and among samples from different cultivation areas, such as the proximity to the Adriatic or Ionian Sea, or to the central mainland. Eventually, these multivariate statistical analyses, besides yielding valuable information about the characteristics of the studied cultivars, could be exploited to improve the already beneficial properties of their EVOOs and to determine a metabolic profile that could be exploited, in combination with other parameters, to guarantee the originality and traceability of these products.

Acknowledgments: This research was supported by the project "Caratterizzazione, valorizzazione ed effetti salutistici dell'olio extravergine di oliva del Salento" funded by MultiLab-Chamber of Commerce of Lecce (Italy). We would like to thank Giuseppe Potenza for his technical assistance and fruitful discussion.

Author Contributions: A.R. and M.M. conceived and designed the experiments; A.R., C.C., M.E.G., M.F.L., and P.F.M. performed the experiments; A.R., F.P.F., and M.M. analyzed the data; A.R., F.P.F., and M.M. wrote the paper.

Conflicts of Interest: The authors declare no conflict of interest.

\section{References}

1. Obied, H.K.; Prenzler, P.D.; Omar, S.H.; Ismael, R.; Servili, M.; Esposto, S.; Taticchi, A.; Selvaggini, R.; Urbani, S. Pharmacology of olive biophenols. In Advances in Molecular Toxicology; Fishbein, J.C., Heilman, J.M., Eds.; Elsevier: Amsterdam, The Netherlands, 2012; pp. 195-242. ISBN 1872-0854.

2. Boskou, D.; Blekas, G.; Tsimidou, M. Olive Oil Composition. In Olive Oil: Chemistry and Technology; Boskou, D., Ed.; AOCS Press: Champaign, IL, USA, 2006; pp. 41-72. ISBN 978-1893997882.

3. Cunha, S.C.; Amaral, J.S.; Fernandes, J.O.; Oliveira, M.B.P.P. Quantification of tocopherols and tocotrienols in Portuguese olive oils using HPLC with three different detection systems. J. Agric. Food Chem. 2006, 54, 3351-3356. [CrossRef] [PubMed]

4. Baldioli, M.; Servili, M.; Perretti, G.; Montedoro, G.F. Antioxidant activity of tocopherols and phenolic compounds of virgin olive oil. J. Am. Oil Chem. Soc. 1996, 73, 1589-1593. [CrossRef]

5. Del Coco, L.; Schena, F.P.; Fanizzi, F.P. 1H Nuclear magnetic resonance study of olive oils commercially available as Italian products in the United States of America. Nutrients 2012, 4, 343-355. [CrossRef] [PubMed]

6. Caponio, F.; Alloggio, V.; Gomes, T. Phenolic compounds of virgin olive oil: Influence of paste preparation techniques. Food Chem. 1999, 64, 203-209. [CrossRef]

7. Caponio, F.; Summo, C.; Paradiso, V.M.; Pasqualone, A. Influence of decanter working parameters on the extra virgin olive oil quality. Eur. J. Lipid Sci. Technol. 2014, 116, 1626-1633. [CrossRef]

8. Longobardi, F.; Ventrella, A.; Casiello, G.; Sacco, D.; Catucci, L.; Agostiano, A.; Kontominas, M.G. Instrumental and multivariate statistical analyses for the characterisation of the geographical origin of Apulian virgin olive oils. Food Chem. 2012, 133, 579-584. [CrossRef] [PubMed]

9. Longobardi, F.; Ventrella, A.; Napoli, C.; Humpfer, E.; Schütz, B.; Schäfer, H.; Kontominas, M.G.; Sacco, A Classification of olive oils according to geographical origin by using $1 \mathrm{H}$ NMR fingerprinting combined with multivariate analysis. Food Chem. 2012, 130, 177-183. [CrossRef] 
10. Gambacorta, G.; Faccia, M.; Trani, A.; Lamacchia, C.; Gomes, T. Phenolic composition and antioxidant activity of Southern Italian monovarietal virgin olive oils. Eur. J. Lipid Sci. Technol. 2012, 114, 958-967. [CrossRef]

11. Papadia, P.; Del Coco, L.; Muzzalupo, I.; Rizzi, M.; Perri, E.; Cesari, G.; Simeone, V.; Mondelli, D.; Schena, F.P.; Fanizzi, F.P. Multivariate analysis of $1 \mathrm{H}-\mathrm{NMR}$ spectra of genetically characterized extra virgin olive oils and growth soil correlations. J. Am. Oil Chem. Soc. 2011, 88, 1463-1475. [CrossRef]

12. Del Coco, L.; Perri, E.; Cesari, G.; Muzzalupo, I.; Zelasco, S.; Simeone, V.; Schena, F.P.; Fanizzi, F.P. NMR-based metabolomic approach for EVOO from secular olive trees of Apulia region. Eur. J. Lipid Sci. Technol. 2013, 115, 1043-1052. [CrossRef]

13. Del Coco, L.; De Pascali, S.A.; Iacovelli, V.; Cesari, G.; Schena, F.P.; Fanizzi, F.P. Following the olive oil production chain: 1D and 2D NMR study of olive paste, pomace, and oil. Eur. J. Lipid Sci. Technol. 2014, 116, 1513-1521. [CrossRef]

14. Girelli, C.R.; Del Coco, L.; Papadia, P.; De Pascali, S.A.; Fanizzi, F.P. Harvest year effects on Apulian EVOOs evaluated by 1H NMR based metabolomics. PeerJ 2016, 4, e2740. [CrossRef] [PubMed]

15. Gallo, V.; Intini, N.; Mastrorilli, P.; Latronico, M.; Scapicchio, P.; Triggiani, M.; Bevilacqua, V.; Fanizzi, P.; Acquotti, D.; Airoldi, C.; et al. Performance Assessment in Fingerprinting and Multi Component Quantitative NMR Analyses. Anal. Chem. 2015, 87, 6709-6717. [CrossRef] [PubMed]

16. Piccinonna, S.; Ragone, R.; Stocchero, M.; Del Coco, L.; De Pascali, S.A.; Schena, F.P.; Fanizzi, F.P. Robustness of NMR-based metabolomics to generate comparable data sets for olive oil cultivar classification. An inter-laboratory study on Apulian olive oils. Food Chem. 2016, 199, 675-683. [CrossRef] [PubMed]

17. Del Coco, L.; Mondelli, D.; Mezzapesa, G.N.; Miano, T.; De Pascali, S.A.; Girelli, C.R.; Fanizzi, F.P. Protected Designation of Origin Extra Virgin Olive Oils Assessment by Nuclear Magnetic Resonance and Multivariate Statistical Analysis: "Terra di Bari", an Apulian (Southeast Italy) Case Study. J. Am. Oil Chem. Soc. 2016, 93, 373-381. [CrossRef]

18. Binetti, G.; Del Coco, L.; Ragone, R.; Zelasco, S.; Perri, E.; Montemurro, C.; Valentini, R.; Naso, D.; Fanizzi, F.P.; Schena, F.P. Cultivar classification of Apulian olive oils: Use of artificial neural networks for comparing NMR, NIR and merceological data. Food Chem. 2017, 219, 131-138. [CrossRef] [PubMed]

19. Del Coco, L.; De Pascali, S.A.; Fanizzi, F.P. NMR-metabolomic study on monocultivar and blend salento EVOOs including some from secular olive trees. Food Nutr. Sci. 2014, 5, 89-95. [CrossRef]

20. Ragusa, A.; Centonze, C.; Grasso, M.; Latronico, M.; Mastrangelo, P.; Sparascio, F.; Fanizzi, F.; Maffia, M. A Comparative Study of Phenols in Apulian Italian Wines. Foods 2017, 6, 24. [CrossRef] [PubMed]

21. "Register of Protected Designations of Origin and Protected Geographical Indications", D.M. 6 August 1998-GURI n. 193, within the Meaning of Reg. CE 1065/97. 2011. Available online: http:/ / www.le.camcom.gov.it/uploaded/Generale/PromozioneTerritorio/Oliodopterrad_otranto/ 2011feb28_Modifica_Disciplinare_Terra_di_Otranto.pdf (accessed on 15 September 2017).

22. Determinazione dei Biofenoli Mediante HPLC. COI/T.20/Doc. n. 29. 2009. Available online: www. internationaloliveoil.org/documents/viewfile/4144-met29it (accessed on 15 September 2017).

23. "Tutela e Valorizzazione del Paesaggio Degli Ulivi Monumentali della Puglia", Legge Regionale 4 Giugno 2007, n. 14; Bollettino Ufficiale della Regione Puglia—n. 83 suppl. del 7-6-2007. 2007. Available online: http:/ / www.regione.puglia.it/documents/10192/7080382/L_14_04_06_2007.pdf (accessed on 15 September 2017).

24. Publication of an amendment application pursuant to Article 50(2)(a) of Regulation (EU) No 1151/2012 of the European Parliament and of the Council on Quality Schemes for Agricultural Products and Foodstuffs. Official Journal of the European Union, C 237/3. 2013. Available online: http://eur-lex.europa.eu/ LexUriServ /LexUriServ.do?uri=OJ:C:2013:237:0036:0039:EN:PDF (accessed on 15 September 2017).

(C) 2017 by the authors. Licensee MDPI, Basel, Switzerland. This article is an open access article distributed under the terms and conditions of the Creative Commons Attribution (CC BY) license (http:/ / creativecommons.org/licenses/by/4.0/). 

Article

\title{
Stimulatory Effects of Cinnamon Extract (Cinnamomum cassia) during the Initiation Stage of 3T3-L1 Adipocyte Differentiation
}

\author{
Sang Gil Lee ${ }^{\dagger}$, Joanna A. Siaw ${ }^{\dagger}$ and Hye Won Kang * \\ Food and Nutritional Sciences, Department of Family and Consumer Sciences, North Carolina Agricultural and \\ Technical State University, 1601 E. Market Street, Greensboro, NC 27411, USA; slee123@ncat.edu (S.G.L.); \\ josiaw5@gmail.com (J.A.S.) \\ * Correspondence: hkang@ncat.edu; Tel.: +1-336-285-4858; Fax: +1-336-334-7239 \\ + These authors contributed equally to this work.
}

Academic Editor: Antonello Santini

Received: 13 October 2016; Accepted: 29 November 2016; Published: 6 December 2016

\begin{abstract}
Cinnamon (Cinnamomum cassia) has an anti-diabetic effect by possibly increasing the lipid storage capacity of white adipocytes; however, this effect remains controversial. The aim of this study was to examine which stage of adipogenesis is critical for the stimulatory effect of cinnamon in adipogenesis using 3T3-L1 cells. Cells were treated with cinnamon extract during three different stages of adipogenesis. We found that genes related to adipogenesis and lipogenesis were enhanced when cinnamon extract was administered during the initiation stage of differentiation but not when administered during the preadipocyte and post stages of differentiation. At the same time, genes that were involved in the regulation of fatty acid oxidation were unexpectedly upregulated. Taken together, cinnamon may boost lipid storage in white adipocytes and increase the fatty acid oxidation capacity throughout the initiation stage of differentiation, which may be beneficial for the prevention of obesity-induced type II diabetes.
\end{abstract}

Keywords: cinnamon; white adipocyte differentiation; fatty acid oxidation; lipogenesis; adipogenesis

\section{Introduction}

White adipose tissue (WAT) is the primary site where extra calories are stored as fat for the body's energy reserve. WAT also secretes several hormones and cytokines that are critical for regulating nutrient metabolism [1]. However, excessive fat accumulation in WAT causes obesity and adipocyte dysfunction [2], resulting in a spillover of fatty acids into non-adipose organs, which further increases susceptibility for the development of type 2 diabetes mellitus, insulin resistance, and dyslipidemia [3]. Therefore, it is important for WAT to maintain its normal function and capacity to safely store fat, which protects other tissues against lipotoxicity [4]. This maintenance can be achieved by acquiring new adipocytes through adipocyte differentiation in WAT. Adipocyte differentiation is the process in which preadipocytes develop into mature white adipocytes that accumulate lipids as a single lipid droplet through early, intermediate, and terminal stages [5].

Various transcriptional factors and enzymes are involved in the adipogenesis process. Peroxisome proliferator-activated receptor gamma $(\operatorname{PPAR} \gamma)$ is a primary transcriptional factor that regulates adipogenesis and also operates as a known therapeutic target for type 2 diabetes mellitus and dyslipidemia to increase the lipid storage capacity of WAT [6]. PPAR $\gamma$ agonists, such as thiazolidinediones (TZDs), increase the WAT storage capacity by activating PPAR $\gamma$, subsequently improving insulin sensitivity [7]. However, various side effects of these drugs have demanded the development of alternative therapeutics from natural sources that activate PPAR $\gamma[6,8]$. Cinnamon, 
the bark of Cinnamomum cassia, has been used extensively as a traditional herb to manage numerous health conditions and as a spice in the food industry [9]. Previous studies have shown that cinnamon extract (CE) and cinnamaldehyde, a bioactive compound of cinnamon, improved insulin sensitivity and reduced plasma glucose levels, possibly via PPAR $\gamma$ [10-12].

However, some discrepancies remain regarding the anti-diabetic effect of cinnamon and whether cinnamon affects the fat storage capacity of adipocytes through PPAR $\gamma$ activation. Type II diabetic patients who took capsules containing cinnamon powder during a two-month period did not exhibit improvement in either plasma glucose or HbA1c levels [13]. In addition, Han and Huang et al. showed an inhibitory effect of cinnamon during adipogenesis [14,15]. Therefore, the aim of this study was to investigate the effects of $\mathrm{CE}$ in the three different stages of adipogenesis that regulate the fat storage capacity of adipocytes. These effects were defined by examining the expression profiles of genes related to adipogenesis, lipogenesis, and fatty acid oxidation in adipocytes that were fully differentiated and matured after CE was administered during the three different stages of adipogenesis.

\section{Materials and Methods}

\subsection{Sample Preparation}

CE (from Cinnamomum cassia) was purchased from New Age Botanicals (Melbourne, Australia). CE powder was diluted in culture media to final concentrations of 50, 100, and $200 \mu \mathrm{g} / \mathrm{mL}$ with $0.1 \%$ dimethyl sulfoxide (DMSO). The sample solution was then filtered using a syringe filter $(0.22 \mu \mathrm{M})$. The nutritional value and phenolic content of CE powder are shown in the Supplementary Table S1.

\subsection{Cell Culture}

3T3-L1 cells were purchased from the American Type Culture Collection (ATCC, Manassas, VA, USA) and were maintained in Dulbecco's Modified Eagle's Medium (DMEM) supplemented with 10\% bovine calf serum in a humidified cell culture incubator $\left(37^{\circ} \mathrm{C}\right.$ and $\left.5 \% \mathrm{CO}_{2}\right)$. For experiments, cells were seeded at a density of 17,500 cells $/ \mathrm{cm}^{2}$ in 12 -well plates with DMEM supplemented with $10 \%$ fetal bovine serum (FBS), indicated as day 0 . On day 3 , the culture medium was switched to differentiation medium (DMEM, 10\% FBS, $1 \mu \mathrm{g} / \mathrm{mL}$ insulin, $0.5 \mathrm{mM}$ 3-isobutyl-1-methylxanthine, and $0.25 \mathrm{mM}$ dexamethasone), and the cultures were incubated for two additional days. On day 5, the differentiation medium was replaced with post differentiation medium (DMEM, 10\% FBS, and $1 \mu \mathrm{g} / \mathrm{mL}$ insulin). The post differentiation medium was refreshed every other day until day 11 . As shown in Figure 1, to determine the effects of CE on preadipocytes, the initiation of differentiationand its progress during the differentiation and maturation process, cells were treated with CE at concentrations of 50, 100, and $200 \mu \mathrm{g} / \mathrm{mL}$ on day 1 (preadipocyte stage), day 3 (initiation stage of differentiation) or days 5, 7, and 9 (post stages of differentiation) and were incubated for two additional days. The cells were then cultured and differentiated as described above until day 11. On day 11, cells were collected for total RNA extraction and Oil-Red O staining.

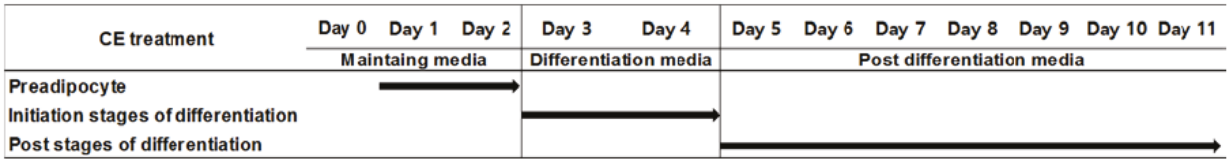

Figure 1. Experimental design to investigate the stimulatory effects of cinnamon extract (CE) treatments at different stages of 3T3-L1 adipocyte adipogenesis. 3T3-L1 adipocytes were treated with CE at the preadipocyte (days 1-2), initiation (days 3-4), and post stages (days 5-11) of differentiation during adipogenesis. When adipocytes were fully differentiated and matured on day 11, cells were harvested to extract total RNA for measuring gene expression using quantitative real-time PCR and were stained with Oil-Red $\mathrm{O}$ to visualize lipid accumulation as a marker of differentiation. 


\subsection{Cell Viability Assay}

Cell viability was determined using a thiazolyl blue tetrazolium bromide (MTT) reduction assay according to the manufacturer's instructions (Cayman, Ann Arbor, MI, USA). Briefly, 3T3-L1 preadipocytes were seeded in a 96-well plate at a density of $17,500 \mathrm{cells} / \mathrm{cm}^{2}$. The next day, the culture medium was replaced with fresh medium containing various concentrations of CE $(0-1000 \mu \mathrm{g} / \mathrm{mL})$. After $48 \mathrm{~h}$ of incubation, the media were replaced again with fresh culture medium containing $0.5 \mathrm{mg} / \mathrm{mL}$ MTT reagent, and cells were incubated for $3 \mathrm{~h}$ at $37^{\circ} \mathrm{C}$. Afterwards, the medium was discarded, and $100 \mu \mathrm{L}$ of dimethyl sulfoxide (DMSO) was added to solubilize the purple formazan products. The absorbance was determined at $570 \mathrm{~nm}$ using a Synergy HT Microplate Reader (BioTek, Winooski, VT, USA), which indicates proportionally the number of viable cells. Cell viability was expressed as a percentage of the absorbance of cells treated with CE relative to the absorbance of cells that were not treated with CE. Experiments were performed in triplicate.

\subsection{Quantitative Real-Time Polymerase Chain Reaction ( $q P C R$ )}

Total RNA was extracted from fully differentiated adipocytes (day 11) using TRIzol (Thermo Fisher Scientific, Waltham, MA, USA) according to the manufacturer's instructions. RNA concentrations and purity were determined using a Take3 micro-volume plate equipped with a Synergy HT microplate reader (BioTek). RNA was transcribed to complementary DNA (cDNA) using XLAScript cDNA MasterMix (Exella GmbH, Feucht, Germany) according to the manufacturer's instructions. To determine the expression of target genes, first-strand cDNA was amplified using a Fast Start Essential DNA Green Light Master kit (Roche, Indianapolis, IN, USA) in a Light Cycler 90 (Roche). PCR conditions were as follows: $10 \mathrm{~min}$ at $95^{\circ} \mathrm{C}$, followed by 50 cycles of $10 \mathrm{~s}$ denaturation at $95^{\circ} \mathrm{C}$, annealing for $10 \mathrm{~s}$ at $60^{\circ} \mathrm{C}$, and extension for $10 \mathrm{~s}$ at $72{ }^{\circ} \mathrm{C}$. The primers used are shown in Table 1 . Ribosomal protein L 32 (RPL32) was used as a housekeeping gene. Cycle threshold $\left(C_{t}\right)$ values were obtained. The expression level of each gene was calculated using the 2 delta $C_{t}$ method by normalizing the $C_{t}$ value of the targeted gene to that of the RPL32 gene. The data are presented as relative percentages of the expression level of each target gene when gene expression levels in adipocytes that were not treated with CE (control) were $100 \%$.

Table 1. Primers designed for quantitative real-time PCR.

\begin{tabular}{ccc}
\hline Gene & Forward Primer & Reverse Primer \\
\hline ACC & TGCATTCTGACCTTCACGAC & ACATCCACTTCCACACACGA \\
C/EBP $\alpha$ & GGACAAGAACAGCAACGAGTA & GCAGTTGCCATGGCCTTGA \\
C/EBP $\beta$ & TGGACAAGCTGAGCGACGAG & TGTGCTGCGTCTCCAGGTTG \\
CIDEA & ATCACAACTGGCCTGGTTACG & TACTACCCGGTGTCCATTTCT \\
CPT1 $\alpha$ & TTTGACTTTGAGAAATACCCTGATA & TGGATGAAATTCTCTCCCACAATAA \\
FAS & TGGGTTCTAGCCAGCAGAGT & ACCACCAGAGACCGTTATGC \\
PGC1 $\alpha$ & TGCCCAGATCTTCCTGAACT & TCTGTGAGAACCGCTAGCAA \\
PPAR $\gamma$ & TTTGACTTTGAGAAATACCC & TGGATGAAATTCTCTCCAC \\
RPL32 & CACCAGTCAGACCGATAT & TTCTCCGCACCCTGTTG \\
SREBP-1c & GAACAGACACTGGCCGAGAT & GAGGCCAGAGAAGCAGAAGAG \\
\hline
\end{tabular}

Abbreviations: ACC, acetyl-CoA carboxylase; $\mathrm{C} / \mathrm{EBP} \alpha, \mathrm{CCAAT}$-enhancer-binding protein $\alpha$; $\mathrm{C} / \mathrm{EBP} \beta$, CCAAT-enhancer-binding protein $\beta$; CIDEA, cell death-inducing DFFA-like effector; CPT1 $\alpha$, carnitine palmitoyltransferase $1 \alpha$; FAS, fatty acid synthase; PGC1 $\alpha$, peroxisome proliferator-activated receptor gamma coactivator $1 \alpha$; PPAR $\gamma$, peroxisome proliferator-activated receptor gamma; RPL32, ribosomal protein L 32; SREBP-1c, sterol regulatory element-binding protein 1.

\subsection{Oil-Red O Staining}

Intracellular lipid accumulation was determined using Oil-Red O staining (Thermo Fisher Scientific). Differentiated adipocytes (day 11) were rinsed with phosphate-buffered saline (PBS) twice and were fixed in $10 \%$ buffered formalin for $1 \mathrm{~h}$ at room temperature. After rinsing with $60 \%$ 
isopropanol, cells were incubated with $60 \%$ isopropanol-based Oil-Red Solution by mixing 2 parts of deionized (DI) water and 3 parts of stock solution ( $350 \mathrm{mg}$ of Oil-Red O in $100 \mathrm{~mL}$ of isopropanol) for $30 \mathrm{~min}$ at room temperature. Oil-Red $\mathrm{O}$, an oil-soluble dye used to stain lipids, was removed and washed twice with DI water. Lipid droplets were visualized based on their red color using an Evos XL-microscope (Thermo Fisher Scientific).

\subsection{Data Analysis}

The data are presented as means \pm standard error of mean (SEM). The comparisons were analyzed using one-way analysis of variance (ANOVA) with Tukey's post-hoc test in Prism 6 (GraphPad Software Inc., La Jolla, CA, USA). All differences were considered significant at $p<0.05$.

\section{Results}

\subsection{Cytotoxicity of CE in Preadipocytes}

CE did not induce cytotoxicity at or below $200 \mu \mathrm{g} / \mathrm{mL}$ (Figure 2). Thus, the concentration ranges of CE selected for treatment in 3T3-L1 cells were 50, 100, and $200 \mu \mathrm{g} / \mathrm{mL}$.

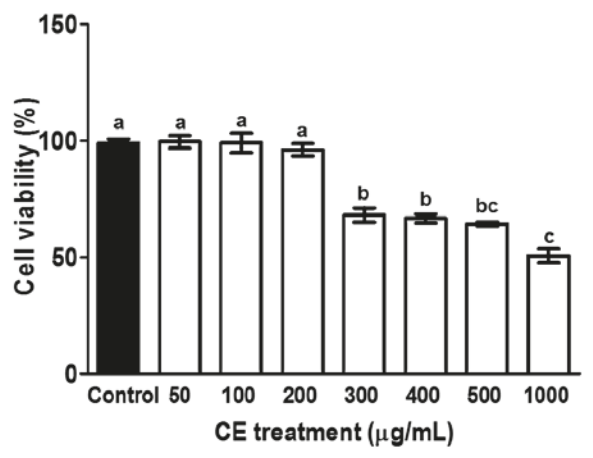

Figure 2. Cytotoxicity of CE in 3T3-L1 preadipocytes. Preadipocytes were treated with different concentrations of CE for $48 \mathrm{~h}$. Cell viability was then measured using a thiazolyl blue tetrazolium bromide (MTT) reduction assay. The experiment was performed in triplicate. A different letter indicates a statistically significant difference $(p<0.05)$.

3.2. CE Increased Lipid Accumulation by Increasing the Expression of Adipogenic and Lipogenic Genes during the Initiation Stage of Differentiation

As shown in Figure 3A, CE treatment during the initiation or post stages of differentiation upregulated PPAR $\gamma$ gene expression during the adipogenesis process. PPAR $\gamma$ coordinately works with CCAAT/enhancer-binding protein alpha and beta $(\mathrm{C} / \mathrm{EBP} \alpha$ and $\beta)$ to mediate a differentiation process that converts preadipocytes into mature adipocytes [16]. Figure 3B,C show that the $C / E B P \alpha$ and $\beta$ genes were upregulated in adipocytes treated with $\mathrm{CE}$ in the initiation stage of differentiation during adipogenesis. Although $C / E B P \beta$ gene expression was increased slightly in adipocytes when $C E$ was administered during the post stages of differentiation, there was no change in $\mathrm{C} / \mathrm{EBP} \alpha$ expression (Figure 3B,C). CE treatment during the preadipocyte stage did not alter the mRNA expression levels for any of the three genes related to adipogenesis, PPAR $\gamma, C / E B P \alpha$, or $\beta$, during adipogenesis (Figure $3 \mathrm{~A}-\mathrm{C}$ ). Consistent with increased expression of genes that are involved in the regulation of adipogenesis, fatty acid synthase (FAS), acetyl-CoA carboxylase (ACC), and sterol regulatory element-binding protein 1c (SREBP-1c) genes, also involved in lipogenesis, were affected in adipocytes treated with CE during the different stages of adipogenesis (Figure 3D-F). The addition of CE in the preadipocyte stages barely affected the expression levels of FAS, ACC, or SREBP-1c genes when 
the cells became fully mature, while CE treatment at $200 \mu \mathrm{g} / \mathrm{mL}$ exhibited an increase in SREBP-1c gene expression. Adipocytes treated with $\mathrm{CE}$ during the initiation stage of differentiation increased SREBP-1c, FAS, and ACC mRNA expression levels compared with control cells when they became mature adipocytes. CE treatment during the post differentiation stage did not affect FAS, ACC, or SREBP-1c gene expression. As shown in Figure 3G, the cell death-inducing DFFA-like effector (CIDEA) gene, which is known to play a role in the formation of lipid droplets, was also upregulated in mature adipocytes following treatment with $200 \mu \mathrm{g} / \mathrm{mL} \mathrm{CE}$ during the initiation stage of differentiation. Figure $3 \mathrm{H}$ shows the increased lipid accumulation in mature adipocytes following treatment with $\mathrm{CE}$ during the initiation stage of differentiation.
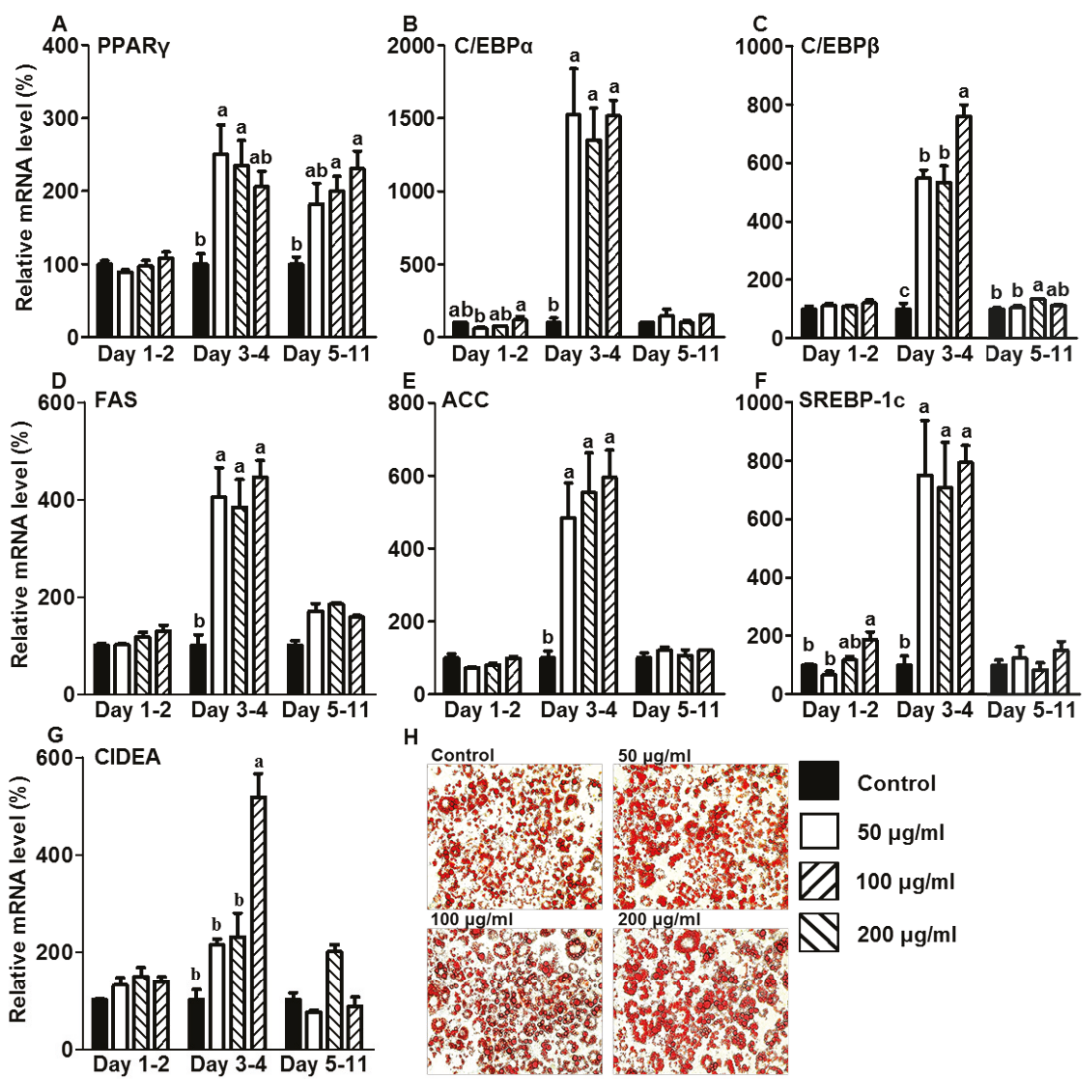

$\mathrm{H}$

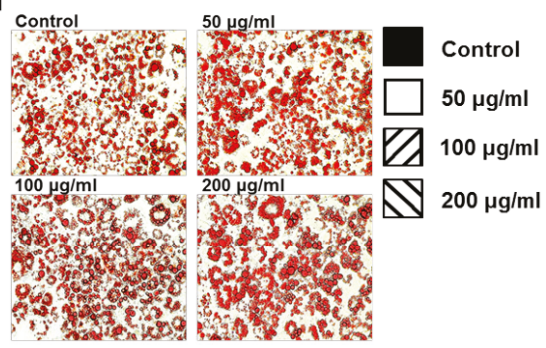

Figure 3. Effects of CE treatment at different stages of 3T3-L1 adipogenesis on adipogenic and lipogenic gene expression levels. Adipocytes were treated with $\mathrm{CE}$ at the preadipocyte (days 1-2), initiation (days 3-4), and post stages (days 5-11) of differentiation during adipogenesis. On day 11, the expression levels of genes related to adipogenesis (A) PPAR $\gamma,(\mathbf{B}) \mathrm{C} / \mathrm{EBP} \alpha,(\mathbf{C}) \mathrm{C} / \mathrm{EBP} \beta$, and lipogenesis (D) FAS, (E) ACC and (F) SREBP-1c, and lipid droplet formation (G) CIDEA, were measured using a quantitative real-time PCR assay. (H) Representative images of Oil-Red O staining in fully matured adipocytes after adipocytes were treated with $\mathrm{CE}$ during the initiation stage of differentiation. The experiment was performed in triplicate. The statistical differences among the four $C E$ concentrations $(0,50,100$, and $200 \mu \mathrm{g} / \mathrm{mL}$ ) that were used to treat cells were separately analyzed for each experiment and each time window (e.g., day 1-2, day 3-4, and day 5-11) using one-way ANOVA with Tukey's post hoc test. A different letter indicates a statistically significant difference $(p<0.05)$. 
3.3. CE Elevated the mRNA Expression Levels of Genes Related to Fatty Acid Oxidation in the Initiation Stage of Differentiation during Adipogenesis

Figure $4 \mathrm{~A}, \mathrm{~B}$ show the effects of $\mathrm{CE}$ on the expression levels of genes related to the regulation of fatty acid oxidation. When preadipocytes were treated with $200 \mu \mathrm{g} / \mathrm{mL} \mathrm{CE}$, the expression of the PPAR $\gamma$-coactivator 1 alpha (PGC1 $\alpha$ ) gene, which encodes a transcriptional factor to regulate energy metabolism including fatty acid oxidation, was increased in fully differentiated mature adipocytes after adipogenesis (Figure 4A). PGC1 $\alpha$ gene induction was also observed in adipocytes treated with $200 \mu \mathrm{g} / \mathrm{mL} \mathrm{CE}$ during the initiation stage of differentiation. However, PGC1 $\alpha$ gene expression was not changed by CE treatment during the post differentiation stages (Figure 4A). Consistent with the stimulatory effect of $\mathrm{CE}$ treatment on the PGC1 $\alpha$ gene at the preadipocyte and initiation stages of differentiation, treatment with $200 \mu \mathrm{g} / \mathrm{mL}$ CE during the initiation stage of differentiation increased mRNA expression levels of the carnitine palmitoyltransferase (CPT) $1 \alpha$ gene, which is involved in promoting fatty acid oxidation during adipogenesis (Figure 4B). However, there were no changes in CPT1 $\alpha$ gene expression when preadipocytes were treated with concentrations of CE below $200 \mu \mathrm{g} / \mathrm{mL}$. Treatment with CE at concentrations of 50, 100, and $200 \mu \mathrm{g} / \mathrm{mL}$ during the initiation stage of differentiation strongly elevated CPT1 $\alpha$ mRNA levels when adipocytes were fully differentiated. Treatment with CE during the post differentiation stages did not affect CPT1 $\alpha$ gene expression during adipogenesis (Figure 4B).
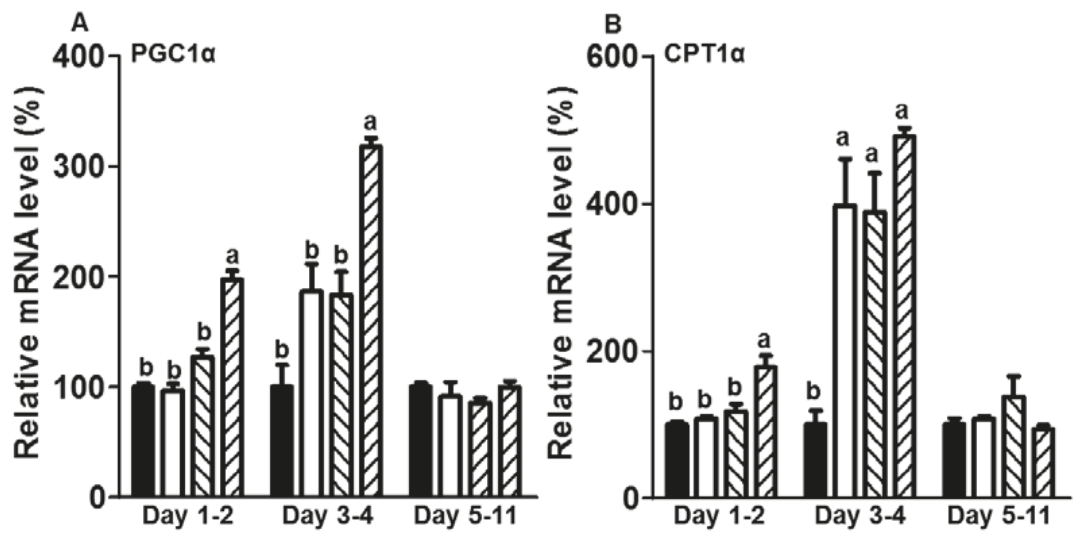

Figure 4. Effects of CE treatment at the different stages of 3T3-L1 adipogenesis on genes related to fatty acid oxidation. Adipocytes were treated with CE at the preadipocyte (days 1-2), initiation (days 3-4), and post stages (days 5-11) of differentiation during adipogenesis. On day 11, the expression levels of genes related to fatty acid oxidation (A) PGC1 $\alpha$ and (B) CPT1 $\alpha$ were measured using a quantitative real-time PCR assay. The experiment was performed in triplicate. The statistical differences among the four CE concentrations $(0,50,100$, and $200 \mu \mathrm{g} / \mathrm{mL})$ that were used to treat cells were separately analyzed for each experiment and each time window (e.g., day 1-2, day 3-4, and day 5-11) using one-way ANOVA with Tukey's post-hoc test. A different letter indicates a statistically significant difference $(p<0.05)$.

\section{Discussion}

Increasing the lipid storage capacity of WAT with anti-diabetic medicines, such as TZDs, can reduce the development of type 2 diabetes by lowering circulating fatty acid and triglyceride levels [6,17]. Cinnamon is a functional food that may improve the lipid loading capacity of WAT by enhancing PPAR $\gamma$ activity $[10,18]$. However, the stimulatory effects of cinnamon on PPAR $\gamma$ remain controversial. It is also unclear which adipogenic stage is critical for the stimulatory effect of cinnamon 
to increase the capacity of white adipocytes to store lipids. In the present study, we found that CE increased the lipid storage capacity during the initiation stage of differentiation by upregulating the expression levels of genes related to adipogenesis and lipogenesis. Additionally, CE showed potential for increasing fatty acid oxidation during adipogenesis, specifically as a result of CE treatment during the initiation stage of differentiation. Therefore, our present study demonstrated that the initiation of differentiation is a critical stage for cinnamon-stimulated effects in adipogenesis and lipogenesis to increase the lipid storage capacity in white adipocytes, as confirmed by increased lipid accumulation as a marker of promoted differentiation. We also observed that CE treatment during the initiation stage of differentiation could induce adipocytes to perform dual functions of lipid storage and utilization.

WAT contains adipocytes that are in various stages of development. For adipocytes to obtain the capacity to store lipids, a process called adipogenesis is required to differentiate preadipocytes into mature adipocytes. Although adipogenesis is regulated by coordinating with various transcriptional factors, e.g., PPAR $\gamma, \mathrm{C} / \mathrm{EBP} \alpha, \mathrm{C} / \mathrm{EBP} \beta$, and adipocyte protein 2 (aP2), PPAR $\gamma$ is recognized as a primary regulator for adipogenesis [16]. $\mathrm{C} / \mathrm{EBP} \beta$ is induced at the early stage of differentiation and increases the activity of $\operatorname{PPAR} \gamma$ and $\mathrm{C} / \mathrm{EBP} \alpha$ throughout the later stages of differentiation to promote differentiation, which further increases the utility of aP2 as a terminal marker of differentiation [16]. Consistent with the increased $\operatorname{PPAR} \gamma, \mathrm{C} / \mathrm{EBP} \alpha$, and $\mathrm{C} / \mathrm{EBP} \beta$ gene expression levels noted in our present study, Sheng at al. observed similar stimulatory effects of $\mathrm{CE}$ during the induction of differentiation in 3T3-L1 cells by increasing PPAR $\gamma$ expression and transcriptional activity at a concentration of $600 \mu \mathrm{g} / \mathrm{mL}$, which was cytotoxic in our present study [18]. In contrast, one study showed that 100 and $500 \mu \mathrm{g} / \mathrm{mL}$ CE inhibited adipogenesis and lipogenesis by decreasing PPAR $\gamma$ gene expression [14]. Another study also reported that cinnamaldehyde, one of the active compounds found in cinnamon, prevented PPAR $\gamma$ transcriptional activity [15]. It has been reported that cinnamon includes various dietary compounds, such as coumarin, 2-hydroxyl cinnamaldehyde, cinnamyl alcohol, cinnamic acid, cinnamaldehyde, 2-methoxy cinnamaldehyde, and eugenol [14]. The differences in the effects of CE between studies may depend on different concentrations of other major dietary compounds as a result of the different extraction methods used. As shown in our present study, the treatment stage was critical for acquiring the different effects of CE.

Along with adipogenesis, lipogenesis is also promoted to store lipids as triglycerides in adipocytes during differentiation. Consistent with the increased expression levels of the $\operatorname{PPAR} \gamma, \mathrm{C} / \mathrm{EBP} \alpha$, and $\mathrm{C} / \mathrm{EBP} \beta$ genes, the FAS, ACC, and SREBP-1c genes, which are involved in the regulation of lipogenesis, were also increased when $\mathrm{CE}$ was administered during the initiation of differentiation. The increases in both adipogenesis and lipogenesis in response to CE treatment during the initiation stage of differentiation were further confirmed by increased lipid accumulation and larger-sized lipid droplets. Mice treated with a PPAR $\gamma$ agonist, rosiglitazone, exhibited upregulated CIDEA expression in WAT [19]. CIDEA plays a role in the enlargement of lipid droplets by transferring triglycerides between neighbored lipid droplets [20]. Transgenic mice expressing human CIDEA became obese by expanding the sizes of their adipose tissues, but had increased insulin sensitivity [21]. In contrast, CIDEA deficient-mice were lean and had small lipid droplets [22]. In the present study, the larger-sized lipid droplets produced in response to CE treatment during the initiation stage of differentiation may have resulted from increased expression of the CIDEA gene. It has also been reported that CIDEA expression was induced by PGC1 $\alpha$ [23]. PGC1 $\alpha$ is a positive regulator of catabolic metabolism, e.g., fatty acid oxidation, and is abundantly present in oxidative tissues, such as brown adipose tissue, muscle, and liver. Our present study showed that CE elevated PGC1 $\alpha$ mRNA levels in adipocytes at the initiation stage of differentiation. Therefore, CE treatment during the initiation stage of differentiation may have increased CIDEA expression by activating PGC1 $\alpha$ and PPAR $\gamma$.

Although the fat storage capacity of WAT may positively improve diabetic conditions, expanding the size of WAT by accumulating excessive fat also presents some concern, e.g., obesity. However, the present study indicated that CE may improve mitochondrial fatty acid oxidation in the initiation of differentiation, likely in part due to the increased expression of CPT $1 \alpha$ and PGC1 $\alpha$ genes. C/EBP $\beta$ is 
involved in not only adipogenesis but also energy metabolism [24]. When C/EBP $\beta$ was transiently overexpressed in 3T3-L1 cells, the cells displayed brown-like characteristics by increasing PGC1 $\alpha$ expression, which is indicated as the browning of white adipocytes [24]. Therefore, increased expression of fatty acid oxidation genes, including CPT $1 \alpha$ and PGC $1 \alpha$ in response to treatment with $\mathrm{CE}$ at the initiation stage of differentiation, would be related to $\mathrm{C} / \mathrm{EBP} \beta$ upregulation.

\section{Conclusions}

In conclusion, the present study demonstrated that $\mathrm{CE}$ allows adipocytes to have enhanced lipid storage capacity and fatty acid oxidation in the initiation stage of differentiation during adipogenesis by simultaneously increasing the expression levels of genes related to adipogenesis, lipogenesis, and fatty acid oxidation. It is possible that the dual effects of CE on both the storage and utilization of fat would be beneficial for obesity related to type II diabetes by increasing insulin sensitivity through enhanced lipid storage capacity and by utilizing stored fat to avoid excess fat accumulation. Although further studies using animal models to understand the effect and efficiency of CE in vivo should be conducted, our findings would provide meaningful information for the development of new anti-diabetic drugs that act on specific target stages of adipogenesis.

Supplementary Materials: The following are available online at www.mdpi.com/2304-8158/5/4/83/s1, Table S1: $F$-values in the statistical analysis for gene expressions level by cinnamon extract (CE) treatments, Table S2: Nutritional components of $100 \mathrm{~g}$ cinnamon extract (CE) powder.

Acknowledgments: This work was supported by the United States Department of Agriculture (NC.X-288-5-15-170-1).

Author Contributions: Sang Gil Lee and Hye Won Kang designed the experiments. Sang Gil Lee and Joanna A. Siaw performed the experiments. Sang Gil Lee, Joanna A. Siaw, and Hye Won Kang wrote the manuscript. All authors approved the final version of the manuscript.

Conflicts of Interest: The authors declare no conflicts of interest.

\section{References}

1. Schuster, D.P. Obesity and the development of type 2 diabetes: The effects of fatty tissue inflammation. Diabetes Metab. Syndr. Obes. 2010, 3, 253-262. [CrossRef] [PubMed]

2. Konige, M.; Wang, H.; Sztalryd, C. Role of adipose specific lipid droplet proteins in maintaining whole body energy homeostasis. Biochim. Biophys. Acta 2014, 1842, 393-401. [CrossRef] [PubMed]

3. Guilherme, A.; Virbasius, J.V.; Puri, V.; Czech, M.P. Adipocyte dysfunctions linking obesity to insulin resistance and type 2 diabetes. Nat. Rev. Mol. Cell Biol. 2008, 9, 367-377. [CrossRef] [PubMed]

4. Sears, B.; Perry, M. The role of fatty acids in insulin resistance. Lipids Health Dis. 2015, 14, 121. [CrossRef] [PubMed]

5. Gregoire, F.M.; Smas, C.M.; Sul, H.S. Understanding adipocyte differentiation. Physiol. Rev. 1998, 78, 783-809. [PubMed]

6. $\quad$ Bermudez, V.; Finol, F.; Parra, N.; Parra, M.; Perez, A.; Penaranda, L.; Vilchez, D.; Rojas, J.; Arraiz, N.; Velasco, M. Ppar-gamma agonists and their role in type 2 diabetes mellitus management. Am. J. Ther. 2010, 17, 274-283. [CrossRef] [PubMed]

7. Hauner, H. The mode of action of thiazolidinediones. Diabetes Metab. Res. Rev. 2002, 18 (Suppl. 2), S10-S15. [CrossRef] [PubMed]

8. Wang, L.; Waltenberger, B.; Pferschy-Wenzig, E.M.; Blunder, M.; Liu, X.; Malainer, C.; Blazevic, T.; Schwaiger, S.; Rollinger, J.M.; Heiss, E.H.; et al. Natural product agonists of peroxisome proliferator-activated receptor gamma (ppargamma): A review. Biochem. Pharmacol. 2014, 92, 73-89. [CrossRef] [PubMed]

9. Sangal, A. Role of cinnamon as beneficial antidiabetic food adjunct: A review. Adv. Appl. Sci. Res. 2011, 2, $440-450$.

10. Khan, A.; Sadafar, M.; Ali Khan, M.M.; Khattak, K.N.; Anderson, R.A. Cinnamon improves glucose and lipids of people with type 2 diabetes. Diabetes Care 2003, 26, 3215-3218. [CrossRef] [PubMed]

11. Crawford, P. Effectiveness of cinnamon for lowering hemoglobin A1C in patients with type 2 diabetes: A randomized, controlled trial. J. Am. Board Fam. Med. 2009, 22, 507-512. [CrossRef] [PubMed] 
12. Li, J.E.; Futawaka, K.; Yamamoto, H.; Kasahara, M.; Tagami, T.; Liu, T.H.; Moriyama, K. Cinnamaldehyde contributes to insulin sensitivity by activating PPARdelta, PPARgamma, and RXR. Am. J. Chin. Med. 2015, 43, 879-892. [CrossRef] [PubMed]

13. Hasanzade, F.; Toliat, M.; Emami, S.A.; Emamimoghaadam, Z. The effect of cinnamon on glucose of type ii diabetes patients. J. Tradit. Complement. Med. 2013, 3, 171-174. [CrossRef] [PubMed]

14. Han, Y.; Jung, H.W.; Bae, H.S.; Kang, J.S.; Park, Y.K. The extract of cinnamomum cassia twigs inhibits adipocyte differentiation via activation of the insulin signaling pathway in 3T3-L1 preadipocytes. Pharm. Biol. 2013, 51, 961-967. [CrossRef] [PubMed]

15. Huang, B.; Yuan, H.D.; Kim, D.Y.; Quan, H.Y.; Chung, S.H. Cinnamaldehyde prevents adipocyte differentiation and adipogenesis via regulation of peroxisome proliferator-activated receptor-gamma (ppargamma) and amp-activated protein kinase (AMPK) pathways. J. Agric. Food Chem. 2011, 59, 3666-3673. [CrossRef] [PubMed]

16. Rosen, E.D.; Spiegelman, B.M. Molecular regulation of adipogenesis. Annu. Rev. Cell Dev. Biol. 2000, 16, 145-171. [CrossRef] [PubMed]

17. Ye, J.M.; Dzamko, N.; Cleasby, M.E.; Hegarty, B.D.; Furler, S.M.; Cooney, G.J.; Kraegen, E.W. Direct demonstration of lipid sequestration as a mechanism by which rosiglitazone prevents fatty-acid-induced insulin resistance in the rat: Comparison with metformin. Diabetologia 2004, 47, 1306-1313. [CrossRef] [PubMed]

18. Sheng, X.; Zhang, Y.; Gong, Z.; Huang, C.; Zang, Y.Q. Improved insulin resistance and lipid metabolism by cinnamon extract through activation of peroxisome proliferator-activated receptors. PPAR Res. 2008, 2008, 581348. [CrossRef] [PubMed]

19. Puri, V.; Ranjit, S.; Konda, S.; Nicoloro, S.M.; Straubhaar, J.; Chawla, A.; Chouinard, M.; Lin, C.; Burkart, A.; Corvera, S.; et al. Cidea is associated with lipid droplets and insulin sensitivity in humans. Proc. Natl. Acad. Sci. USA 2008, 105, 7833-7838. [CrossRef] [PubMed]

20. Barneda, D.; Planas-Iglesias, J.; Gaspar, M.L.; Mohammadyani, D.; Prasannan, S.; Dormann, D.; Han, G.S.; Jesch, S.A.; Carman, G.M.; Kagan, V.; et al. The brown adipocyte protein cidea promotes lipid droplet fusion via a phosphatidic acid-binding amphipathic helix. eLife 2015, 4, e07485. [CrossRef] [PubMed]

21. Abreu-Vieira, G.; Fischer, A.W.; Mattsson, C.; de Jong, J.M.; Shabalina, I.G.; Rydén, M.; Laurencikiene, J.; Arner, P.; Cannon, B.; Nedergaard, J.; et al. Cidea improves the metabolic profile through expansion of adipose tissue. Nat. Commun. 2015, 6, 7433. [CrossRef] [PubMed]

22. Zhou, Z.; Yon Toh, S.; Chen, Z.; Guo, K.; Ng, C.P.; Ponniah, S.; Lin, S.C.; Hong, W.; Li, P. CIDEA-deficient mice have lean phenotype and are resistant to obesity. Nat. Genet. 2003, 35, 49-56. [CrossRef] [PubMed]

23. Hallberg, M.; Morganstein, D.L.; Kiskinis, E.; Shah, K.; Kralli, A.; Dilworth, S.M.; White, R.; Parker, M.G.; Christian, M. A functional interaction between RIP140 and PGC-1alpha regulates the expression of the lipid droplet protein CIDEA. Mol. Cell Biol. 2008, 28, 6785-6795. [CrossRef] [PubMed]

24. Karamanlidis, G.; Karamitri, A.; Docherty, K.; Hazlerigg, D.G.; Lomax, M.A. C/EBPbeta reprograms white 3T3-L1 preadipocytes to a brown adipocyte pattern of gene expression. J. Biol. Chem. 2007, 282, 24660-24669. [CrossRef] [PubMed]

(C) 2016 by the authors; licensee MDPI, Basel, Switzerland. This article is an open access article distributed under the terms and conditions of the Creative Commons Attribution (CC-BY) license (http:/ / creativecommons.org/licenses/by/4.0/). 



\title{
Commentary \\ Red Yeast Rice
}

\author{
Thu Nguyen ${ }^{1, *}$, Mitchell Karl ${ }^{1}$ and Antonello Santini ${ }^{2}$ \\ 1 Boca Raton Hospital Campus, Internal Medicine Residency Program, FAU/ Schmidt School of Medicine, \\ Boca Raton, FL 33486, USA; karlm@health.fau.edu \\ 2 Department of Pharmacy, University of Napoli Federico II, Via D. Montesano 49, Napoli 80131, Italy; \\ asantini@unina.it \\ * Correspondence: nguyent@health.fau.edu; Tel.: +1-561-213-7012 or +1-561-392-9214
}

Academic Editor: Christopher J. Smith

Received: 18 December 2016; Accepted: 27 February 2017; Published: 1 March 2017

\begin{abstract}
Red yeast rice (RYR), produced by the fermentation of the Monascus purpureus mold, has been used for a long time in Asian cuisine and traditional medicine. It consists of multiple bioactive substances, including monacolins, which potentially can be used as a nutraceutical. Monacolin K, which is chemically identical to lovastatin, has been recognized as responsible for the cholesterol-reducing effect of this compound. While the European Food Safety Authority maintains that the use of monacolin K from RYR preparations of at least $10 \mathrm{mg}$ can produce a normal blood cholesterol level, the United States Food and Drug Administration considers monacolin K, due to its similarity with lovastatin, an unapproved drug, and therefore marketing of products that label the monacolin content is prohibited. This mini-review summarizes the benefit of RYR in hyperlipidemia, maintains RYR use as a food, and addresses the importance of regulation regarding RYR and the need for clinical data and clear label information for consumers with reference to a toxin-free, non-augmented, standardized amount of monacolins.
\end{abstract}

Keywords: red yeast rice; lovastatin; nutraceutical; safety; health

\section{Red Yeast Rice as Nutraceutical}

The term "nutraceutical" was coined in 1989 by Stephen DeFelice, founder and chairman of the Foundation for Innovation in Medicine, and it identifies a food or part of a food, which can be of vegetal or animal origin, that has a potential pharmaceutical activity [1]. The goal of assessing the possible role of a nutraceutical and its use in medicine is an important challenge for the future.

In general, any food, due to its content of active compounds, has the potential to go beyond its nutritional value as a source of macro- and micronutrients, and can also be used as a drug depending on the dose. Nonetheless, attention should be paid to potential risk factors related to the use of vegetal- or animal-origin foodstuffs as starting matrices to constitute a nutraceutical, e.g., the safety of the starting material, the presence of allergenic compounds, the absence of toxicity, the absence of exogenous and endogenous contaminants, the possible presence of toxic secondary metabolites and/or environmental pollutants, which could potentially cause a health threat [2,3].

Red yeast rice (RYR) is a nutraceutical made by fermenting white rice with the yeast Monascus purpureus and other related molds. RYR has been used as an herbal supplement and in the cuisine of East Asian countries including China, Japan, and Korea. It has been used for flavoring, coloring, and preservation of food and in traditional Chinese medicine for many years [4].

RYR consists of a multitude of compounds including polyketides, unsaturated fatty acids, phytosterols, pigments, and monacolins [5]. Monacolins inhibit HMG CoA (3-hydroxy-3-methylglutaryl-coenzyme A) reductase, the rate-limiting step in cholesterol synthesis. At least 13 monacolins have been isolated from $\mathrm{RYR}$, of which monacolin $\mathrm{K}$ is chemically similar to lovastatin, a cholesterol-lowering drug [6]. 
Several clinical trials have been conducted to examine the efficacy and safety of RYR. A recent meta-analysis in 2015 examined 20 randomized trials consisting of 6663 patients and showed a reduction in low density lipoprotein (LDL) cholesterol when comparing RYR to placebo groups $(-1.02 \mathrm{mmol} / \mathrm{L}(-1.20,-0.83))$; there was no difference in LDL between RYR and statin therapy $(0.03 \mathrm{mmol} / \mathrm{L}(-0.36,0.41))$, with an incidence of kidney injury and liver abnormalities of less than $5 \%$ in both the RYR and control groups [7]. RYR has been demonstrated to not only improve lipid metabolism, but it can also reduce blood pressure, and may possess anti-inflammatory, antidiabetic, anticancer, and osteogenic properties [5]. The largest randomized controlled trial examining RYR in secondary cardiovascular prevention consisted of 4870 Chinese patients and showed that RYR reduces nonfatal myocardial infarction, coronary disease mortality, coronary revasculization, and total mortality in patients with a history of myocardial infarction and moderate hypercholesterolemia [8].

Furthermore, a number of clinical trials have shown RYR to be effective in reducing cholesterol in those who are intolerant of statins because of statin-associated myalgias, gastrointestinal side effects, or elevated transaminase levels [4]. For those who are skeptical of drugs and are more interested in complementary and alternative medications, RYR has been used as a cholesterol-lowering option [9]. RYR in combination with other nutraceuticals including berberine, policosanol, astaxanthin, and coenzyme Q10 has been shown to be effective in reducing lipids and glucose. A recent meta-analysis of 14 randomized controlled trials showed that nutraceutical combinations containing RYR improve lipid and glucose levels [10]. Although statins have been shown to cause hyperglycemia, a 2014 meta-analysis of five trials consisting of 352 patients showed that RYR does not significantly increase glucose compared to placebo [8]. In addition, RYR in combination with antioxidants has been demonstrated to reduce high sensitivity C-reactive protein (hs-CRP) and endothelial dysfunction [11].

Adverse effects of RYR include gastrointestinal effects and may cause myopathy, hepatotoxicity, rhabdomyolysis, and anaphylaxis similar to the use of statins $[9,12]$. The mycotoxin citrinin, found in poorly produced RYR products, can pose a health risk as it may be mutagenic as found in animal models, genotoxic to human lymphocytes, and can cause kidney failure in animals, although acute toxicity is a rare event [13-16]. Furthermore, drug-herb interactions can potentially be harmful. Statins are metabolized by Cytochrome P450 (CYP) enzymes, and the administration of RYR with CYP enzyme inhibitors (e.g., ketoconazole, human immunodeficiency virus (HIV) protease inhibitors, erythromycin) can lead to worsening undesirable adverse effects, such as myopathy $[5,17]$. Nonetheless, the clinical studies that showed the effectiveness of RYR in dyslipidemia also demonstrated that it is a relatively safe product $[7,18]$.

The European Food Safety Authority (EFSA) allows for health claims that RYR products can cause pharmacotherapeutic effects. The EFSA has established "a cause and effect relationship...between the consumption of monacolin $\mathrm{K}$ in red yeast rice preparations....and maintenance of normal blood LDL cholesterol concentrations", given that the daily dietary intake level is at least $10 \mathrm{mg}$ of monacolin K from RYR [19]. This value is considered acceptable even though recently it has been called into question due to the variable contents of different RYR products, thus representing a health risk in the absence of appropriate information for the customer [17].

The U.S. Food and Drug Administration (FDA) maintains a different perspective. Because of its functional similarity to lovastatin, monacolin $\mathrm{K}$ is considered an unapproved drug by the U.S. FDA, and as such all RYR products that contain a specific amount of monacolin $\mathrm{K}$ are prohibited. In fact, RYR supplements on the market are not standardized and contain variable amounts of monacolins, including monacolin $\mathrm{K}$, citrinin, and other contaminants. Manufacturers do not admit the monacolin content in their RYR products on the packaging for fear it would prompt regulatory action from the FDA $[9,20]$.

In order to reduce the variability of the monacolin contents of different RYR preparations and to minimize toxic compounds, such as citrinin, quality control should be implemented and enforced by entities responsible for food and supplement oversight. 
Due to its extensive use as a dietary supplement for many years before its medicinal purposes were discovered, RYR is a food and should be treated as such. Because of its wide potential health benefits, RYR should be produced as a standardized preparation for those who would potentially benefit from it. By not augmenting this product, it could be made available to consumers as a supplement and thus does not need to be rigorously regulated as a drug. Requiring a statement on the product label assuring a toxin-free, non-augmented, standardized amount of monacolins would be advantageous to consumers, allowing more predictable efficacy and better safety. In addition, a safety warning should also be included to caution those with myopathy, liver disease, or concomitant use of CYP inhibitors. Those who are taking this supplement should be advised to have regular follow-ups with a medical professional to monitor for potential side effects and interactions with drugs and other nutraceuticals.

Conflicts of Interest: The authors declare no conflict of interest.

\section{References}

1. DeFelice, S.L. The nutraceutical revolution: its impact on food industry R\&D. Trends Food Sci. Tech. 1995, 6, 59-61.

2. Otles, S.; Ozlem, C. Safety considerations of nutraceuticals and functional foods. Novel Technol. Food Sci. 2012, 7, 121-136.

3. Yates, A.A.; Erdman, J.W., Jr.; Shao, A.; Dolan, L.C.; Griffiths, J.C. Bioactive nutrients-time for tolerable upper intake levels to address safety. Rep. Prog. Phys. 2017, 84, 94-101. [CrossRef] [PubMed]

4. Burke, F.M. Red yeast rice for the treatment of dyslipidemia. Curr. Atheroscler. Rep. 2015. [CrossRef] [PubMed]

5. Patel, S. Functional food red yeast rice (RYR) for metabolic syndrome amelioration: a review on pros and cons. World J. Microb. Biot. 2016, 32, 2035-2042. [CrossRef] [PubMed]

6. Zhang, Z.; Ali, Z.; Khan, S.I.; Khan, I.A. Cytotoxic monacolins from red yeast rice, a Chinese medicine and food. Food Chem. 2016, 202, 262-268. [CrossRef] [PubMed]

7. Gerards, M.C.; Terlou, R.J.; Yu, H.; Koks, C.H.W.; Gerdes, V.E.A. Traditional Chinese lipid-lowering agent red yeast rice results in significant LDL reduction but safety is uncertain-A systematic review and meta-analysis. Atherosclerosis 2015, 240, 415-423. [CrossRef] [PubMed]

8. Lu, Z.; Kou, W.; Du, B.; Wu, Y.; Zhao, S.; Brusco, O.A.; Morgan, J.M.; Capuzzi, D.M. Chinese CoronarySecondary Prevention Study Group, Li S. Effect of Xuezhikang, an extract from red yeast Chinese rice, on coronary events in a Chinese population with previous myocardial infarction. Am. J. Cardiol. 2008, 10, 1689-1693. [CrossRef] [PubMed]

9. Gordon, R.Y.; Cooperman, T.; Obermeyer, W.; Becker, D.J. Marked variability of monacolin levels in commercial red yeast rice products: Buyer beware! Arch. Intern. Med. 2010, 170, 1722-1727. [CrossRef] [PubMed]

10. Pirro, M.; Mannarino, M.R.; Bianconi, V.; Simental-Mendía, L.E.; Bagaglia, F.; Mannarino, E.; Sahebkar, A. The effects of a nutraceutical combination on plasma lipids and glucose: A systematic review and meta-analysis of randomized controlled trials. Pharmacol. Res. 2016, 110, 76-88. [CrossRef] [PubMed]

11. Cicero, A.F.; Morbini, M.; Parini, A.; Urso, R.; Rosticci, M.; Grandi, E.; Borghi, C. Effect of red yeast rice combined with antioxidants on lipid pattern, hs-CRP level, and endothelial function in moderately hypercholesterolemic subjects. Ther. Clin. Risk Manag. 2016, 12, 281-286. [CrossRef] [PubMed]

12. Klimek, M.; Wang, S.; Ogunkanmi, A. Safety and efficacy of red yeast rice (Monascus purpureus) as an alternative therapy for hyperlipidemia. P T. 2009, 32, 313-327.

13. Endo, A.; Kuroda, M. Citrinin, an inhibitor of cholesterol synthesis. J. Antibiot. 1976, 29, 841-843. [CrossRef] [PubMed]

14. Sabater-Vilar, M.; Maas, R.F.M.; Fink-Gremmels, J. Mutagenicity of commercial Monascus fermentation products and the role of citrinin contamination. Mutat. Res. 1999, 444, 7-16. [CrossRef]

15. Dönmez-Altuntas, H.; Dumlupinar, G.; Imamoglu, N.; Hamurcu, Z.; Liman, B.C. Effects of the mycotoxin citrinin on micronucleus formation in a cytokinesis-block genotoxicity assay in cultured human lymphocytes. J. Appl. Toxicol. 2007, 27, 337-341. [CrossRef] [PubMed] 
16. Pascual-Ahuir, A.; Vanacloig-Pedros, E.; Proft, M. Toxicity mechanisms of the food contaminant citrinin: Application of a quantitative yeast model. Nutrients 2014, 6, 2077-2087. [CrossRef] [PubMed]

17. Venhuis, B.J.; van Hunsel, F.; van de Koppel, S.; Keizers, P.H.J.; Jeurissen, S.M.F.; De Kaste, D. Pharmacologically effective red yeast rice preparations marketed as dietary supplements illustrated by a case report. Drug Test Anal. 2016, 8, 315-318. [CrossRef] [PubMed]

18. Li, Y.; Jiang, L.; Jia, Z.; Xin, W.; Yang, S.; Yang, Q.; Wang, L. A meta-analysis of red yeast rice: An effective and relatively safe alternative approach for dyslipidemia. PLoS ONE 2014. [CrossRef] [PubMed]

19. Agostoni, C.; Bresson, J.L.; Fairweather-Tait, S.; Flynn, A.; Golly, I.; Korhonen, H.; Pagona, L.; Lovik, M.; Marchelli, R.; Martin, A.; et al. Scientific opinion on the substantiation of health claims related to monacolin $\mathrm{K}$ from red yeast rice and maintenance of normal blood LDL cholesterol concentrations (ID 1648, 1700) pursuant to Article 13(1) of Regulation (EC) No 1924/2006. EFSA J. 2011, 9, 2304-2320.

20. Childress, L.; Gay, A.; Zargar, A.; Ito, M.K. Review of red yeast rice content and current Food and Drug Administration oversight. J. Clin. Lipidol. 2013, 7, 117-122. [CrossRef] [PubMed]

(C) 2017 by the authors. Licensee MDPI, Basel, Switzerland. This article is an open access article distributed under the terms and conditions of the Creative Commons Attribution (CC BY) license (http:/ / creativecommons.org/licenses/by/4.0/). 


\title{
Review
}

\section{Microalgae Nutraceuticals}

\author{
Marcello Nicoletti \\ Department of Environmental Biology, University Sapienza of Rome, P.le A. Moro, 500185 Rome, Italy;
} marcello.nicoletti@uniroma1.it; Tel.: +39-0649-912-195

Academic Editor: Antonello Santini

Received: 23 June 2016; Accepted: 16 August 2016; Published: 22 August 2016

\begin{abstract}
Among the new entries in the food supplements sector, an important place must be assigned to nutraceuticals containing microalgae, nowadays accounting for a large and rapidly expanding market. The marketed products are mainly based on three production strains, i.e., Spirulina and Chlorella, followed at a distance by Klamath. It is a composite situation, since two of them are cyanobacteria and the second one is eukaryotic. The reality is that each presents similarities in shape and appearance concerning the marketed form and several utilizations, and peculiarities that need special attention and adequate studies. First, general information is reported about the current scientific knowledge on each microalga, in particular the nutritional value and properties in prevention and wellbeing. Second, original studies are presented concerning the quality control of marketed products. Quality control is a key argument in nutraceuticals validation. Microalgae are particular organisms that need specific approaches to confirm identity and validate properties. The proposed control of quality is based on microscopic analysis of the morphologic characteristics. The final parts of this paper are dedicated to the need for specificity in uses and claims and to considerations about the future of microalgae in food supplements.
\end{abstract}

Keywords: microalgae; Spirulina; Chlorella; Klamath; food supplement; quality control

\section{Introduction}

International agencies like the FAO have announced the goal of food to feed everyone in the world [1,2]. However, to gain this success against any Malthusian prophecy, we must consider two main aspects, production and quality. Besides the eternal challenge concerning the production of a necessary quantity of food, recently quality is becoming fundamental for health maintaining and lifestyle improvements, as evidenced by the global obesity phenomenon [3-5]. Both aspects can be considered as decisive characteristics of the so-called nutritional environment. The nutritional environment is actually at the center of everybody's attention, from governments to ordinary people, in consideration of the related problems including health and social costs.

Recently, rapid changes have impacted the food scenario, involving the appearance of several new products. These products-nutraceuticals, botanicals, and others-deeply influenced the market for their hybrid nature, located somewhere between ordinary food and medical drugs [6,7]. Actually, they are considered part of the food supplements sector, although the situation is continuously subject to changes and new interpretations [8-10]. The result is a complex, dynamic situation, needing a careful study and information about each of the different aspects [11].

A clear example of the actual and future situation of food, including food supplements, is offered by microalgae [12-15], nowadays accounting for a large and rapidly expanding market [16-18]. As a matter of fact, microalgae chemical composition is a complex mixture of minerals, vitamins, and primary and secondary products, offering a large spectrum of possible applications and utilizations for humans, from nutritional properties to antioxidant and anti-aging, also considering the preventative effects. In other words, microalgae are a case study in nutraceuticals. 
On this occasion, after a set of necessary information on the raw materials, three arguments concerning microalgae products will be considered in detail:

(a) Quality control, a problem involving the whole food supplements market.

(b) The specificity of use and claim, since the derived products in food supplements are still not sufficiently tailored in terms of possible utilization.

(c) The real need of microalgae for mankind, in particular as nutraceuticals.

\section{The Evolution of Food Supplements}

At the beginning of their appearance in the market, food supplements were considered as concentrated nutrients useful to support nutritional needs and/or supply alimentary deficiencies in the ordinary diet and, consequently, their composition clearly evidenced the presence of vitamins, minerals, proteins, and carbohydrates [8]. Later, their composition showed a massive introduction of "other substances," mainly consisting of extracts of medicinal plants. Composition, targets, and marketing clearly changed, as well as denominations, with possible names including nutraceuticals (the most frequently used, but still not officially recognized), dietary supplements, medical devices, herbal drug preparations, traditional medicine herbal products, botanical food supplements, botanical supplements, or simply botanicals, in the case of utilization of raw plant materials [10,11]. The main difference consists in the organic composition, since food supplements of the first generation mainly contain substances of primary metabolism, like carbohydrates, vitamins, and proteins, whereas other substances, typical of nutraceuticals, are secondary products, like flavonoids, terpenes, polyphenols, organic acids, pigments, etc., usually present in raw plant materials or extracts. This simplified scheme is contradicted by microalgae, which are a rich source of both types of substances, as evidenced by the reported chemical analyses. Similar to food supplements evolution, for a long time seaweed was mainly considered a source of animal feed and human alimentation, but the introduction in the market of nutraceuticals radically changed the scenario. To deal with this particular situation, the attractive term "superfood" was suggested [19]. The so-called superfoods are now present in supermarkets and herbal shops, although their composition and nature were not determined and clarified (Figure 1).

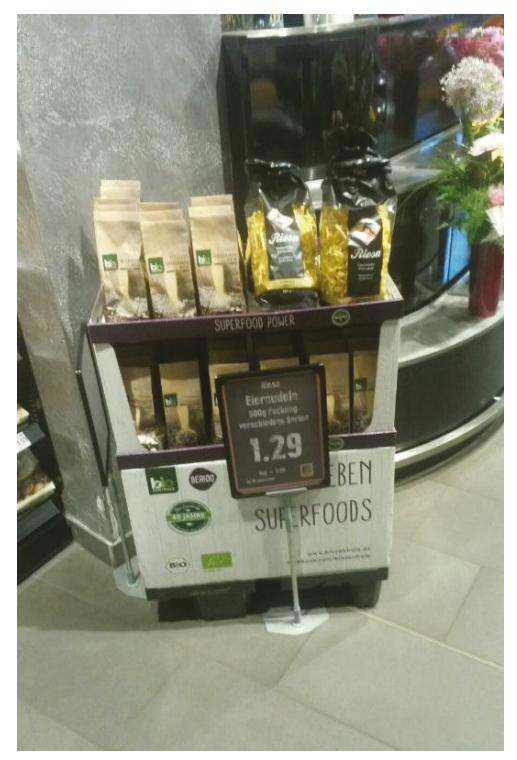

Figure 1. So-called superfoods can now be easily found in supermarkets. 
The third type of food supplements, now emerging, is functional foods or pharmafoods, based on the addition of special ingredients with certain physiological properties to ordinary foods. This is probably the best future use of microalgae, bypassing the limits of attractiveness in the current utilizations and opening the way for a wide variety of different products, like green pasta or special desserts.

\section{Aquatic Autotrophics}

Life depends on water. Seaweed, together with animals and plants, is fundamental to the current food scenario [20,21]. Ordinary people may not aware, but a standard diet is full of seaweed products, directly or indirectly, and not even considering that planet life largely depends on the photosynthetic work of phytoplankton and that most living organisms are marine. The main biomass of seaweeds present in the planet are microscopic unicellular organisms named microalgae. Microalgae are not only naturally abundant in the sea and terrestrial water, but can be cultivated easily and in large quantities, giving rise to a low-cost raw material with many potential uses. Food supplements were able to enlarge the application horizon of microalgae, but this is probably only the beginning.

For a long time, seaweed use, including microalgae, was limited to livestock feed and fertilizer. Recently, new important uses for microalgae have been emerging, fuelled by increasing interest and curiosity from consumers. Again, technology has a fundamental role in transforming raw materials into a myriad of different products. From food to biodiesel, the microalgae empire is coming [22-27].

Algae are a polyphyletic group of autotrophic marine organisms (alga in Latin means marine plant), erroneously considered as plants due to the common photosynthetic trophic pathway. Generally speaking, they are known as seaweed; however, "seaweed" is a colloquial term and lacks a formal definition. In addition, some tuft-forming blue-green algae are sometimes considered to be algae, but they must be linked to prokaryotes (cyanobacteria) [28,29]. The classic classification of algae, now obsolete, is based on colour, being the most direct evident morphologic character. Colourations derive from different pigments associated with the photosynthetic process, according to the water depth where they live. Therefore, we have blue-green, yellow, green, brown, and red algae. Algae can be unicellular or multicellular, microscopic or giant, simple or complex, similar in form to plants or to bacteria. Inside these organisms, we can read the complete story of autotrophic living beings, from the beginning until 450 million years ago, when life left the water. Primordial microalgae were very similar to those present in our seas. Although primordial habitats were totally different from current ones, these cells have been able to survive practically unchanged until now and are still the main part of the biomass of the planet. Considering their massive distribution, they are still dominating the planet.

The potential use of microalgae is enormous: three-quarters of the planet's surface is occupied by water and most marine water is available for life. The space habitable by marine organisms is far greater to that available for terrestrial plants. Microalgae, which cover almost $75 \%$ of algae species, contribute approximately $40 \%$ of the oxygen in the atmosphere. Despite the apparent simplicity of their cells, at least 40,000 species of microalgae phytoplankton have been identified [29]. The key of this success is in the metabolism, i.e., in the completeness of substances present in the cytoplasm. This is the key to their importance in nutraceuticals. For this reason, in this paper the analytical part is a particular focus.

\section{Cyanobacteria in Nutraceuticals}

The market for microalgae nutraceuticals is dominated by two cyanobacteria, universally known as Spirulina and Klamath, and the chloroficean Chlorella. To understand cyanobacteria, we must start with the outset of life, 4.5 billion years ago, when these microscopic cells started the experiment of life [20]. From that beginning, organic life was separated by the trophic level. On one side were the autotrophic cyanobacteria, and on the other side were the heterotrophic consumers, the Eubacteria, which use the organic substances produced by the former. Besides them, Archaea prokaryotes were experimenting with other methods of producing energy and organic matter. We are here because that 
model, despite the apparent simplicity, was (and still is) successful; its capacity is nowadays testified to by its presence. Despite the absence of a nucleus, bacteria possess all the biochemical tools to produce any kind of products, including precious essential amino acids and enzyme supply [30-32].

Cyanobacteria are also known as blue-green algae and are traditionally associated with seaweed, in consideration of the trophic level, the environmental condition, and several other similarities. The evolutionary line leading to modern plants started from that model based on the chlorophyll work in autotrophic algae. Following the evolutionary pathways, we focused on advanced organisms, considering them a major source of food and medicinal drugs. It is now time to reverse this attitude. Again, the first signal of novelty comes from nutraceuticals. Microalgae are heavily used as raw materials in food supplements. The claim is to obtain both equilibrium in the diet and a specific activity, in accordance with the characters of the functional food.

Production of microalgae must be carefully considered. Microalgae need some special conditions to produce large quantities of biomass. This can be obtained in natural, as well as artificial, habitats. Attention must be focused on algal bloom, which in some periods can interest particular species in certain seas, as the result of optimal biological, physical, and chemical conditions. The resulting toxic water contamination can be dangerous directly or in the food chain [33]. On the other side, certain species of microalgae can be successfully used to clean contaminated gas or water, in particular from industrial production [23].

\section{Spiralated Cianobacteria}

\subsection{Spirulina}

Spirulina (classified as Arthrospira sp.) is a cyanobacterium present in free-floating filaments in the form of an open left-hand helix characterized by cylindrical multicellular trichromes (Figures 2 and 3). It occurs naturally in tropical and subtropical alkaline hot lakes with high $\mathrm{pH}$ values and high salt concentrations, like carbonate and bicarbonate. Two species, S. platensis and S. maxima, are mainly present, the first occurring in Africa, Asia, and South America, whereas the second is confined to Central America. Cultivation of Spirulina on a large scale started 30 years ago in Mexico and China, and later in other parts of the world, owing to the easy conditions for cultivation. Most cultivated Spirulina is produced in open channel raceway ponds, with paddle-wheels used to agitate the water. The largest commercial producers of Spirulina are located in the USA, Thailand, India, Taiwan, China, Bangladesh, Pakistan, Burma (Myanmar), Greece, and Chile. Spirulina is primarily known across the world for its potential nutritional value. It is one of the rare edible bacteria, due to its low purine concentration, which allows it to pose a minimal risk of uric acid build-up in the body [22]. The food industry classifies $A$. platensis as a single-celled protein, meaning that it is an edible microbe with a high food value [32]. The nutritional value of Spirulina was already known to the Aztecs, who harvested the alga from Texcoco Lake, near Mexico City. Spanish soldiers led by Cortes described its use as a daily food and the sale as cakes [33,34]. It is rich in vitamins, minerals, $\beta$-carotene, essential fatty acids, and antioxidants, all of which have facilitated its commercial production as a human food supplement over the course of the past decade $[35,36]$. Its consumption has been shown to have cardiovascular positive effects, lowering blood pressure and reducing cholesterol [36]. In consideration of its anti-carcinogenic properties, it was used to treat radiation sickness in people that were affected by the 1986 Chernobyl nuclear accident [37-40].

Nowadays, it is used in food supplements, in the form of tablets or power, alone or in association with other algae or plant extracts, for human or animal uses. Actually, Spirulina is considered a good source of vitamins and essential amino acids. It also has very high protein content with a well-balanced composition, making it even more desirable as a food supplement [31,32]. It is also noteworthy for its oil content, in quantity $(7 \%)$ and in quality ( $\alpha$-linolenic acid (ALA), linoleic acid (LA), stearidonic acid (SDA), eicosapentaenoic acid (EPA), docosahexaenoic acid (DHA), and arachidonic acid (AA)). 
The content in vitamins, like those of the group B, and hydrocarbons is considered relevant and complete [31].

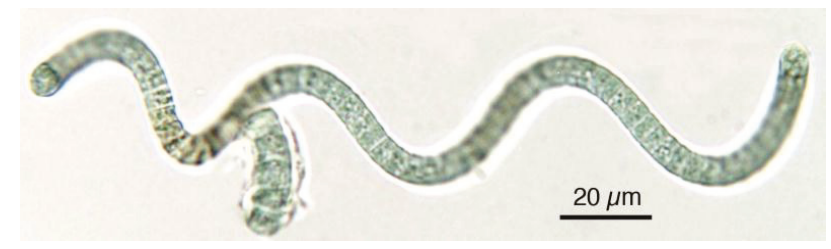

Figure 2. In Spirulina, cells are aggregated into filaments that tend to form spirals. Note the blue-green colour typical of cyanobacteria.

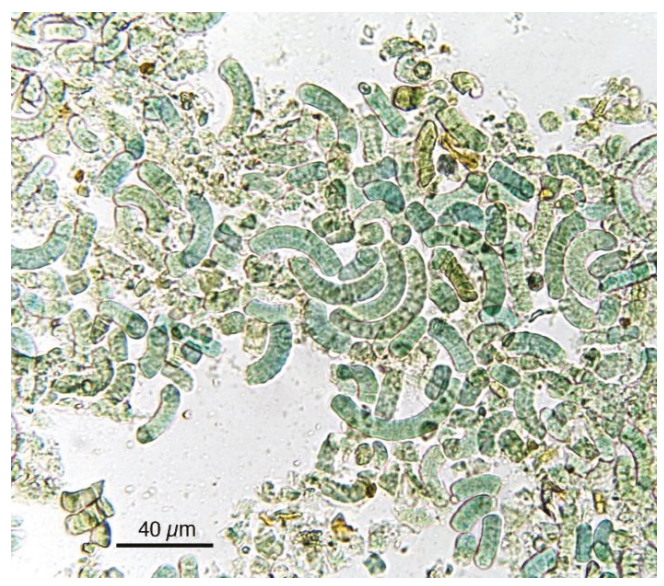

Figure 3. Most Spirulina cells, after their exsiccation and transformation into marketed products, are fragmented, but the original characteristics useful for identification are still evident.

\section{Algae in Environmental Niches}

\subsection{Alga Klamath}

Klamath is the name of a lake in Oregon (USA, perimeter $161 \mathrm{~km}$, medium deep $2.4 \mathrm{~m}$ ), where the cyanobacterium Aphanizomenon flos-aquae grows spontaneously and therefore is commonly known as alga Klamath (Figure 4). Several other Aphanizomenon spp. occur in other parts of the planet, but Lake Klamath allows for good production and easy harvesting. It can be considered a living fossil, survived into a particular ecological niche [41]. Therefore, alga Klamath's environmental condition is very different from that of Spirulina. Spirulina algae can be grown in controlled conditions that do not exclude completely contaminations, but Klamath microalgae are in a natural and very large place, open to the presence of other microalgae and microorganisms and subjected to seasonal cycles. In March, the Fragilaria spp. dominate the phytoplankton of the lake, followed by A. flos-aquae between May and July. In the same period, also Anabaena flos-aquae (less that $1 \%$ of the total algae) and later in July-October Microcystis aeruginosa and Coelopshaerium are present. Therefore, during the collection of Spirulina, several algal species can be collected, giving rise to warnings about the presence of neurotoxins produced by other algae, in particular about Anabaena, Microcystis, and Oscillatoria spp. that are normally present in the lake and can produce toxins. However, so far there is not complete and reliable information about the production of toxins, like microcystins, from A. flos aque; analyses 
on Lake Klamath phytotoxins, as well as on marketed products, are a controversial matter, including the analytic method, although all reports only concern the possibility of contamination and toxic effects [42].
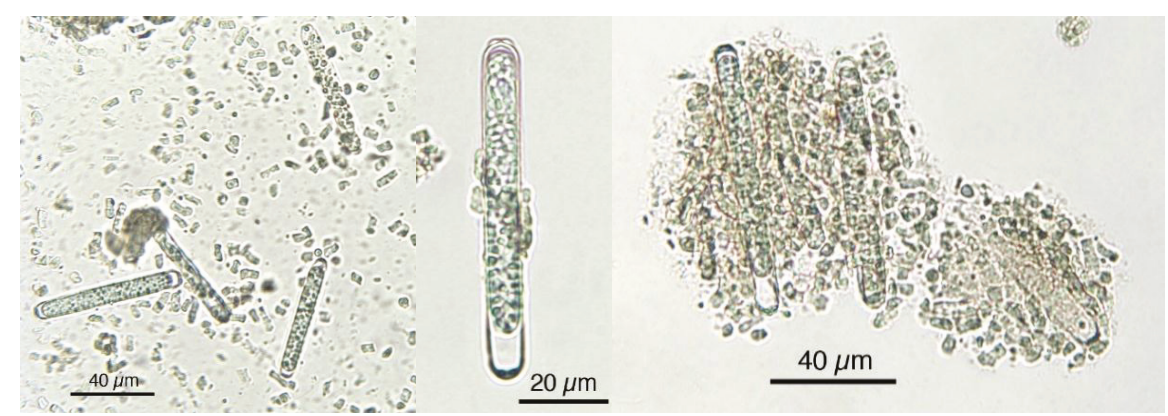

Figure 4. Microphotographs of Klamath power showing fragmented as well as intact cells with resistant cell wall and characteristic form.

Both Spirulina and alga Klamath are marketed with suggestive adjectives, such as superfood or the food of the future. Several activities are reported and in part confirmed by different types of experiments and clinical trials; however, as for several food supplements, the scientific validation is not considered complete. In the first place, despite the poorly inviting taste, the nutritional value and the anti-obesity effect are the object of considerable marketing appeals.

\subsection{Chlorella}

Chlorella is a microscopic unicellular seaweed pertaining to the green algae (Chlorophyta) (Figure 5). The evident green pigmentation is due to the presence of the two chlorophylls, $a$ and $b$, the same ones in terrestrial plants. It can be easily cultivated in simple conditions, producing enormous quantities of biomass in little time. It needs only water, $\mathrm{CO}_{2}$, light, and a small quantity of minerals. Considering its quantity of proteins, amino acids, minerals, vitamins, and pigments [43,44], it should be considered the ideal food [45].

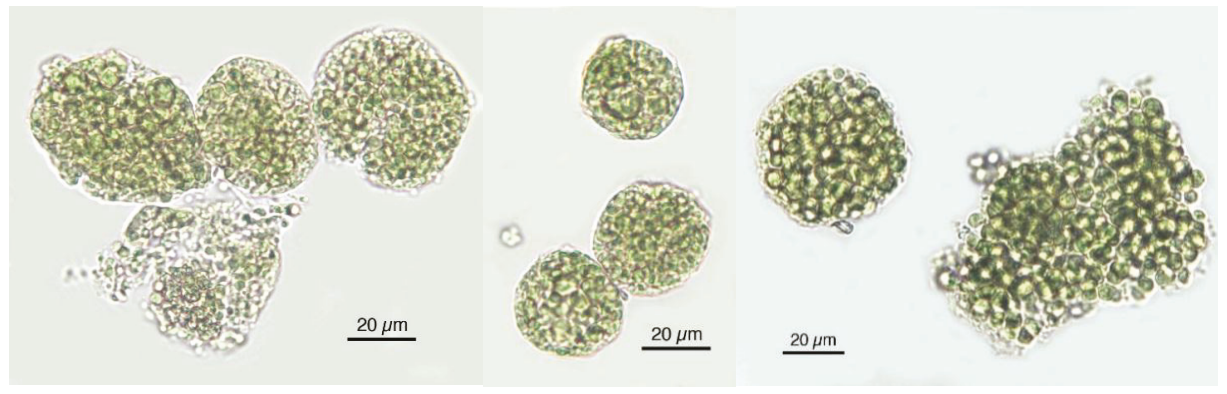

Figure 5. The microscopic unicellular Chlorella cells tend to agglomerate also in food supplements.

Its properties and capacities have been idealized and emphasized in various ways. Yury Viktorovich Romanenko, cosmonaut, twice hero of the Soviet Union, holds the record for the longest stay in space, with a total of 430 days, 20 h, $21 \mathrm{~min}, 30 \mathrm{~s}$ in several missions, before the space station came about (Figure 6). During his time in space, he was able to perform a series of important experiments on seaweed of the Chlorella genus, in consideration of its future utilization as a food in 
long space journeys. However, simple chemistry is not the only consideration. The flavour of this seaweed, as well as of other ones, is not enjoyable in comparison with ordinary dishes. Also, in this case, there is a long list of assigned health activities and properties, including the detoxicant action and the stimulation of the immune system. On the side of wellbeing, evidence of improved digestion and normalization of sugar metabolism has been reported.

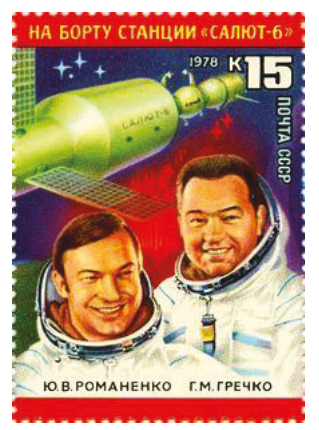

Figure 6. The soviet cosmonaut Yury Viktorovich Romanenko tested the utilization of Chlorella as an ideal food in long space journeys.

\section{Quality Control in Microalgae}

There is a concern about toxins produced by cyanobacteria [33]. Microcystins, produced by Microcystis sp., were in the news as they caused acute liver failure in more than 100 Brazilian haemodialysis patients. The problem arose due to the use of a contaminated water reservoir, whose filters and carbon adsorption tanks had not been changed for a long time. Another typical alarm comes from the consumption of saltwater mussels (Mytilus edulis), which feed on Microcystis and accumulate microcystins persisting for several days after the transfer of the mussels into clean water [46]. In Southern Italy, there is a tradition of consumption of fresh mussels, without any form of cooking, causing in some cases acute gastrointestinal problems and dysentery, albeit in some cases it is unclear that the problems were attributable to the mussels. When production is operated in clean water and controls are performed, no alarms or problems were registered. Another case comes from another species, Pfiesteria sp., which produces neurotoxins. In 1997 in Maryland, USA, the so-called "Pfisteria panic" produced a $210 \%$ reduction in sales of fish and shellfish due to a public perception of danger $[47,48]$. Harmful seaweed blooms are caused by the unusual proliferation of certain toxic microalgae, which are regular constituents of the plankton microflora found in the Austral ecosystem of Chile, when environmental conditions are favourable to their blooming [49-51]. They can be due to the presence of toxins, as occurs with the dinoflagellates responsible for paralytic shellfish poison and diarrhoeic shellfish poison. Therefore, some of the marine organisms that filter microalgae, such as bivalve shellfish, concentrate these toxins. Consumption of these organisms may seriously harm human health and may even be lethal.

In food supplements, only the reported microalgae species are utilized and they are considered devoid of any toxin production. They are used alone or together. The marketed raw material consists of lyophilized or dried seaweed as a fine green powder, so that is very difficult to ascertain at a glance the identity of the utilised species. A control is necessary, not least because the cost of each one is very different and therefore the combination is not always reported on the label, but the real danger comes from the incidental occurrence of toxic algae.

As evidenced in Figure 7, each microalga utilized in nutraceuticals possesses a distinct microscopic morphologic shape. The morphological analysis at the microscope is very useful and the results prove the presence of alien species. Figure 8 shows the presence of Oscillatoria sp. in a Spirulina commercial 
sample, whereas in Figure 9 the co-occurrence of Spirulina and Chlorella is shown. However, to obtain a reliable result, the quality control needs a specialized treatment, a good instrument, and a specialist in algology able to identify the species, in particular in case of the presence of alien toxic microalgae that can be easily cultivated, or casually present, together with the required ones. Furthermore, during the process of preparation of tablets, the delicate original form of the microalgae can be partially destroyed. In particular, high-quality images should be obtained and presented, as those reported here. Also, a sufficient number of analyses is necessary to ascertain the amount of contamination. In case of contamination, it is necessary to identify the alien species, but the presence of a contaminant species, like in Figure 8, must be considered only as an indication of the possible presence of toxins in the marketed products.
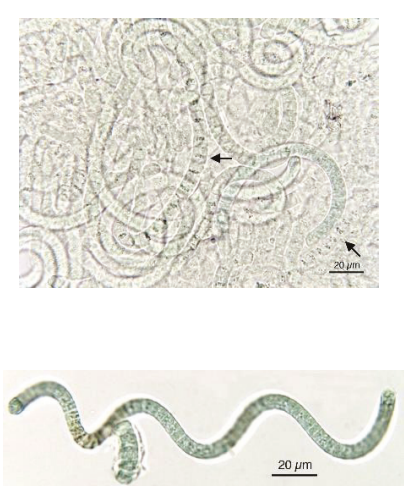

Spirulina
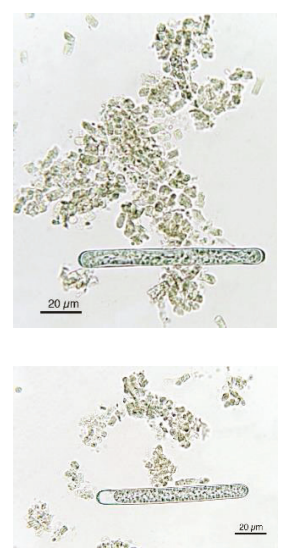

Klamath

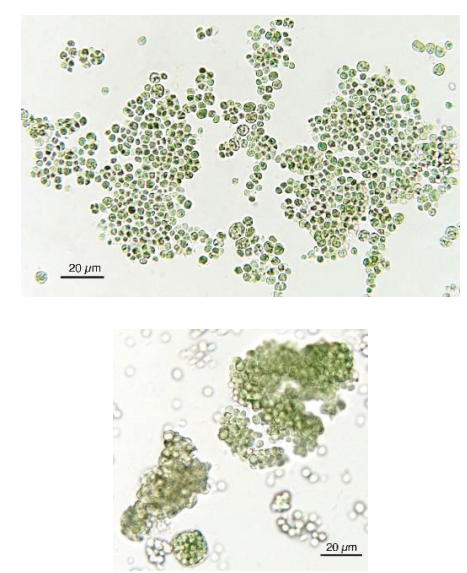

Chlorella

Figure 7. Microscopic characteristics of each microalga, allowing for identification.

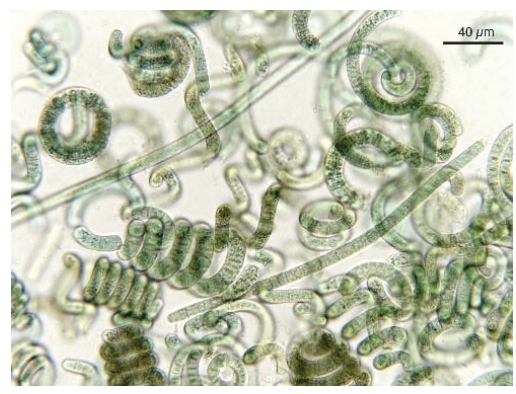

Figure 8. Spirulina product showing the presence of Oscillatoria sp. (long linear cells). 


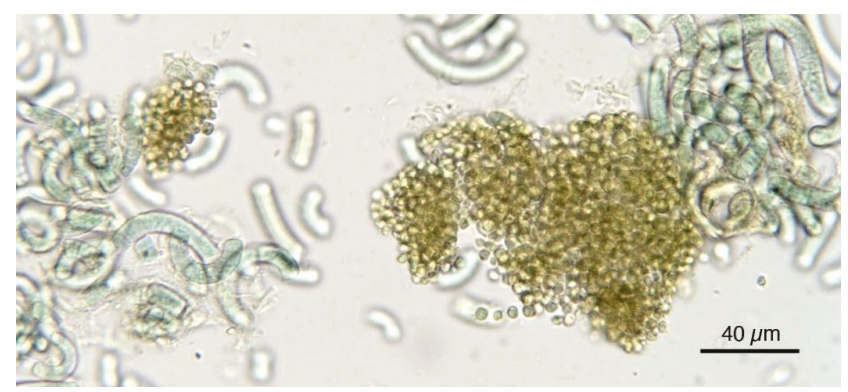

Figure 9. Spirulina product showing the presence of Chlorella-like and/or unicellular cyanobacterial cells.

\section{The Importance of Microalgae in Food Supplements}

Nowadays, microalgae are mainly utilized to feed livestock and pets. However, human consumption is increasing, in particular in food supplements. There are several cases of interest in the use of microalgae in food supplements. Vegans adopt a diet characterized by the practice of abstaining from the use of animal products [52]. Generally, the diet is associated with a philosophy that rejects the commodity status of animals and other ethical tendencies [53]. Therefore, vegans and omnivores can get into confrontations and debates $[52,54]$. So far, vegans seem to be victorious, with their numbers constantly increasing. Vegans account for ca. $5 \%$ of the total population in Israel, $2 \%$ in the United Kingdom and United States, and 1\% in Germany and in Italy, which means anywhere from several thousand to seven million inhabitants.

The vegan diet is often considered nutrient-deficient, due to unbalanced protein sources and a low intake of some vitamins and minerals. Recently, some scientific data has been produced that gives substance to the debates. A recent study reports the results of a comparison between a group of vegetarians and a group of non-vegetarians for an average period of eight years [55]. The study stated: "A vegan diet should involve a balanced intake of whole grain products, legumes, seeds and sources of proteins, as well as vegetables, fruits, berries and unsaturated fats. In addition, vegans should consume calcium-fortified drinks and use vitamin B12, vitamin D and iodine supplements to complete their diet." The results mean that vegans face nutritional problems due to a shortage of vitamin B12, 25-hydroxyvitamin D, selenium, and long-chain omega-3 fatty acids.

Factors that influence vegetarian food intake should include knowledge of a balanced diet, vegetarian food variety, as well as the use of enriched food items and food supplements. Among the available food supplements, for their content microalgae seem one of the best candidates to supplement vegans' and vegetarians' diet.

The vegan diet debate, including the recent WHO alert concerning the need for limiting meat intake, evidences the tendency to obtain health implements by a hypocaloric intake. This aspect has been recently considered in a study reported by an interdisciplinary group [56-60]. The paper, published in Cell Metabolism in 2015, showed that in mice a diet alternating prolonged fasting (PF) and a nutrient-rich medium resulted in extended yeast lifespan $(+20 \%)$, independently of established pro-longevity genes [60]. Besides extended middle-age longevity, bi-monthly FMD cycles of four days of a diet that mimics fasting (FMD), developed to minimize the burden of PF, lowered visceral fat, reduced cancer incidence and skin lesions, rejuvenated the immune system, and retarded bone mineral density loss. In old mice, FMD cycles promoted hippocampal neurogenesis, lowered IGF-1 levels and PKA activity, elevated NeuroD1, and improved cognitive performance. In a pilot clinical trial, three FMD cycles decreased risk factors/biomarkers for aging, diabetes, cardiovascular disease, and cancer without major adverse effects, providing support for the use of FMDs to promote health span. The results and conclusions of the research find an independent confirmation in Laron Syndrome. 
The Laron population lives in remote villages of Ecuador. They are very small people, suffering from an incredibly rare genetic disorder that stops them from growing taller than 4 feet and produces elderly features even in children. The syndrome is a consequence of low IGF-1 levels, but the same factor also seems to protect them against cancer and diabetes, and maybe even heart disease and Alzheimer's.

Therefore, the mima hypocaloric diet shows that: (a) a high protein intake is linked to increased cancer, diabetes, and overall mortality; (b) high IGF-1 levels increase the relationship between mortality and high protein levels; (c) higher protein consumption may be protective for older adults; and (d) plant-derived proteins are associated with lower mortality than animal-derived proteins. Therefore, in this case also, microalgae can play a role in the diet.

\section{Conclusions}

As already reported, algae food supplements can be particularly useful to support some diets. However, some aspects need to be considered and research should play a central role. Microalgae are considered more or less at the same level of utilization in nutraceuticals, albeit with several differences. Dried spirulina used in food supplements contains about $60 \%(51 \%-71 \%)$ protein, with a composition rich in all essential amino acids, though with reduced amounts of methionine, cysteine, and lysine when compared to meat, eggs, and milk, although superior to typical plant protein, such as that from legumes [32,61-63]. Furthermore, an interesting debate concerns vitamin B12. Most edible cyanobacteria, like spirulina, do not naturally contain vitamin B12, but predominantly contain pseudovitamin B12, which is inactive in humans [64,65]. Therefore, the American Dietetic Association and Dieticians of Canada, in their position paper on vegetarian diets, state that spirulina cannot be counted on as a reliable source of active vitamin B12 [66]. However, companies that grow and market spirulina have claimed it to be a significant source of the vitamin on the basis of alternative, unpublished assays, although their claims are not accepted by independent scientific organizations. However, there is a general rule to be considered: plant drugs contain plenty of secondary metabolites acting as non-active biochemical precursors, usually named pro-drugs, from alliin in garlic to THC-A in cannabis, as reported in Table 1. There are several reported reasons for its situation: active products are precious and must be preserved or the metabolite must act on the right please, etc.

Table 1. Examples of plant pro-drugs.

\begin{tabular}{cc}
\hline Prodrug & Active Substances \\
\hline Glucosinolates & Isothiocyanates \\
Alliin & Allicin, ajoenes \\
Cumaroylglucoside & Coumarin \\
Arbutin & Hydroquinone \\
Salicin & Saligenin, salicylic acid \\
Bi-desmosidic saponin & Mono-desmosidic saponins \\
Ranunculin & Protoanemonin \\
THC-A & THC \\
Proto-vitamin B12 & Vitamin B12 \\
Cyanogenic glucoside & HCN \\
Rhein, sennosides & Antraquinonic aglucone \\
Hennosides & Lawsone \\
Vanilloside & Vanillin \\
Gein & Eugenol \\
Methylazoxymethanol & Cycasin \\
\hline
\end{tabular}

The vitamin B12 debate is only an example of the general debate concerning the real necessity and effectiveness of nutraceuticals consumption. Probably, more research is needed on these as on many other food supplements, in order to obtain the right utilization. Food supplements, so far fuelled by a billion-dollar market, urgently need scientific validation. 
Conflicts of Interest: The author declares no conflict of interest.

\section{References}

1. Food and Agriculture Organization. FAO Statistical Yearbook 2012; FAO: Rome, Italy, 2013.

2. Food and Agriculture Organization; International Fund for Agricultural Development; World Food Program. The State of Food Insecurity in the World 2014. Strengthening the Enabling Environment for Food Security and Nutrition; FAO: Rome, Italy, 2015.

3. Ogden, C.L.; Carroll, M.D.; Kit, B.K.; Flegal, K.M. Prevalence of childhood and adult obesity in the United States, 2011-2012. JAMA 2014, 311, 806-814. [CrossRef] [PubMed]

4. James, R. Obesity, Prevention and Treatment; Book News, Inc.: Portland, OR, USA, 2012.

5. Eckel, R.H.; Grundy, S.M.; Zimmet, P.Z. The metabolic syndrome. Lancet 2005, 365, 1415-1428. [CrossRef]

6. Zeisel, S.H. Regulation of "nutraceuticals". Science 1999, 285, 1853-1855. [CrossRef] [PubMed]

7. SANCO. Directorate General European Commission the Use of Substances with Nutritional Effect Other than Vitamins and Minerals in Food Supplements; Study undertaken for European Advisory Services (EAS); SANCO: Brussel, Belgium, 2007.

8. Kalra, E.K. Nutraceutical-definition and introduction. AAPS PharmSci. 2003, 5, E25. [CrossRef] [PubMed]

9. Eskin, N.A.M.; Tamir, S. Dictionary of Nutraceuticals and Functional Foods; CRC Press: Boca Raton, FL, USA, 2006.

10. Nicoletti, M. Nutraceuticals and botanicals: Overview and perspectives. Int. J. Food Sci. Nutr. 2012, 63, 2-6. [CrossRef] [PubMed]

11. Rajasekaran, A.; Sivagnanam, G.; Xavier, R. Nutraceuticals as therapeutic agents: A review. Res. J. Pharm. Technol. 2008, 1, 328-340.

12. Nicoletti, M. Nutraceuticals and botanicals appeal for new analytical solutions. J. Chromatogr. Sep. Tech. 2012, 3, e103. [CrossRef]

13. Hardy, G. Nutraceuticals and functional foods: Introduction and meaning. Nutrition 2000, 16, 688-689. [CrossRef]

14. El Schaimy, E. Functional foods and nutraceuticals-Modern approach. World Appl. Sci. J. 2012, 20, 691-708.

15. Christaki, E.; Florou-Paneri, P.; Bonos, E. Microalgae: A novel ingredient in nutrition. Int. J. Food Sci. Nutr. 2011, 62, 794-799. [CrossRef] [PubMed]

16. Tramroy, P. Microalgae Market Outlook Report Website. CBDM.T—Market and Business Intelligence. 2011. Available online: http:/ / www.microalgae-market.com/ (accessed on 24 August 2011).

17. Benkouider, C. The world's emerging markets. Funct. Foods Nutraceuticals 2005, 44, 8-11.

18. Bishop, W.M.; Zubeck, H.M. Evaluation of microalgae for use as nutraceuticals and nutritional supplements. J. Nutr. Food Sci. 2012, 2, 147. [CrossRef]

19. Lunn, J. Superfoods. Nutr. Bull. 2006, 31, 171-172. [CrossRef]

20. Nadis, S. The cells that rule the seas. Sci. Am. 2013, 289, 52-53. [CrossRef]

21. Guiry, M.D. How many species of algae are there? J. Phycol. 2012, 48, 1057-1063. [CrossRef] [PubMed]

22. Pittman, J.K.; Dean, A.P.; Osundeko, O. The potential of sustainable algal biofuel production using wastewater resources. Bioresour. Technol. 2011, 102, 17-25. [CrossRef] [PubMed]

23. Ponnuswamy, I.; Madhavan, S.; Shabudeen, S. Isolation and Characterization of Green Microalgae for Carbon Sequestration, Waste Water Treatment and Bio-fuel Production. Int. J. BioSci. BioTechnol. 2013, 5, 17-23.

24. Spolaore, P.; Joannis-Cassan, C.; Duran, E.; Isambert, A.; Joannis-Cassan, D.; Isambert, I. Commercial applications of microalgae. J. Biosci. Bioeng. 2006, 101, 87-96. [CrossRef] [PubMed]

25. Quintana, N.; Van der Kooy, F.; Van de Rhee, M.D.; Voshol, G.P.; Verpoorte, R. Renewable energy from Cyanobacteria: Energy production optimization by metabolic pathway engineering. Appl. Microbiol. Biotechnol. 2011, 91, 471-490. [CrossRef] [PubMed]

26. Milledge, J.J. Commercial application of microalgae other than as biofuels: A brief review. Rev. Environ. Sci. Biotechnol. 2011, 10, 31-41. [CrossRef]

27. Rodolfi, L.; Zittelli, G.C.; Bassi, N.; Padovani, G.; Biondi, N.; Bonini, G.; Tredici, M.R. Microalgae for oil: Strain selection, induction of lipid synthesis and outdoor mass cultivation in a low-cost photobioreactor. Biotechnol. Bioeng. 2008, 102, 100-112. [CrossRef] [PubMed] 
28. Komárek, J.; Kaštovský, J.; Mareš, J.; Johansen, J.R. Taxonomic classification of cyanoprokaryotes (cyanobacterial genera), using a polyphasic approach. Preslia 2014, 86, 295-335.

29. Singh, N.K.; Dolly, W.D. phylogenetic relatedness among spirulina and related cyanobacterial genera. World J. Microbiol. Biotechnol. 2011, 27, 941-951. [CrossRef]

30. Ciferri, O. Spirulina, the edible microorganism. Microbiol. Rev. 1983, 47, 551-578. [PubMed]

31. Campanella, L.; Russo, M.V.; Avino, P. Free and total amino acid composition in blue-green algae. Ann. Chim. 2002, 92, 343-352. [PubMed]

32. Habib, M.A.B.; Parvin, M.; Huntington, T.C.; Hasan, M.R. A Review on Culture, Production and Use of Spirulina as Food for Humans and Feeds for Domestic Animals and Fish; Food and Agriculture Organization of the United Nations: Rome, Italy, 2008.

33. Nyenje, M.E.; Ndip, R.K. The Challenges of foodborne pathogens and antimicrobial chemotherapy: A global perspective. Afric. J. Microb. 2013, 7, 1158-1172.

34. Del Castillo, B. The Discovery and Conquest of Mexico, 1517-1521; Routledge: London, UK, 1928; p. 300.

35. Capelli, B.; Cysewski, G.R. Potential Health Benefits of Spirulina Microalgae: A Review of the Existing Literature; Cyanotech Corporation: Kailua-Kona, HI, USA, 2010.

36. Juarez-Oropeza, M.A.; Mascher, D.; Torres-Durán, P.V.; Farias, J.M.; Paredes-Carbajal, M.C. Effects of Spirulina on vascular reactivity. J. Med. Food 2009, 12, 15-20. [CrossRef] [PubMed]

37. Hirahashi, T.; Matsumoto, M.; Hazeki, K.; Saeki, Y.; Ui, M.; Seya, T. Activation of the human innate immune system by Spirulina: Augmentation of interferon production and NK cytotoxicity by oral administration of hot water extract of Spirulina platensis. Int. Immunopharmacol. 2002, 2, 423-434. [CrossRef]

38. Ku, C.S.; Pham, T.X.; Park, Y.; Kim, B.; Shin, M.; Kang, I.; Lee, J. Edible blue-green algae reduce the production of pro-inflammatory cytokines by inhibiting NF- $\mathrm{BB}$ pathway in macrophages and splenocytes. Biochim. Biophys. Acta 2013, 1830, 2981-2988. [CrossRef] [PubMed]

39. Mišurcová, L.; Škrovánková, S.A.; Samek, D.A.; Ambrožová, J.; Machů, L. Health benefits of algal polysaccharides in human nutrition. Adv. Food Nutr. Res. 2012, 6, 75-145.

40. Mosulishvili, L.M.; Kirkesali, E.I.; Beiokobylsky, A.I.; Khizanishvili, A.I. Experimental substantion of the possibility of developing selenium and iodine containing pharmaceuticals based on blue-green algae spirulina platensis. J. Pharm. Biomed. Anal. 2012, 30, 87-97. [CrossRef]

41. Carmichael, W.W.; Drapeau, C.; Anderson, D.M. Harvesting of Aphanizomenon flos-aquae Ralfs ex Born. \& Flah. variflos-aquae (Cyanobacteria) from Klamath Lake for human dietary use. J. Appl. Phycol. 2000, 12, 585-595.

42. Saker, M.L.; Jungblut, A.-D.; Neilan, B.A.; Rawn, D.F.K.; Vasconcelos, V.M. Detection of microcystin synthetase genes in health food supplements containing the freshwater cyanobacterium Aphanizomenon flos-aquae. Toxicon 2005, 46, 555-562. [CrossRef] [PubMed]

43. Bertoldi, F.C.; Sant'anna, E.; Oliveira, J.L.B. Chlorophyll content and mineral profile in the microalgae Chlorella vulgaris cultivated in hydroponic wastewater. Cienc. Rural 2008, 38, 54-58. [CrossRef]

44. Shoaf, W.T.; Lium, B.W. Improved extraction of chlorophyll a and b from algae using dimethyl sulfoxide. Limnol. Oceanogr. 1976, 21, 926-928. [CrossRef]

45. Chia, M.A.; Lombardi, A.T.; Melao, M.D.A. Growth and biochemical composition of Chlorella vulgaris in different growth media. An. Acad. Bras. Ciênc. 2013, 85, 1428-1437. [CrossRef] [PubMed]

46. Vasconcelos, V.M.; Wiegand, C.; Pflugmacher, S. Dynamics of glutathione-S-transferases in Mytilus galloprovincialis exposed to toxic Microcystis aeruginosa cells, extracts and pure toxins. Toxicon 2007, 50, 740-745. [CrossRef] [PubMed]

47. Greenberg, D.R.; Tracy, J.K.; Grattan, L.M. A critical review of the Pfiesteria hysteria hypothesis. Md. Med. J. 1998, 47, 133-136. [PubMed]

48. Collier, D.N.; Burke, W.A. Pfiesteria complex organisms and human illness. South. Med. J. 2002, 95, 720-726. [CrossRef] [PubMed]

49. Lembeye, G. Harmful algal blooms in the austral Chilean channels and fjords. In Progress in the Oceanographic Knowledge of Chilean Interior Waters, from Puerto Mont to Cape Horn; Silva, N., Palma, S., Eds.; Comité Oceanográfico Nacional-Pontificia Universidad Católica de Valparaíso: Valparaíso, Chile, 2008; pp. 99-103.

50. Anderson, D.M.; Garrison, D.J. The ecology and oceanography of harmful algal blooms. Limnol. Oceanogr. 1997, 42, 1009-1305. [CrossRef]

51. Roelke, D.; Buyukates, Y. The diversity of harmful algal bloom-triggering mechanisms and the complexity of bloom initiation. Hum. Ecol. Risk Assess. 2001, 7, 1347-1362. [CrossRef] 
52. Craig, W.J. Health effects of vegan diets. Am. J. Clin. Nutr. 2009, 68, 1627S-1638S. [CrossRef] [PubMed]

53. Francione, G. Animal Welfare, Happy Meat and Veganism as the Moral Baseline in David M. Kaplan; The Philosophy of Food, University of California Press: Berkeley, CA, USA, 2012; pp. 169-189.

54. Appleby, P.N. The Oxford vegetarian study: An overview. Am. J. Clin. Nutr. 1999, 70, 525S-531S. [PubMed]

55. Elorinne, A.L.; Alfthan, G.; Erlund, I.; Kivimaki, H.; Paju, A.; Salminen, I.; Turpeinen, U.; Voutilainen, S.; Lakso, J. Food and nutrient intake and nutritional state of finnish vegans and non-vegans. PLoS ONE 2016, 11, e0148235. [CrossRef] [PubMed]

56. Chia-Wei, C.; Adams, G.B.; Perin, L.; Wei, M.; Zhou, X.; Lam, B.S.; Da Sacco, S.; Mirisola, M.; Quinn, D.I.; Dorff, T.B.; et al. Prolonged fasting reduces IGF-1/PKA to promote hematopoietic-stem-cell-based regeneration and reverse immunosuppression. Cell Stem Cell 2014, 14, 810-823.

57. Levine, M.E.; Suarez, J.A.; Brandhorst, S.; Balasubramanian, P.; Cheng, C.W.; Madia, F.; Fontana, L.; Mirisola, M.G.; Guevara-Aguirre, J.; Wan, J.; et al. Low protein intake is associated with a major reduction in IGF-1, cancer, and overall mortality in the 65 and younger but not older population. Cell Metab. 2014, 19, 407-417. [CrossRef] [PubMed]

58. Lee, C.; Longo, V.D. Fasting vs. dietary restriction in cellular protection and cancer treatment: From model organisms to patients. Oncogene 2011, 30, 3305-3306. [CrossRef] [PubMed]

59. Lee, C.; Raffaghello, L.; Brandhorst, S.; Safdie, F.M.; Bianchi, G.; Martin-Montalvo, A.; Pistoia, V.; Wei, M.; Hwang, S.; Merlino, A.; et al. Fasting cycles retard growth of tumors and sensitize a range of cancer cell types to chemotherapy. Sci. Transl. Med. 2012, 4, 124. [CrossRef] [PubMed]

60. Brandhorst, S.; Choi, I.Y.; Wei, M.; Cheng, C.W.; Sedrakyan, S.; Navarrete, G.; Dubeau, L.; Yap, L.P.; Park, R.; Vinciguerra, M.; et al. A periodic diet that mimics fasting promotes multi-system regeneration, enhanced cognitive performance, and healthspan. Cell Metab. 2015, 22, 86-99. [CrossRef] [PubMed]

61. Khan, Z.; Bhadouria, P.; Bisen, P.S. Nutritional and therapeutic potential of Spirulina. Curr. Pharm. Biotechnol. 2005, 6, 373-379. [CrossRef] [PubMed]

62. Kulpys, J.; Paulauskas, E.; Pilipavičius, V.; Stankevičius, R. Influence of cyanobacteria Arthrospira (Spirulina) platensis biomass additive towards the body condition of lactation cows and biochemical milk indexes. Agron. Res. 2009, 7, 823-835.

63. Heidarpour, A.; Fourouzandeh-Shahraki, A.-D.; Eghbalsaied, S. Effects of Spirulina platensis on performance, digestibility and serum biochemical parameters of Holstein calves. Afr. J. Agric. Res. 2011, 6, 5061-5065.

64. Watanabe, F.; Katsura, H.; Takenaka, S.; Fujita, T.; Abe, K.; Tamura, Y.; Nakatsuka, T.; Nakano, Y. Pseudovitamin $\mathrm{B}(12)$ is the predominant cobamide of an algal health food, spirulina tablets. J. Agric. Food Chem. 1999, 47, 4736-4741. [CrossRef] [PubMed]

65. Watanabe, F. Vitamin B12 sources and bioavailability. Exp. Biol. Med. (Maywood) 2007, 232, 1266-1274. [CrossRef] [PubMed]

66. American Dietetic Association; Dietitians of Canada. Position of the American Dietetic Association and Dietitians of Canada: Vegetarian diets. J. Am. Diet. Assoc. 2003, 103, 748-765.

(C) 2016 by the author; licensee MDPI, Basel, Switzerland. This article is an open access article distributed under the terms and conditions of the Creative Commons Attribution (CC-BY) license (http:/ / creativecommons.org/licenses/by/4.0/). 

MDPI

St. Alban-Anlage 66

4052 Basel

Switzerland

Tel. +41616837734

Fax +41 613028918

www.mdpi.com

Foods Editorial Office

E-mail: foods@mdpi.com

www.mdpi.com/journal/foods

口舟回

-

$47+$

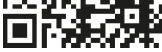





\section{MDPI}

St. Alban-Anlage 66 4052 Basel

Switzerland

Tel: +41 616837734

Fax: +41 613028918 